UFRN - Universidade Federal do Rio Grande do Norte

CT - Centro de Tecnologia

PPGEM - Programa de Pós-Graduação em Engenharia Mecânica

ELTON GIL XAVIER MOURA

Desenvolvimento de um sistema de captura de baixo custo destinado a determinação da cinemática humana. 
ELTON GIL XAVIER MOURA

\section{Desenvolvimento de um sistema de captura de baixo custo destinado a determinação da cinemática humana.}

Dissertação apresentada ao Programa de PósGraduação em Engenharia Mecânica, Centro de Tecnologia da Universidade Federal do Rio Grande do Norte, como requisito parcial para obtenção do título de Mestre em Engenharia Mecânica.

Áreas de concentração: Engenharias

Orientador: Danilo Alves Pinto Nagem 


\title{
DESENVOLVIMENTO DE UM SISTEMA DE CAPTURA DE BAIXO CUSTO DESTINADO A DETERMINAÇÃO DA CINEMÁTICA HUMANA.
}

\author{
Dissertação apresentada ao Programa de Pós- \\ Graduação em Engenharia Mecânica, Centro de \\ Tecnologia da Universidade Federal do Rio Grande \\ do Norte, como requisito parcial para obtenção do \\ título de Mestre em Engenharia Mecânica. \\ Orientador: Danilo Alves Pinto Nagem
}

COMISSÃO EXAMINADORA

Prof. Dr. Danilo Alvez Pinto Nagem (Orientador)
UFRN

Prof. ${ }^{\text {a }}$ Dra. Fabricia Azevedo da Costa Cavalcanti UFRN

Prof. Dr. William Fernandes de Queiroz UFRN

\author{
Prof. ${ }^{a}$ Dra. Tálita Saemi Payossim Sono \\ CEFET - MG
}


ERRATA

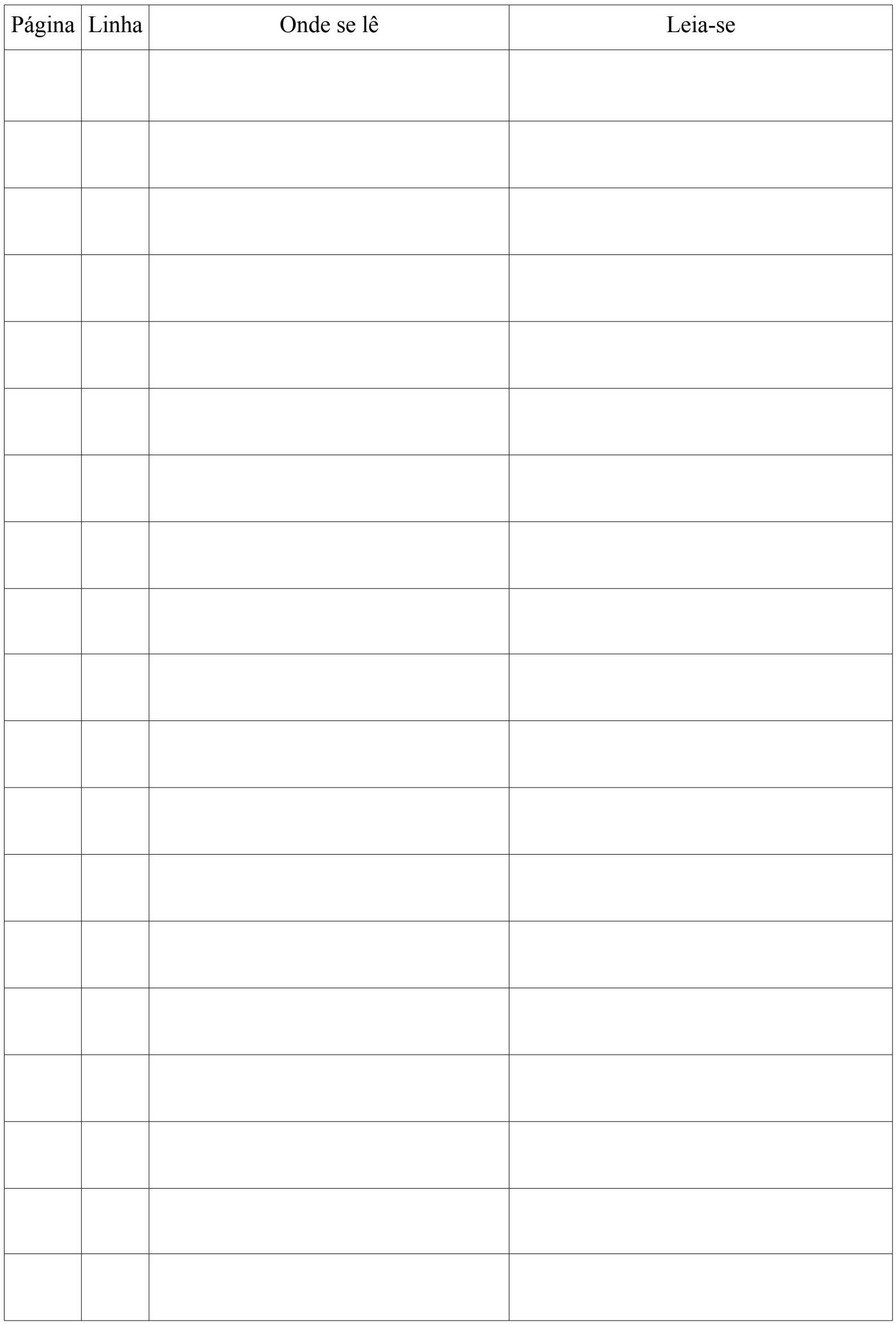




\section{Agradecimentos}

Agradeço sim a Deus, fonte de todo amor, sabedoria, misericórdia. Meu refúgio, força e fortaleza, a quem busco a todo tempo, assim como o quero fazer conhecer. Que este trabalho seja para honra e glória do Cristo ressuscitado que com a própria morte, na Cruz, nos deu a vida eterna.

Agradeço a meus pais, meus maiores patrocinadores e apoiadores, presentes numa bronca ou numa disponibilidade de me ajudar com o texto, sempre festejando ao ver meu progresso intelectual e em todas as áreas de minha vida. Nossas diferenças são pequenas diante de nossos laços.

Agradeço a meu primo-irmão Jackson, por todo companheirismo que me ofertou durante toda a nossa vida, das brincadeiras de infância até as dores de cabeça da fase adulta. Entro nos eixos de um jeito ou de outro meu irmão!

Agradeço grandemente a minha namorada Delci, apoio $24 \mathrm{~h}$ por dia, sete dias por semana, mesmo muito antes de namorarmos. Agradeço por orar comigo, por todo seu carinho e dedicação fantásticos. Nunca esquecerei quantas noites passou acordada a meu lado enquanto eu escrevia esta dissertação ou corrigia provas, com uma chamada de atenção quando me dispersava, fazendo comida, massagens e até revisões ortográficas no meu texto. Uma mulher de ouro que quero para toda a vida.

Agradeço à Comunidade Católica Shalom que me levou a Deus e cujas músicas embalaram a escrita deste trabalho e me acompanhou para que eu me mantivesse humano.

Aos meus irmãos com seus jeitos tão distintos de participar da minha vida. A minha querida avó tão atenciosa.

Agradeço aos meus colegas de curso e trabalho que sempre davam uma motivação ou partilhavam das mesmas dificuldades.

Agradeço a meu orientador Danilo, pois foi mais do que um orientador, sabe me motivar como ninguém! 


\section{Dedicatória}

Dedico este trabalho à honra e glória de Deus, meu Senhor e salvador. Que Ele cresça e que eu desapareça. 
"Ainda que eu fale todas as línguas humanas e angélicas, se não tenho Amor, sou um metal estridente e um címbalo que tine. Ainda que eu possua o dom de profecia e conheça todos os mistérios e a ciência inteira, ainda que tenha uma fé capaz de mover montanhas, se não tenho Amor, não sou nada. Ainda que eu reparta todos meus bens e entregue meu corpo às chamas, se não tenho Amor, de nada me serve".

(1Cor 13,1-3) 


\section{Resumo}

A captura de movimentos é uma ferramenta fundamental para a análise de movimentos quantitativos. Desde o século XIX, foram desenvolvidos diversos sistemas de captura de movimento para estudos biomecânicos, animações, jogos e cinema. O estudo da biomecânica e cinesiologia envolve e depende de conhecimentos de áreas distintas, as engenharias e as ciências da saúde. Uma análise precisa do movimento humano requer conhecimentos de ambas as áreas. É necessário então o uso de ferramentas e métodos didáticos de pesquisa e ensino que auxiliem este aprendizado. Os dispositivos atualmente encontrados no mercado para análise e captura de movimentos e usados nas instituições de ensino apresentam dificuldades para a prática didática, pois são de difícil transporte, possuem custo elevado e limitações quanto à liberdade do usuário diante da aquisição de dados. Dessa forma a análise de movimento é realizada de forma qualitativa ou é realizada de forma quantitativa em laboratórios de alta complexidade. Baseado nesses problemas, este trabalho apresenta o desenvolvimento de um sistema de captura para uso didático por meio de um dispositivo barato, leve, portátil e de fácil uso, em conjunto com um software livre. Este desenvolvimento inclui a escolha do dispositivo de captura, o desenvolvimento de softwares para seu uso e testes. O sistema desenvolvido utiliza o dispositivo Kinect, da Microsoft, por ser barato, leve, portátil, de fácil uso e dispõe de dados tridimensionais com apenas um periférico. Os programas propostos utilizam o hardware para fazer capturas de movimentos, armazená-la, reproduzi-la, processar dados desta movimentação e apresentar os dados de forma gráfica.

Palavras Chave: Biomecânica, Kinect, Captura de movimentos. 


\begin{abstract}
"Development of a low cost motion capture system destined for the determination of human's kinematics"

The motion capture is a main tool for quantitative motion analyses. Since the XIX century, several motion caption systems have been developed for biomechanics study, animations, games and movies. The biomechanics and kinesiology involves and depends on knowledge from distinct fields, the engineering and health sciences. A precise human motion analysis requires knowledge from both fields. It is necessary then the use of didactics tools and methods for research and teaching for learning aid. The devices for analysis and motion capture currently that are found on the market and on educational institutes presents difficulties for didactical practice, which are the difficulty of transportation, high cost and limited freedom for the user towards the data acquisition. Therefore, the motion analysis is qualitatively performed or is quantitatively performed in highly complex laboratories. Based is these problems, this work presents the development of a motion capture system for didactic use hence a cheap, light, portable and easily used device with a free software. This design includes the selection of the device, the software development for that and tests. The developed system uses the device Kinect, from Microsoft, for its low cost, low weight, portability and easy use, and delivery tree-dimensional data with only one peripheral device. The proposed programs use the hardware to make motion captures, store them, reproduce them, process the motion data and graphically presents the data.
\end{abstract}

Keywords: Biomechanics, Kinect, Motion Caption. 


\section{Lista de Figuras}

Figura 1 - Alguns sistemas de captura de movimento com tecnologia magnética: (a)

Polhemus ${ }^{\circledR}$ Fastrak(b) Polhemus ${ }^{\circledR}$ Liberty (c) Ascention ${ }^{\circledR}$ MotionStar.

Figura 2 - Dispositivos de captura de movimento eletromecânicos(a) Animazoo® Gypsy 7 (b)

Inition ${ }^{\circledR}$ CyberGlove (c) Measurand ${ }^{\circledR}$ ShapeTape.

Figura 3 - Dispositivos de captura de movimentos com método inercial (a) Synertial ${ }^{\circledR}$ IGS180 (b) Xsens ${ }^{\circledR}$ MVN Biomech (c) ST® iNemo ${ }^{\mathrm{TM}}$

Figura 4 - Marcadores para captura ótica da empresa Qualisys ${ }^{\circledR}$ (a)Marcadores passivos, esféricos e com velcro de diversos tamanhos (b) Marcador passivo em forma de fita adesiva (c) Marcador ativo.

Figura 5 - Dispositivos para captura de movimentos com métodos óticos (a) Camera para captura com marcadores passivo Vicon ${ }^{\circledR}$ Serie T (b) Camera para captura com marcadores ativos ou passivos Qualisys ${ }^{\circledR}$ Oqus (c) Dispositivo de captura sem marcadores Sony ${ }^{\circledR}$ PlayStaion Eye.

Figura 6 - Dispositivo Kinect (a) e seus componentes internos (b)..... .25

Figura 7 - Espaço capturado pela câmera do Kinect. .26

Figura 8 - Juntas reconhecidas pelo software embarcado do Kinect.

Figura 9 - Planos de referência do corpo humano.

Figura 10 - Representação da junta do joelho a partir dos ossos envolvidos. .30

Figura 11 - Movimentações do pé.

Figura 12 - Conversão de uma imagem analógica a dados discretos.

Figura 13 - Projeção de um padrão de círculos, captura feita em frequência de luz infravermelha, imagem obtida pelo Kinect.

Figura 14 - Fluxograma das principais funções do programa de captura. 38

Figura 15 - Representação da relação entre as distâncias, para conversão em uma imagem bidimensional. 
Figura 16 - Vista superior do espaço de captura do Kinect.

Figura 17 - Fluxograma do programa de leitura e processamento.........................................45

Figura 18 - Representação dos vetores e o ângulo entre eles.................................................46

Figura 19 - Programa de captura de movimentos em funcionamento....................................50

Figura 20 - Interface do programa de análise e processamento de dado................................51

Figura 21 - Captura de movimentos de um bisão em movimento, feita por Eadweard Muybridge.

Figura 22 - Camera fuzil de Étienne-Jules Marey.

Figura 23 -"A branca de neve" foi o primeiro filme a utilizar captura de movimentos. .65

Figura 24 - "The Sexy Robot", primeiro personagem completamente digital animado por captura de movimentos. .66

Figura 25 - Personagem T-1000, do Filme " Terminator 2: Judgement day”, primeiro filme a combinar personagens digitais com atores reais.

Figura 26 - Dispositivo de aquisição G4.

Figura 27 - Sistema de aquisição de dados de sensore magnéticos Polhemus Liberty...... 68

Figura 28 - Uso do sistema Fastrak para controlar um dispositivo de realidade virtual...... .68

Figura 29 - Posição do equipamento no gabinete do computador. .70

Figura 30 - Receptor TrakStar e um Transmissor de curto alcance.........................................71

Figura 31 - Cena da personagem Lara Croft no jogo Tomb Raider.................................... 72

Figura 32 - Exemplo de animação produzida pelo MotionStar.............................................72

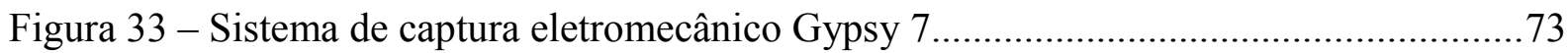

Figura 34 - CyberGlove, equipamento eletromecânico para capturar movimentos da mão....73

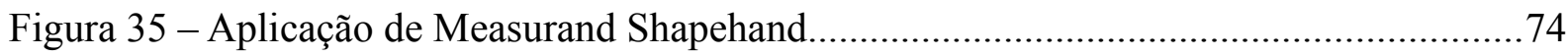

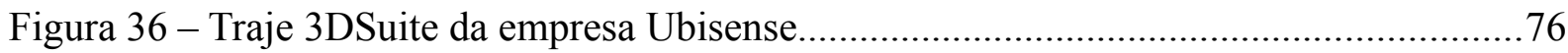


Figura 37 - Traje de captura de movimentos IGS-180.......

Figura 38 - Traje de captura de movimentos MVN Biomech..............................................77

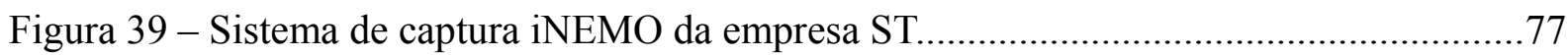

Figura 40 - Ator Andy Serkis, interpretando o personagem Gollum para o filme "The Hobbit" de 2012, é visível o grande número de marcadores passivos no seu corpo e rosto. .78

Figura 41 - Comparação da mesma cena capturada com ilulminação normal e com captura de alto contrasate, realçando os marcadores reflexivos. .78

Figura 42 - Usuário com diversos marcadores e algumas câmeras Vicon ao fundo. 81

Figura 43 - Sistema de captura ótico com marcadores ativos PhaseSpace Impulse 2x.

Figura 44 - Marcadores ativos da Qualisys, longo alcance à esquerda e curto à direita...... .83

Figura 45 - Sistema de captura OrganicMotion e resposta em tempo real. 84

Figura 46 - PlayStation Eye, dispositivo de captura de movimento sem marcadores da Sony. Adaptada de: (SONY, 2014). .85

Figura 47 - Gerenciador de Dispositivos reconhecendo corretamente um Kinect conectado ao computador. 


\section{LISTA DE TABELAS}

Tabela 1 - Apresentação de sistemas de captura encontrados no mercado, comparados qualitativamente a partir dos dados encontrados

Tabela 2 - Interpretação mecânica dos movimentos do pé.......................................................31

Tabela 3 - Movimentos do corpo humano segundos segmento e articulação..........................32

Tabela 4- Enumeração nas juntas capturadas, seus respectivos índices no algoritmo e seus identificadores na biblioteca do Kinect SDK

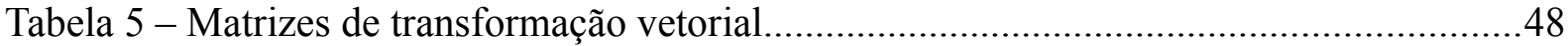

Tabela 6 - Comparação entre os sensores Kinect para XBox 360 e para XBox One...............52

Tabela 7 - Comparativo de sistemas da empresa Polhemus.................................................69

Tabela 8 - Opções de sensores da empresa Ascention Technology.........................................69

Tabela 9 - Atribuições dos transmissores da empresa Ascention.............................................70

Tabela 10 - Comparação entre os produtos da empresa Ascension...........................................71

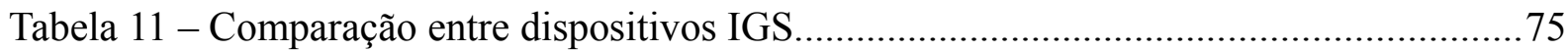

Tabela 12 - Características dos marcadores passivos da empresa Qualisys...........................79

Tabela 13 - Comparativo entre as diversas câmeras da empresa Qualisys.............................80

Tabela 14 - Características das câmeras da empresa Vicon..................................................82 


\section{SUMÁRIO}

1 INTRODUÇÃO

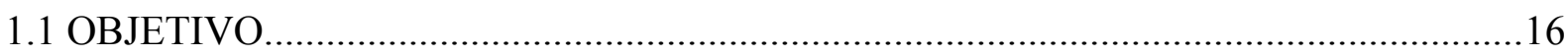

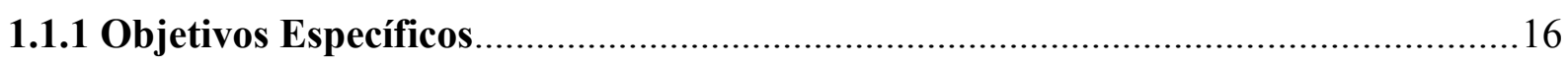

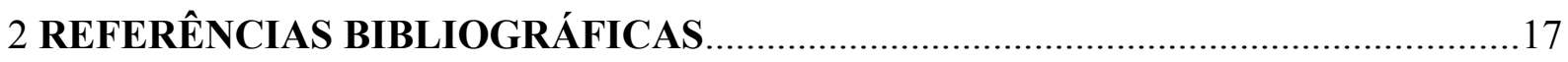

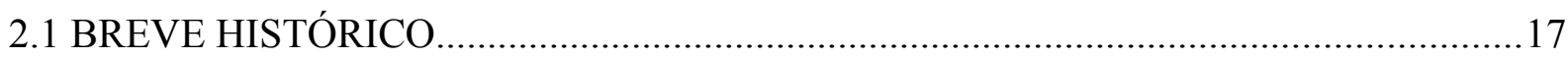

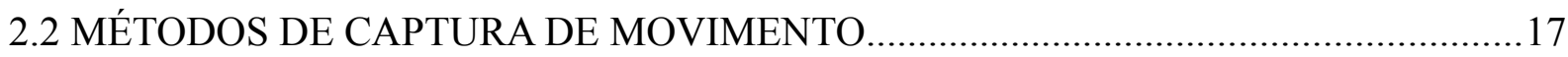

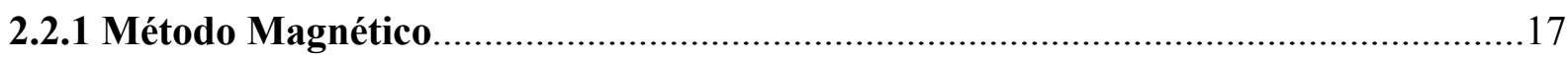

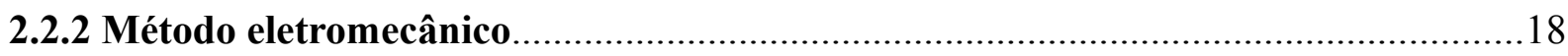

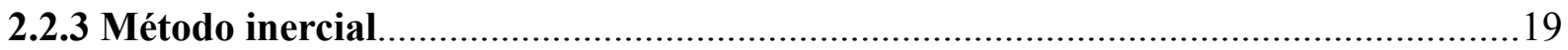

2.2.4 Método ótico

2.2.5 Tabela comparativa

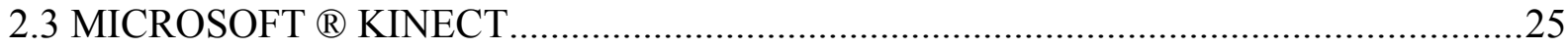

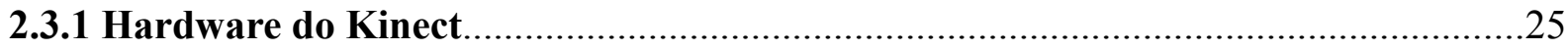

2.3.2 Software do Kinect............................................................................................2

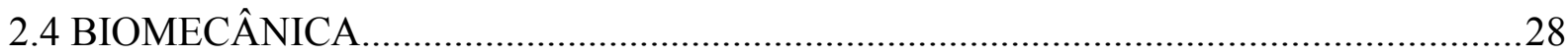

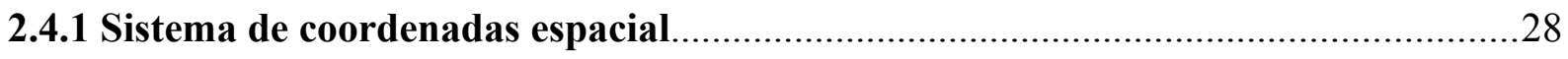

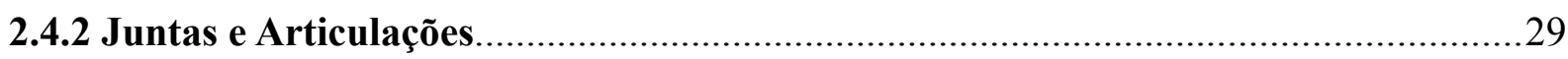

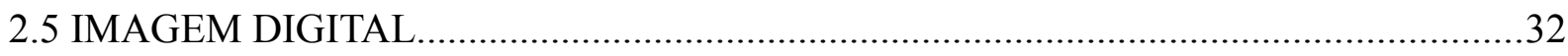

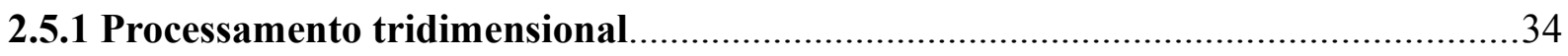

3 METODOLOGIA

3.1 METODOLOGIA DE PROGRAMAÇÃO...................................................................36

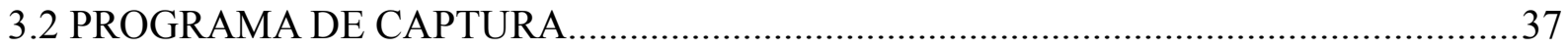

3.2.1 A captura

3.2.2 O retorno visual.............................................................................................. 41

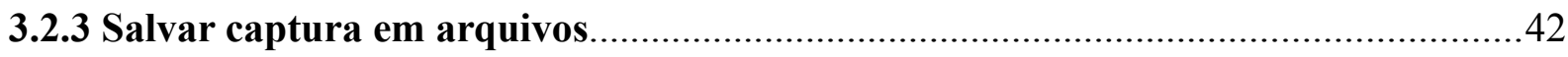




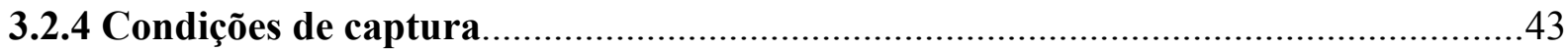

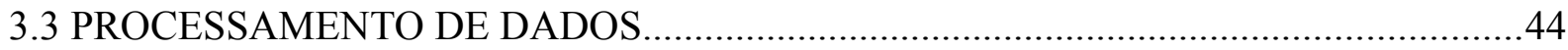

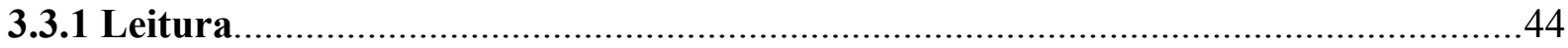

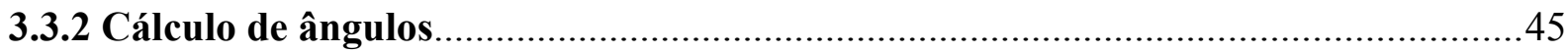

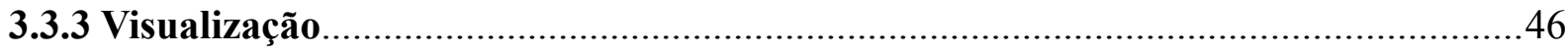

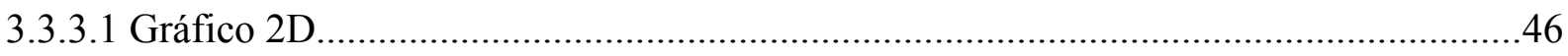

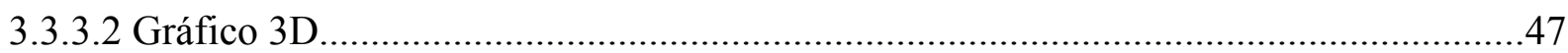

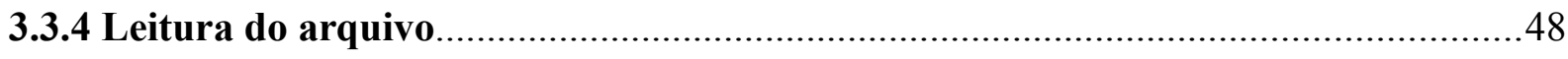

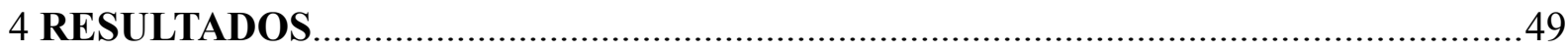

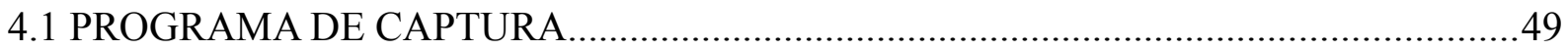

4.2 PROGRAMA DE LEITURA E PROCESSAMENTO......................................................49

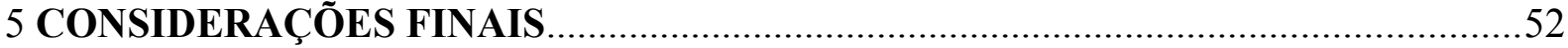

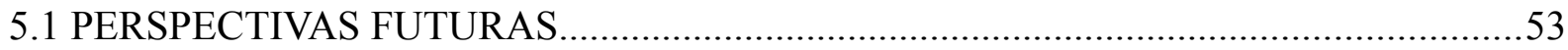

6 BIBLIOGRAFIA

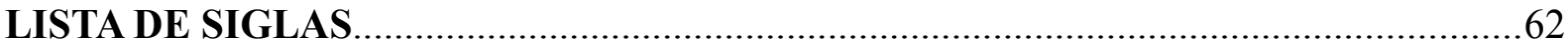

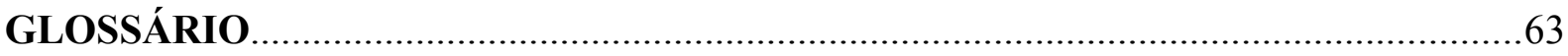

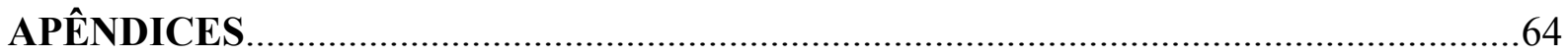

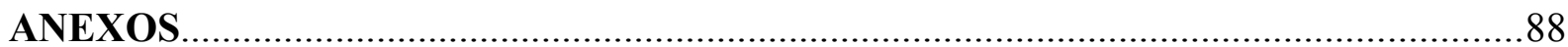




\section{INTRODUÇÃO}

A captura de movimentos é um conjunto de métodos que se baseiam no registro de posições específicas ao longo do tempo. Os objetivos desta captura são estudos biomecânicos, animação de personagens para jogos ou vídeos, análises clínicas, análises com animais ou plantas para engenharia biomimética (SARAIVA, 2009), assim como a análise de movimentos de máquinas entre outros.

Os primeiros estudos sobre captura de movimentos foram realizados por Edweard Muybrige nos Estados Unidos (RONDINELLA, 1929) e Étienne-Jules Marey na França (HOFFMANN, 2013), ambos em meados de 1860 e com objetivos biomecânicos, o primeiro estudou animais e o segundo humanos. O estudo de movimentos humanos cresceu principalmente no século XX devido ao desenvolvimento dos métodos de captura para uso no cinema, na televisão e posteriormente nos videogames (GOMIDE et al., 2011).

Um sistema de captura de movimento inclui um dispositivo, uma central de processamentos e um método de análise. Os dispositivos são equipamentos capazes de converter posições ou movimentos em sinais elétricos, como câmeras e acelerômetros. A central de processamento converte estes sinais em números e pode armazená-los, como computadores ou revelação de fotos. O método de análise pode ser computacional (software) ou por observação dos dados coletados.

Existe hoje uma diversidade de sistema de capturas de movimento (PHOENIX, 2012). Porém o custo, o tamanho, a complexidade de instalação e transporte destes aparelhos inviabilizam seu uso em pequenas clínicas e o acesso a estudantes. Os estudantes somente tem acesso a equipamentos de análise de movimento em aulas de laboratórios específicos (CARSE et al., 2013). Os dados gerados e os procedimentos apresentados pelos equipamentos são predeterminados, fixos e nem sempre de fácil interpretação. Os softwares oferecidos são fechados não permitindo uma variação no método de captura e análise biomecânica, o que limita o desenvolvimento em sala de aula ou clínicas.

O estudo da análise de movimentos é fundamental para formação de profissionais da fisioterapia, da educação física, da engenharia biomédica além de esportistas entre outros. Este estudo exige conhecimento de mecânica, cinesiologia, anatomia entre outros. Para uma análise precisa do movimento, ferramentas de engenharia são utilizadas em conjunto com técnicas e conhecimentos anatômicos, fisioterápicos entre outros. Dessa forma os conceitos utilizados nessas análises devem estar difundidos entre os profissionais de ambas as áreas. É 
desejável a obtenção de aparatos e técnicas para auxílio didático no ensino da Biomecânica que possa esclarecer as dúvidas de ambas as áreas e apresentar os conceitos corretos na análise do movimento e suas origens.

Para auxiliar na captura de movimentos e na análise biomecânica em pequenas clínicas e salas de aula neste trabalho será apresentado a metodologia de desenvolvimento de um sistema leve, portátil e de baixo custo.

\subsection{OBJETIVO}

O objetivo deste trabalho é propor um novo sistema de captura que utilize um dispositivo disponível no mercado, um computador como central de processamento e desenvolver o programa de análise e visualização dos dados, o qual deve facilitar a comunicação entre as áreas de engenharia ou saúde que estudem ou trabalhem com cinesiologia.

\subsubsection{Objetivos Específicos}

a) Selecionar um dispositivo de captura de movimento oferecido no mercado, que atenda aos requisitos;

- Custo baixo;

- Capacidade de examinar o corpo todo;

- Fácil transporte;

- Acessibilidade comercial;

- Conexão com computador.

b) Desenvolver um programa para processar os dados obtidos pelo dispositivo selecionado que possa:

- Ler dados armazenados pelo programa de captura;

- Exibição de grandezas como velocidade, aceleração e ângulo das articulações;

- Representar em vídeo os movimentos capturados; 


\section{REFERÊNCIAS BIBLIOGRÁFICAS}

\subsection{BREVE HISTÓRICO}

Os primeiros registros de análises de movimento datam do século IV antes de Cristo, pelo filósofo grego Aristóteles. Muitos outros se dedicaram a estudar o assunto e deram contribuições ao conhecimento da biomecânica, mas todos baseados em observações e desenhos, por não possuírem métodos para capturar o movimento mais eficientes (BAKER, 2007).

Apenas na década de 1860, o americano Eadweard Muybridge e o francês ÉtienneJules Marey, desenvolveram técnicas e dispositivos para capturar movimentos utilizando fotografias sequenciais para o estudo da biomecânica. Apesar de terem trabalhado separadamente, o trabalho de um influenciou no do outro, tiveram contato e discorreram sobre seus experimentos (LEFFMANN, 1929).

No século XX, a indústria cinematográfica foi a principal investidora nos sistemas de captura de movimento para produção de filmes e animações. Ao final do século o desenvolvimento de videogames também impulsionou os avanços na captura de movimentos. Um histórico mais detalhado do uso dos sistemas de captura de movimentos na indústria cinematográfica e nos videogames pode ser encontrado no apêndice A.

\subsection{MÉTODOS DE CAPTURA DE MOVIMENTO}

Existem hoje diversas empresas de desenvolvimento de sistemas de capturas de movimentos no mercado, tais como Qualiys ${ }^{\circledR}$, Vicon ${ }^{\circledR}$, Polhemus ${ }^{\circledR}$, MationStar ${ }^{\circledR}$ e MVN ${ }^{\circledR}$. Cada empresa apresenta uma variedade de produtos e dispositivos para captura de movimentos. Mesmo com esta diversidade de produtos, seus princípios de funcionamento podem ser classificado em apenas quatro métodos principais: magnético, eletromecânico, inercial e ótico. A descrição de cada um desses métodos está descrita a seguir e os principais dispositivos, suas vantagens/limitações podem ser observadas na (Tabela 1) na página 22. Cada dispositivo está melhor descrito no Apêndice B.

\subsubsection{Método Magnético}

Sistemas magnéticos são baseados no fenômeno da indução magnética, que consiste 
na variação de um campo magnético que atravessa uma espira e tem como consequência uma corrente elétrica. Variações diferentes geram correntes diferentes, por isto, uma central de processamento pode identificar a posição da espira, desde que o campo magnético seja conhecido e controlado.

Este método depende de um gerador de campo magnético, para controlar o campo no espaço medido. Os sensores são fixados no usuário e podem ser encontrados em diversos tamanhos. Uma central de processamento interpreta as informações do gerador e dos sensores para calcular a posição e orientação relativa entre eles (KAUR, 2012).

Este método implica em algumas dificuldades, entre elas, as perturbações no campo magnético interferindo nas medições causadas por dispositivos eletrônicos, ímãs, eletroímãs e materiais ferromagnéticos. $\mathrm{O}$ alcance da medição é limitado pela potência do gerador (METAMOTION, 2012b).

Estão apresentados na Figura 1 três modelos de mecanismos encontrados no mercado que funcionam pelo método magnético.

Figura 1 - Alguns sistemas de captura de movimento com tecnologia magnética: (a) Polhemus ${ }^{\circledR}$ Fastrak(b) Polhemus ${ }^{\circledR}$ Liberty (c) Ascention ${ }^{\circledR}$ MotionStar

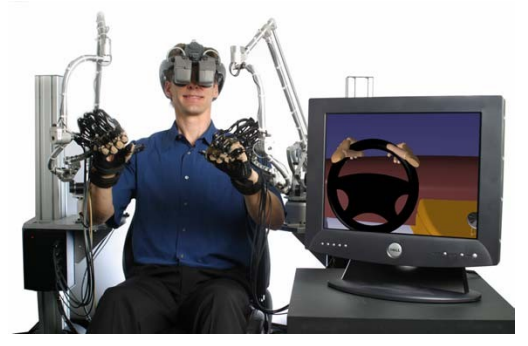

(a)

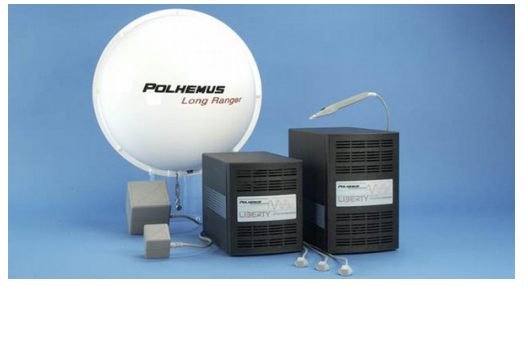

(b)

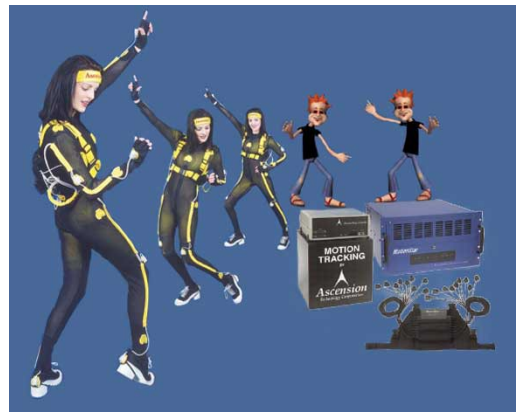

(c)

Fontes: (a)(POLHEMUS, 2014a) (b)(POLHEMUS, 2014b) (c)(ASCENSION, 2000)

\subsubsection{Método eletromecânico}

O método eletromecânico consiste em variações de propriedades elétricas, mecânicas ou óticas de um dispositivo por meio de ações mecânicas, como deformação ou em movimentos articulados dos sensores (GOUVINHAS; FANTASIA, 2008).

Alguns destes dispositivos são compostos de fibras óticas, cuja transmissividade de luz varia quando deformada. Um sensor capta a variação da intensidade de luz que sai da fibra ótica calculando a sua variação angular. 
Sensores como potenciômetros utilizam a variação da posição de contato em um resistor para medir a movimentação em uma articulação de seu sensor. Devido à mudança neste contato a resistência do sistema é alterada, podendo assim calcular o deslocamento dos sensores.

Outros materiais têm propriedades elétricas afetadas por deformação ou vibração, como o compósito IPMC (LOPES et al., 2011). Deformações em sua estrutura causam diferença de potencial entre suas superfícies gerando um sinal elétrico.

A sua fixação exige trajes específicos e podem gerar resistências ao movimento, modificando a movimentação normal do usuário.

Estão apresentados na figura 2 três modelos de mecanismos encontrados no mercado com tecnologia de captura eletromecânica.

Figura 2 - Dispositivos de captura de movimento eletromecânicos(a) Animazoo ${ }^{\circledR}$ Gypsy 7 (b) Inition ${ }^{\circledR}$ CyberGlove (c) Measurand $\AA$ ShapeTape

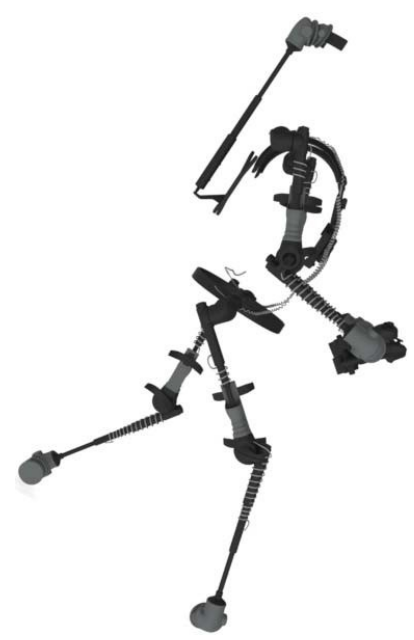

(a)

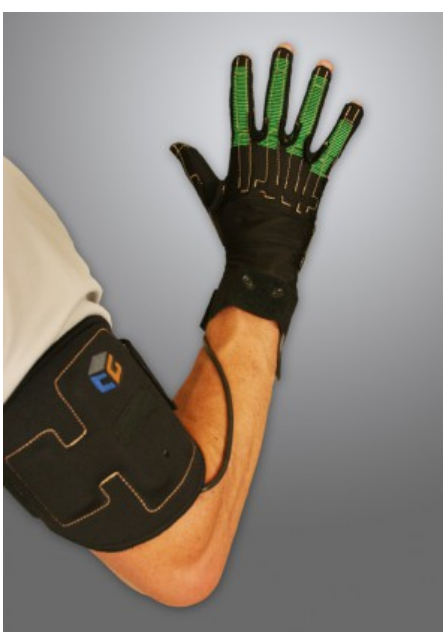

(b)

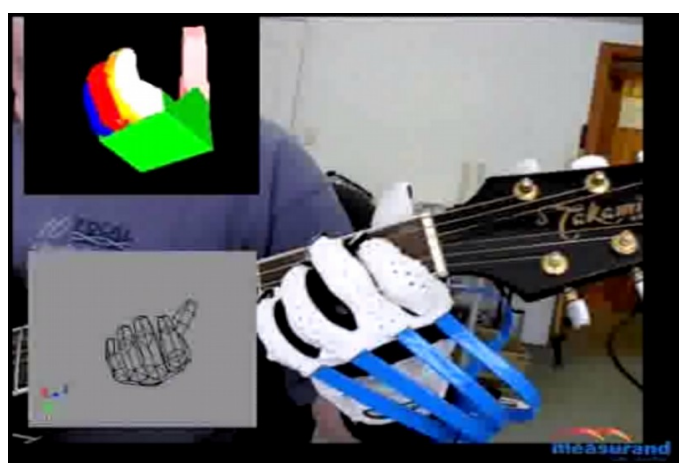

(c)

Fontes: (a) (MOTIONWERX, [S.d.]) (b)(INITION, 2014) (c)(SURVR, 2014)

\subsubsection{Método inercial}

Os sistemas inerciais consistem em sensores dos tipos acelerômetros e giroscópios, conhecidos por microssistemas mecânico-eletrônicos (Microelectromechanical systems, MEMS) que são afixadas a membros moveis. Estes sensores são capazes de captar a própria aceleração (RODRIGUEZ-MARTIN et al., 2013).

Os sensores inercias possuem uma estrutura interna com uma massa conhecida e uma fixação elástica. Ao ocorrer uma aceleração, é gerada uma força que deforma o fixador da 
massa. Devido as $1^{\mathrm{a}}$ e $2^{\mathrm{a}}$ Leis de Newton, inercia e variação da quantidade de movimento (HALLIDAY; RESNICK; WALKER, 2011). Essa movimentação interna modifica propriedades elétricas do conjunto transformando, assim, acelerações dinâmicas em sinais elétricos. Cada sensor precisa de um MEMS para cada grau de liberdade medido.

Estão apresentados na figura 3 três sistemas de captura de movimento com dispositivos inerciais.

Figura 3 - Dispositivos de captura de movimentos com método inercial (a) Synertial ${ }^{\circledR}$ IGS-180 (b) Xsens ${ }^{\circledR}$ MVN Biomech (c) ST® iNemo ${ }^{\mathrm{TM}}$

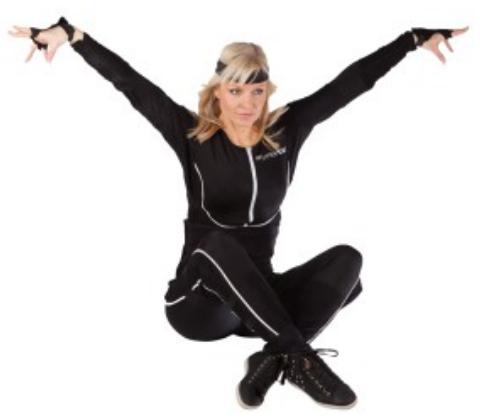

(a)

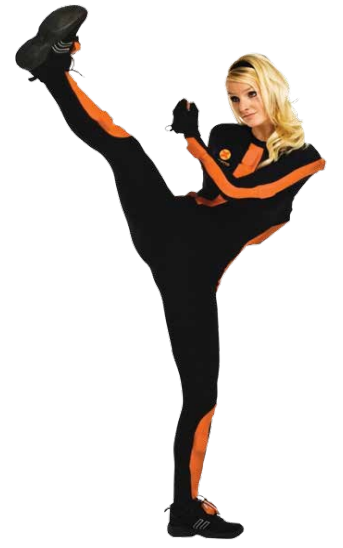

(b)

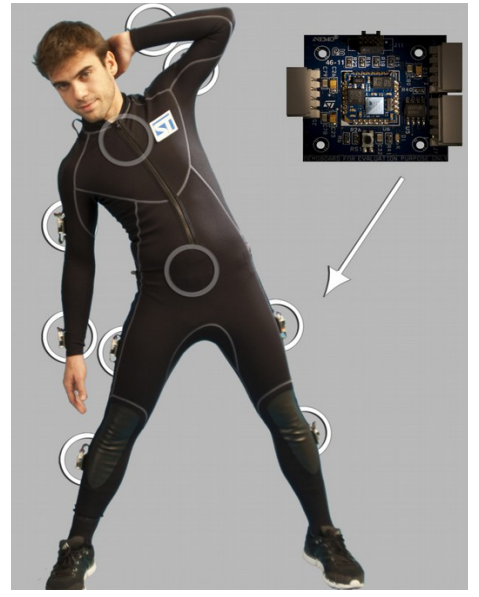

(c)

Fontes: (a) (SYNERTIAL, 2013b) (b) (XSENS, 2014)(c) (ST, 2013)

\subsubsection{Método ótico}

Os métodos óticos consistem em análises quantitativas de imagens, capturadas por uma ou mais câmeras. Podem ser subdivididos em três grandes categorias de acordo com sua forma de captura: com marcadores passivos, com marcadores ativos e sem marcadores. Marcadores são aparatos fixados ao indivíduo em análise. Os marcadores passivos são reflexivos e os ativos são emissores de luz.

Os marcadores passivos, por serem reflexivos exigem uma emissão de luz externa para funcionar, a qual costuma ser acoplada à própria câmera. As câmeras capturam apenas as luzes na frequência emitida, assim os marcadores aparecem com destaque nas imagens capturadas. Desta forma os marcadores são facilmente isolados computacionalmente, permitindo assim uma análise como pouca influência externa, ainda que dificultada por outros objetos reflexivos. Alguns destes marcadores estão representados na figura 4.

Os sistemas de captura com marcadores ativos também utilizam câmeras combinadas 
para capturar os marcadores que são emissores de luz. Isto reduz na câmera a necessidade de emissão luminosa, ainda que os marcadores necessitem de alimentação por bateria ou cabos (SIGAL, 2012).

Figura 4-Marcadores para captura ótica da empresa Qualisys ${ }^{\circledR}($ (a)Marcadores passivos, esféricos e com velcro de diversos tamanhos (b) Marcador passivo em forma de fita adesiva (c) Marcador ativo.

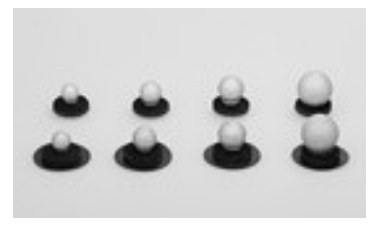

(a)

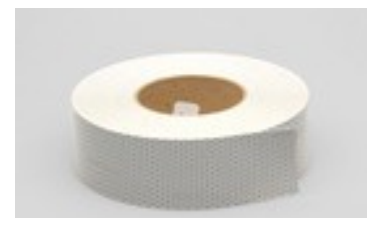

(b)

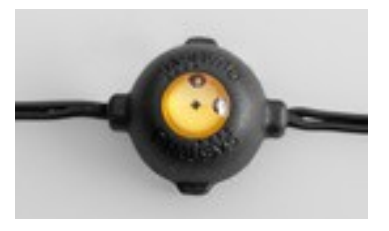

(c)

Fontes: (a) e (b) (QUALISYS, 2013b) (c) (QUALISYS, 2013a)

Sistemas de captura de movimento sem marcadores são os pioneiros na captura de imagens. Os trabalhos de Muybridge (MUYBRIDGE, 1883) e Marey (LAPORTE, 1998) foram realizados com essa técnica no século XIX. A tecnologia atual favoreceu esta técnica por equipamentos capazes de fazer capturas tridimensionais, câmeras com alta resolução e taxa de captura, acrescidas de computadores capazes de processar os dados com confiabilidade e rapidez.

Na figura 5 pode-se observar exemplos de câmeras de sistemas de captura óticos.

Figura 5 - Dispositivos para captura de movimentos com métodos óticos (a) Camera para captura com marcadores passivo Vicon ${ }^{\circledR}$ Serie T (b) Camera para captura com marcadores ativos ou passivos Qualisys ${ }^{\circledR}$ Oqus (c) Dispositivo de captura sem marcadores Sony ${ }^{\circledR}$ PlayStaion Eye

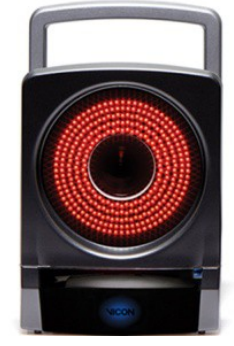

(a)

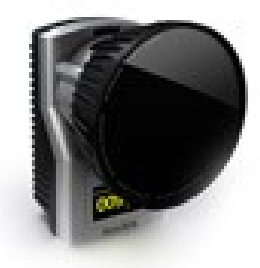

(b)

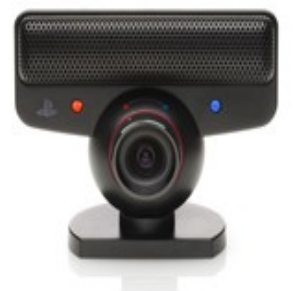

(c)

Fontes:(a)(VICON, 2014) (b) (QUALISYS, 2014) (c) (SONY, 2014)

Uma vantagem destes sistemas é não necessitar de fixar qualquer tipo de dispositivo no usuário, nem de trajes especiais. O que torna bastante prático para aplicações que necessitem de um menor tempo de execução de preparo. 


\subsubsection{Tabela comparativa}

Tabela 1 - Apresentação de sistemas de captura encontrados no mercado, comparados qualitativamente a partir dos dados encontrados.

\begin{tabular}{|c|c|c|c|c|c|}
\hline SISTEMA & VANTAGENS & PRECISÃO & $\begin{array}{l}\text { FREQUÊNCIA } \\
\text { DE CAPTURA }\end{array}$ & LIMITAÇÕES & PREÇO ESTIMADO \\
\hline \multicolumn{6}{|c|}{ Sistemas Magnéticos } \\
\hline G4 & Portátil & Baixa & $120 \mathrm{~Hz}^{*}$ & Pode capturar apenas quatro pontos do corpo & 5.250 a 2.995 USD \\
\hline Liberty & 16 sensores & Baixa & $\begin{array}{l}240 \mathrm{~Hz} \text { (com fios) } \\
188 / 94 \mathrm{~Hz} \text { (sem fios) }\end{array}$ & $\begin{array}{l}\text { Frequência de captura reduzida quanto mais sensores } \\
\text { forem utilizados na versão sem fios }\end{array}$ & 7.955 a 20.345 USD \\
\hline Fastrak & Sistema automatizado & Média & $120 / 60 / 40 / 30 \mathrm{~Hz}$ & Pode capturar apenas quatro pontos do corpo & 6.350 a 7.850 USD \\
\hline DriveBay & Frequência de captura & Média & $420 / 240 \mathrm{~Hz}$ & $\begin{array}{l}\text { Pode capturar apenas quatro pontos do corpo, alcance } \\
\text { curto }\end{array}$ & 3.540 a 6.145 USD \\
\hline TrakStar & $\begin{array}{l}\text { Frequência de captura e } 16 \\
\text { sensores }\end{array}$ & Média & $420 / 240 \mathrm{~Hz}$ & Apenas $2,1 \mathrm{~m}$ de alcance & 4.797 a 7.663 USD \\
\hline MotionStar & 18 sensores & Baixa & $144 \mathrm{~Hz}$ & Custo incoerente com a precisão & 29.000 a 88.000 USD \\
\hline \multicolumn{6}{|c|}{ Sistemas Eletromecânicos } \\
\hline Gypsi 7 & É um traje & Média & $30 / 60 / 120 \mathrm{~Hz}$ & $\begin{array}{l}\text { Apenas coordenadas relativas e limitado número de juntas } \\
\text { medidas }\end{array}$ & 7.995 a 16.100 USD \\
\hline CyberGlove & Captura muito detalhada & Média & $100 \mathrm{~Hz}$ & Apenas mãos & 12.995 USD \\
\hline $\begin{array}{l}\text { Measurand } \\
\text { ShapeTape }\end{array}$ & Captura muito detalhada & Média & $110 \mathrm{~Hz}$ & Apenas mãos & 4.550 a 15.275 USD \\
\hline
\end{tabular}




\begin{tabular}{|c|c|c|c|c|c|}
\hline SISTEMA & VANTAGENS & PRECISÃO & $\begin{array}{l}\text { FREQUÊNCIA } \\
\text { DE CAPTURA }\end{array}$ & LIMITAÇÕES & PREÇO ESTIMADO \\
\hline \multicolumn{6}{|c|}{ Sistemas Inerciais } \\
\hline IGS-150 Wireless & $\begin{array}{l}\text { Taxa de captura e alcance de } \\
30 \mathrm{~m}\end{array}$ & Média & $500 \mathrm{~Hz}^{*}$ & Limite de aceleração e custo & 31.500 USD \\
\hline IGS-180 & $\begin{array}{l}\text { Taxa de captura, } 18 \text { sensores e } \\
\text { alcance de } 50 \mathrm{~m}\end{array}$ & Alta & $500 \mathrm{~Hz}^{*}$ & Custo muito alto & 50.400 USD \\
\hline IGS-180i & $\begin{array}{l}\text { Taxa de captura, } 25 \text { sensores e } \\
\text { alcance de } 50 \mathrm{~m}\end{array}$ & Alta & $500 \mathrm{~Hz}^{*}$ & Custo muito alto & 68.500 USD \\
\hline 3DSuit & Alcance de $30 \mathrm{~m}$ sem fios & Média & $100 \mathrm{~Hz}^{*}$ & Apenas coordenadas relativas & 9.094 a 15.594 USD \\
\hline MVN Biomech & Alcance de $150 \mathrm{~m}$ & Média & $120 / 100 / 80 / 60 \mathrm{~Hz}^{*}$ & Custo muito alto & $48.000 \mathrm{USD}$ \\
\hline iNEMO & $\begin{array}{l}15 \text { sensores com } 9 \text { graus de } \\
\text { liberdade }\end{array}$ & Média & $70 \mathrm{~Hz}^{*}$ & Taxa de captura inferior aos concorrentes & N/A \\
\hline
\end{tabular}

Sistemas Óticos com marcadores passivos ou ativos

\begin{tabular}{|c|c|c|c|c|c|}
\hline Oqus & Serie padrão da empresa & Média /alta & 180 a $1750 \mathrm{fps}^{* *}$ & Necessidade de muitas câmeras & N/A \\
\hline Oqus MRI & $\begin{array}{l}\text { Compatível com ressonância } \\
\text { magnética }\end{array}$ & Média /alta & 180 a 1750 fps** & Necessidade de muitas câmeras & N/A \\
\hline Oqus Underwater & À prova de água & Média /alta & 180 a 1750 fps** & Necessidade de muitas câmeras & N/A \\
\hline Oqus FX & Resposta rápida & Média /alta & 180 a $1750 \mathrm{fps}^{* *}$ & Necessidade de muitas câmeras & N/A \\
\hline Oqus Video & Imagem em HD & Média & 337 a $750 \mathrm{fps}^{* *}$ & Necessidade de muitas câmeras & N/A \\
\hline Vicon $T$ & $\begin{array}{l}\text { Resolução de até } 16 \text { MP, } \\
\text { disponível em cinco séries } \\
\text { diferentes }\end{array}$ & $\begin{array}{l}\text { Média/ Alta/ } \\
\text { Muito alta }\end{array}$ & $\begin{array}{l}120 / 515 / 690 / 1000 / 2 \\
50 \mathrm{fps}^{* *}\end{array}$ & Custo muito alto & N/A \\
\hline Vicon Bonita & Modelo básico & Média & $240 / 250$ fps $^{* *}$ & Apenas 1 MP de resolução & N/A \\
\hline
\end{tabular}




\begin{tabular}{|c|c|c|c|c|c|}
\hline SISTEMA & VANTAGENS & PRECISÃO & $\begin{array}{l}\text { FREQUÊNCIA } \\
\text { DE CAPTURA }\end{array}$ & LIMITAÇÕES & PREÇO ESTIMADO \\
\hline Impulse $2 x$ & Resolução até $12 \mathrm{MP}$ & Muito Alta & $960 \mathrm{fps}^{* *}$ & Gasto em baterias & N/A \\
\hline Improv & Resolução até $12 \mathrm{MP}$ & Alta & $240 \mathrm{fps}^{* *}$ & Gasto em baterias & N/A \\
\hline Qualisys Longo & Alcance de $100 \mathrm{~m}$ & Média & $200 \mathrm{fps}^{* *}$ & $\begin{array}{l}\text { Objetos que cruzem o espaço entre a câmera e os } \\
\text { transmissores }\end{array}$ & N/A \\
\hline Qualisys Curto & Alcance de $100 \mathrm{~m}$ & Muito Alta & $500 \mathrm{fps}^{* *}$ & Nível de processamento elevado & $\mathrm{N} / \mathrm{A}$ \\
\hline \multicolumn{6}{|c|}{ Sistemas Óticos sem marcadores } \\
\hline Organic Motion & $\begin{array}{l}\text { Frequência de captura e } \\
\text { qualidade da imagem }\end{array}$ & Alta & 80 a $160 \mathrm{fps}^{* *}$ & Quantidade elevada de câmeras, custo muito elevado & 40.000 a 80.000 USD \\
\hline PlayStation Eye & Custo muito baixo, portátil & Baixa & 60 ou $120 \mathrm{fps}^{* *}$ & Não reconhece posições, apenas gestos & Menos de $50 \mathrm{BRL}$ \\
\hline Kinect & $\begin{array}{l}\text { Custo baixo, captura } \\
\text { tridimensional com um } \\
\text { dispositivo, portátil }\end{array}$ & Baixa & $30 \mathrm{fps}^{* *}$ & Alto ruido, influência de luz externa & $220 \mathrm{BRL}$ \\
\hline
\end{tabular}

* Hertz, unidade de medida de frequência, ciclos por segundos

**Frames per Seconds, quadros por segundo, unidade de medida de frequência de captura 


\subsection{MICROSOFT ${ }^{\circledR}$ KINECT}

Dentre os sistemas apresentados, vale destacar o Kinect (Figura 6) da Microsoft, pois ele é portátil, tem um preço acessível, é facilmente encontrado no mercado, pode ser utilizado com porta USB e com apenas uma câmera faz medições tridimensionais.

Figura 6-Dispositivo Kinect (a) e seus componentes internos (b)

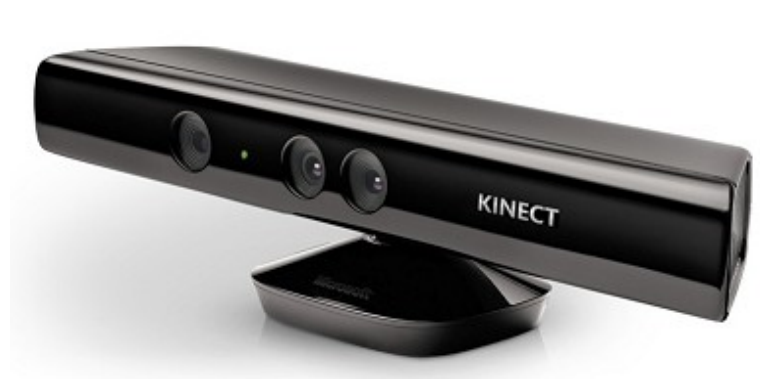

(a)

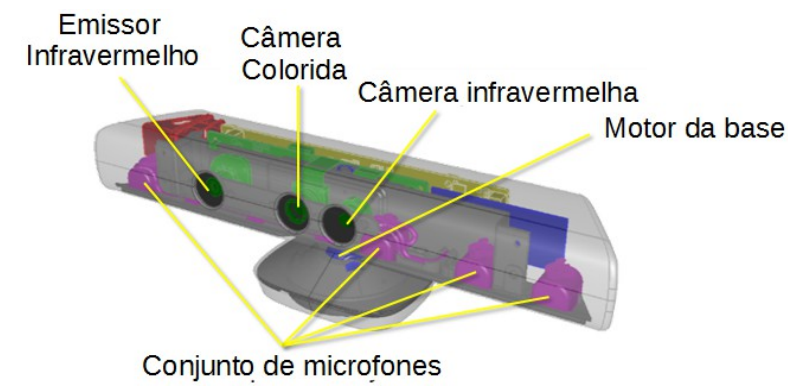

(b)

Fonte:(MICROSOFT, [S.d.])

\subsubsection{Hardware do Kinect}

O dispositivo Kinect é um periférico para o videogame Xbox 360 e para computadores. Mede $7 \mathrm{~cm}$ de altura, $7 \mathrm{~cm}$ de espessura e $27 \mathrm{~cm}$ de largura, com a forma de uma barra horizontal (chamada de câmara daqui em diante) presa a uma base (MICROSOFT, ROBOTICS DEVELOPER STUDIO, 2011), seus componentes estão representados na figura 6 e apresentados em seguida:

a) Câmera colorida

Uma câmera digital semelhante a uma webcam ou câmeras encontradas em aparelhos de celular. Pode capturar a cores visíveis em combinações de vermelho, verde e azul (RGB, Red, Green and Blue, tradução nossa). Pode funcionar desde uma resolução de 640 × 480 pixeis (0,3 MP) a 30 pfs, até uma resolução de $1280 \times 960$ pixeis (1,2 MP) a 12 fps. As capturas são feitas dentro de um espaço de $0,8 \mathrm{~m}$ a $4 \mathrm{~m}$ à frente do dispositivo com um escopo piramidal de $43^{\circ}$ verticalmente e $57^{\circ}$ horizontalmente. A figura 7 representa uma vista lateral do espaço capturado pela câmera verticalmente e da variação possibilitada pelo motor da base; 
Figura 7 - Espaço capturado pela câmera do Kinect.

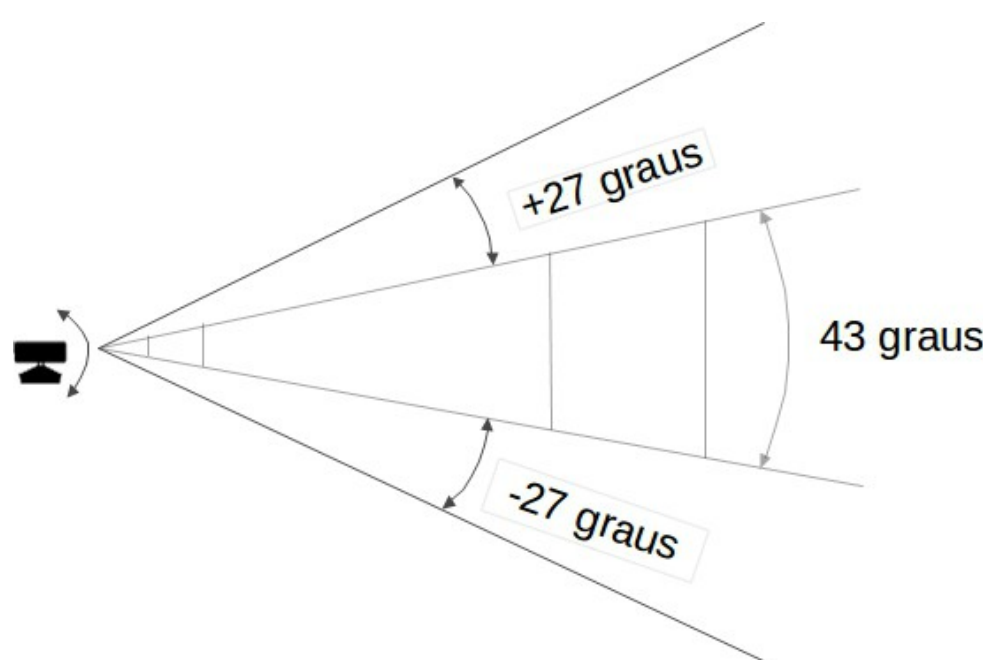

Fonte:(MICROSOFT, 2013)

b) Emissor infravermelho

Este emissor funciona como um projetor de luz, emite uma malha com padrão de círculos à frente do dispositivo, a projeção emitida é em frequência infravermelha, por isto é invisível a olho nu;

c) Câmera infravermelha

Esta é uma câmera digital que só capta luz na frequência infravermelha, funciona em conjunto com o emissor para capturar a projeção feita pelo dispositivo. A sua resolução pode ser ajustada para 640 × 480 pixeis, $320 \times 240$ pixeis ou $80 \times 60$ pixeis. O espaço alcançado por esta câmera é semelhante ao da câmera colorida e pode fazer capturas em até 30 fps. O processamento para interpretar os dados desta câmera em três dimensões foi desenvolvido pela empresa israelita Primesense.

d) Motor de inclinação

É capaz de alterar o ângulo relativo entre a câmara e a base, útil para regular o espaço capturado com relação à altura que o Kinect for colocado, pode variar o ângulo de captura em $27^{\circ}$ para cima ou para baixo;

e) Acelerômetro

Este componente é capaz de capturar a inclinação da câmara em relação à aceleração da gravidade e possui resolução de um grau;

f) Conjunto de microfones

São quatro microfones dispostos ao longo da câmara, três à direita e um à esquerda. A 
distância entre eles permite reconhecer a direção da qual o som vem. Esta distribuição das posições dos microfones se deve ao espaço onde os dispositivos óticos ocupam na câmara do Kinect;

g) Luz de estado

É um LED localizado entre o emissor infravermelho e a câmera colorida, pode assumir as cores: verde, laranja ou vermelho;

h) Microchip do sistema

Central de processamento interna do dispositivo. Possui um software embarcado que controla os componentes, responsável pelo envio dos dados capturados pelos componentes e receber os comandos do console (videogame ou computador).

Estas informações são fornecidas por JANA (2012).

\subsubsection{Software do Kinect}

O software embarcado do Kinect foi desenvolvido pela Microsoft (MICROSOFT, 2013) e é essencial para o funcionamento do sistema. Funciona com base em redes neurais e continuidade de renderização, programadas para reconhecer corpos humanos a partir dos dados de profundidade obtidos.

Este software reconhece pontos próximos entre si como uma continuidade de um único objeto. Após reconhecer um objeto grande o suficiente para ser uma pessoa ele procura formas humanas. A partir de uma rede neural treinada com uma grande diversidade de humanos. O reconhecimento de um corpo inteiro é obtido pelo reconhecimento de segmentos do corpo, como braço, antebraço e ombro.

Após reconhecer os segmentos, o software posiciona as juntas conhecidas, representadas na figura 8 , de acordo com a posição mais provável que eles podem assumir segundo a posição dos segmentos.

Como o algoritmo busca por continuidades, roupas largas geram interpretações erradas sobre as formas dos segmentos do corpo, o que pode atrapalhar o posicionamento das juntas. Por isto é mais adequado para medição usar roupas mais justas. 
Figura 8 - Juntas reconhecidas pelo software embarcado do Kinect.

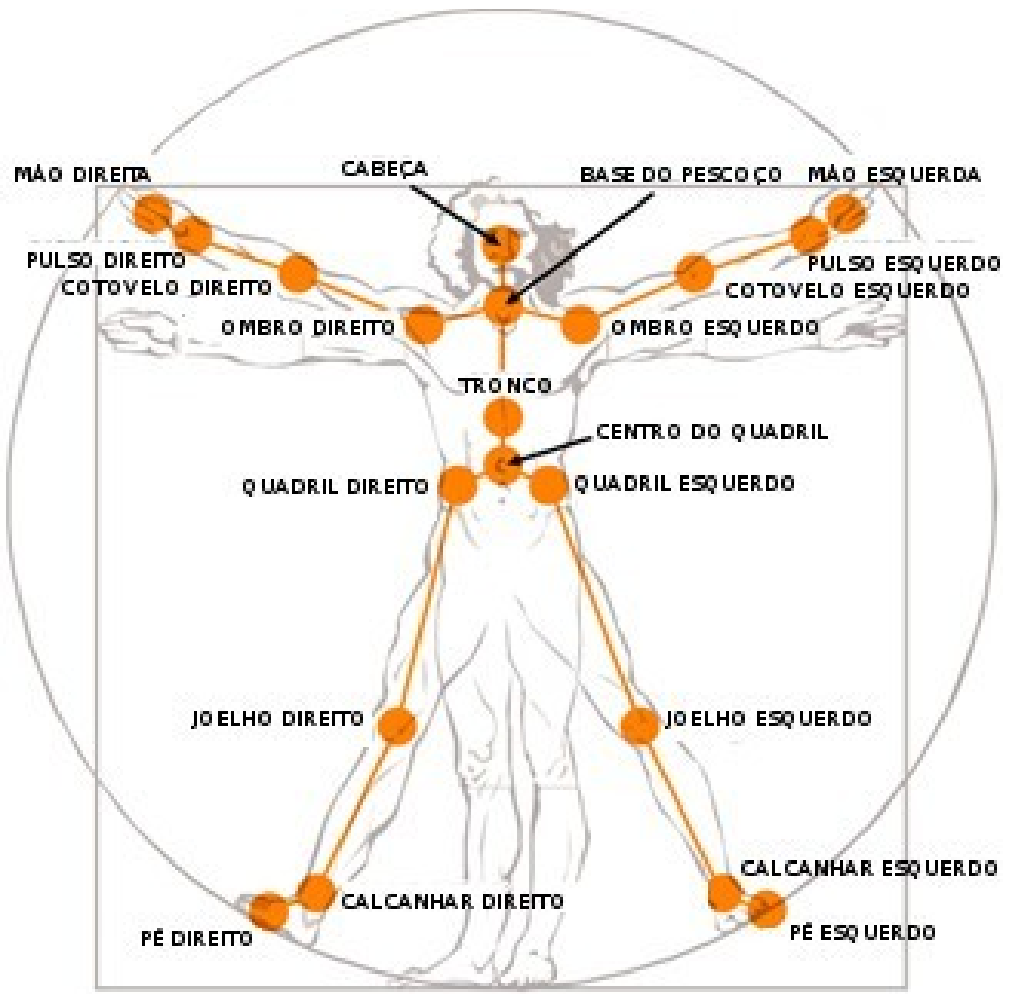

Fonte: Adptado de:(MICROSOFT, [S.d.])

\subsection{BIOMECÂNICA}

\subsubsection{Sistema de coordenadas espacial}

Um sistema de coordenadas espacial é um elemento da análise de grandezas vetoriais, como velocidade, posição, aceleração e outras grandezas secundárias baseadas nelas, como o tamanho, o volume e a área. Um sistema de coordenadas trata numericamente estas grandezas dentro de um espaço limitado para estudo, permitindo métodos matemáticos para analisar objetos e seres vivos. O sistema cartesiano é o mais comum sistema de coordenadas utilizados em Engenharia, é definido por três eixos ortogonais formando uma base. Todas as representações nesse sistema são por meio de vetores de três coordenadas, que representam o quão grande é aquele vetor na direção de cada eixo. O sistema é formado por três planos, normalmente chamados como: horizontal, longitudinal e transversal, que se encontram no centro do sistema, o qual varia de acordo com o ponto de referência utilizado (ANTON; RORRES, 2002).

Um sistema de coordenadas espacial na análise de movimento humano utiliza planos 
de referência conhecidos como: Sagital, frontal e transverso (Figura 9). Estes planos são ortogonais entre si e todos se cruzam no centro de gravidade do corpo (próximo à cavidade umbilical). O plano sagital divide o corpo entre direita e esquerda, o frontal entre posterior (frente) e anterior (trás), enquanto o plano transverso divide em superior e inferior (KAZEROONI; CHU; STEGER, 2007). Esse plano é definido como plano anatômico e é utilizado como referência para a análise do movimento de qualquer articulação.

Para o corpo humano pode-se adotar sistemas de coordenadas segundo os seguimentos como pélvis, fêmur e pé, ou segundo as juntas como joelho, cotovelo e tornozelo. A escolha do sistema deve ser feita de acordo com a necessidade do estudo. Para estudos com a parte inferior do corpo, deve-se usar o sistema segundo as juntas (HILAL et al., 2002).

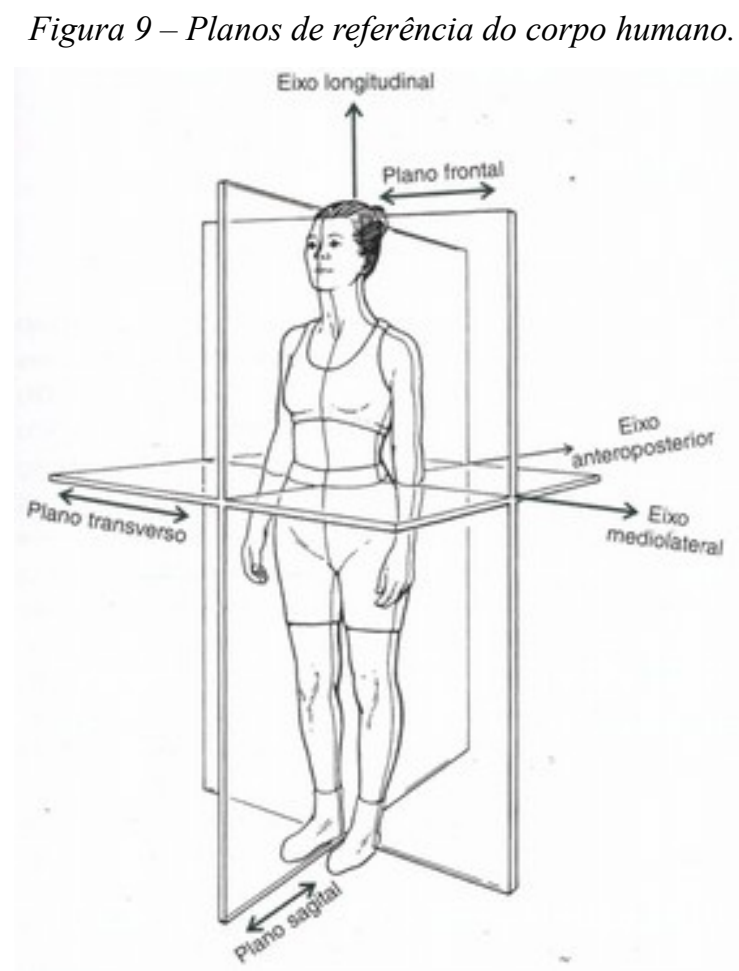

Fonte: (HAMILL; KNUTZEN, 2012)

\subsubsection{Juntas e Articulações}

As juntas do corpo humano, ou articulações, são conexões entre membros do corpo que possuem movimento relativo entre si. Normalmente o termo junta é utilizado na área de engenharia e o termo articulação na área da saúde. Mecanicamente as juntas podem ser classificadas quanto a seus graus de liberdade. Cada grau representa a liberdade de girar em 
torno de um eixo num sistema de coordenadas ou de mover-se paralelamente a um.

O Standardization Terminology Committee (STC, Comitê de Padronização e Terminologia, tradução nossa) da International Society of Biomechanics (ISB, Sociedade Internacional de Biomecânica, tradução nossa) nomeou cada movimento das articulações do corpo humano (WU et al., 2002).

Os planos de referência biomecânica são redefinidos quando se estuda um membro isoladamente, tomando como exemplo a junta do pé com a canela (tornozelo), representada na figura10. O plano frontal inclui o ponto médio (IM) entre o maléolo mais medial (próximo do plano sagital) e mais lateral (distante do plano sagital), respectivamente MM e LM. O plano sagital é perpendicular ao plano frontal e contém o IM e o ponto médio (IC) entre os côndilos medial (MC) e lateral (LC). O plano transverso é perpendicular aos dois planos citados. Há também um plano torcional, que inclui o IC, MM e LM.

Figura 10 - Representação da junta do joelho a partir dos ossos envolvidos.

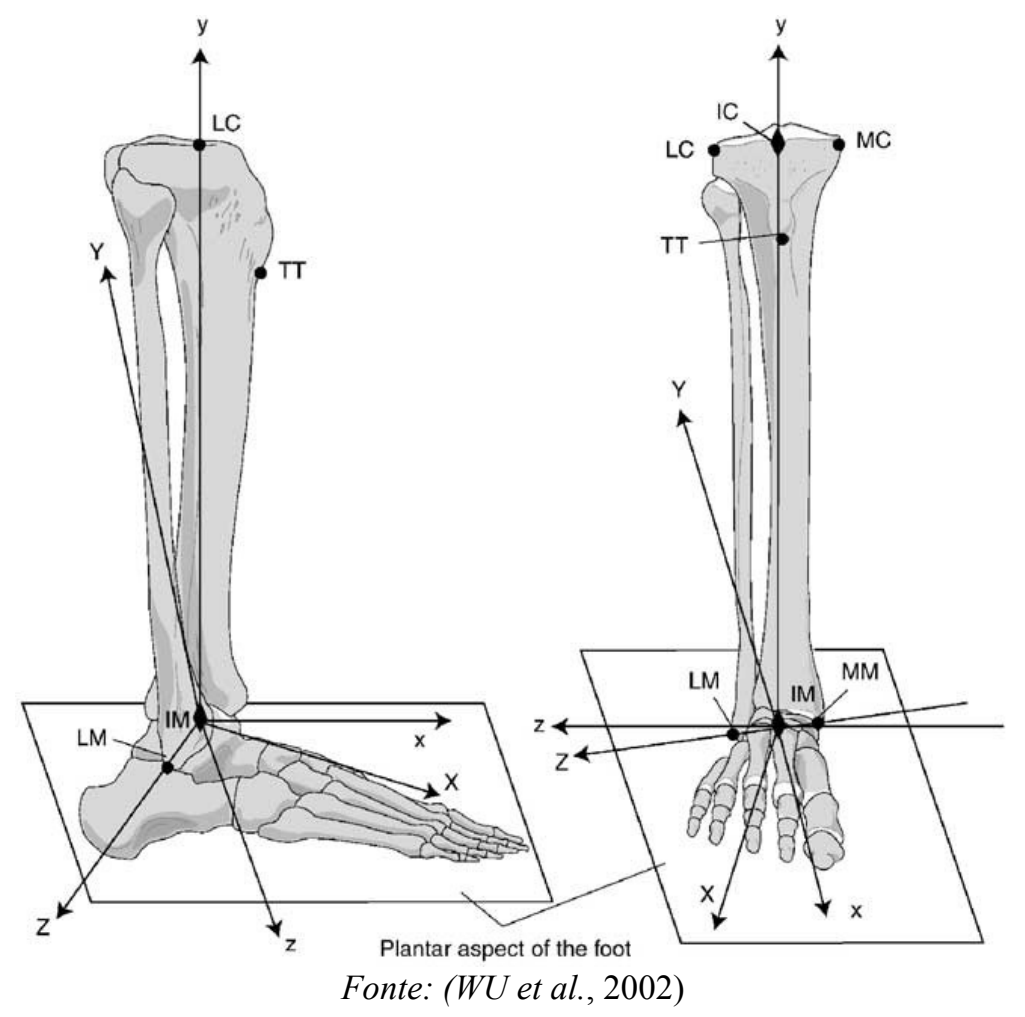

Esta junta é subdividida em duas outras juntas: tornozelo e subtalar, a primeira entre os ossos da tíbia e da fíbula, a segunda entre o tálus e calcâneo. Este conjunto de sistemas de coordenadas centradas no ponto médio (IM) entre a parte mais medial (MM) e lateral (LM), respectivamente são as partes dos ossos da canela mais próxima e mais distante do plano 
sagital. O plano frontal inclui os pontos IM, LC e MC.

São formados dois sistemas de coordenadas, um representado com letras maiúsculas (XYZ) o eixo anteroposterior (Z) passa por MM e LM, eixo longitudinal (Y e y) parte de IM até o ponto médio (IC) entre a parte mais lateral do encontro do osso da canela com o joelho (LC) e a parte mais medial deste encontro (MC), enquanto o eixo mediolateral (X) é perpendicular a ambos. No outro sistema, o eixo longitudinal (x) é perpendicular ao plano frontal e o eixo transversal (z) é perpendicular aos eixos x e y.

Os movimentos possíveis para o pé são descritos de formas diferentes. A tabela 2 apresenta como comparar a nomenclatura da área da saúde com os movimentos estudados em modelos mecânicos e a figura 11 os ilustra.

Tabela 2 - Interpretação mecânica dos movimentos do pé.

\begin{tabular}{c|c} 
Cinesiologia & Mecânica \\
\hline Dorsiflexão & Rotação em torno do eixo Z negativa \\
Flexão planar & Rotação em torno do eixo Z positiva \\
Abdução & Rotação em torno do eixo Y, positiva no pé esquerdo e negativa no direito \\
Adução & Rotação em torno do eixo Y, positiva no pé direito e negativa no esquerdo \\
Inversão & Rotação em torno do eixo X, positiva no pé esquerdo e negativa no direito \\
Eversão & Rotação em torno do eixo X, positiva no pé direito e negativa no esquerdo
\end{tabular}

Fonte: (WU et al., 2002)

Figura 11 - Movimentações do pé.
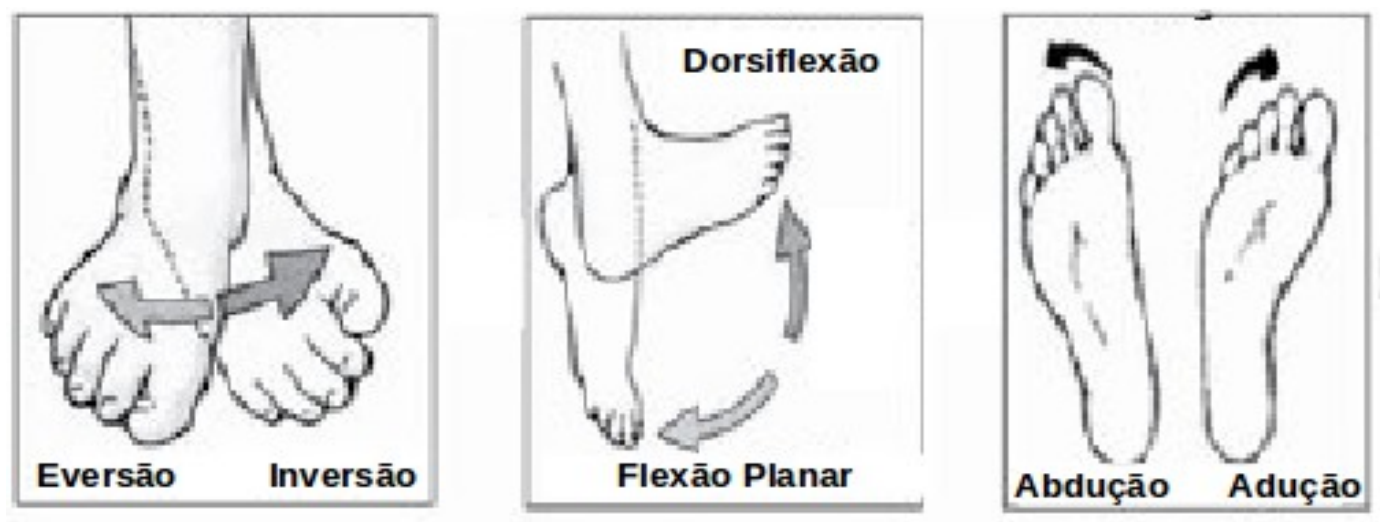

Fonte: Adaptado de OLIVEIRA et al. (2013)

Cada junta tem seu próprio sistema de coordenadas definido anatomicamente e interpretado da forma mecânica e de forma cinesiológica. Porém, todos podem ser representados como rotações em torno dos eixos do sistema local. Do ponto de vista da 
mecânica, as juntas dos ombros, dos cotovelos, dos quadris e dos joelhos só possuem graus de liberdade rotacionais. Três graus para ombros e quadris, um grau para joelhos e cotovelos.

A tabela 3 apresenta os movimentos, graus de liberdade e os nomes dos movimentos das articulações de interesse para a biomecânica segundo HAMILL e KNUTZEN (2012)

Tabela 3 - Movimentos do corpo humano segundos segmento e articulação

\begin{tabular}{|c|c|c|c|}
\hline Segmento & Articulação & $\begin{array}{l}\text { Grau de } \\
\text { liberdade } \\
\text { (gl) }\end{array}$ & Movimentos \\
\hline Cabeça & $\begin{array}{c}\text { Intervertebral } \\
\text { Atlantoaxial ( } 3 \text { art.) }\end{array}$ & 1 (cada) & $\begin{array}{l}\text { Flexão, extensão, hiperextensão, flexão lateral D/E, circundução } \\
\text { Rotação D/E }\end{array}$ \\
\hline Tronco & Intervertebral & 3 & $\begin{array}{l}\text { Flexão, extensão, hiperextensão, Rotação D/E, flexão lateral D/E, } \\
\text { circundução }\end{array}$ \\
\hline Braço & Ombro & 3 & $\begin{array}{l}\text { Flexão, extensão, hiperextensão, abdução, adução, hiperabdução, } \\
\text { hiperadução, abdução horizontal, adução horizontal, rotação med/lat, } \\
\text { circundução }\end{array}$ \\
\hline Braço/ombro & Esternoclavicular & 3 & Elevação, depressão, abdução, adução (pronação, retração), rotação \\
\hline $\begin{array}{l}\text { Cíngulo do } \\
\text { membro } \\
\text { superior }\end{array}$ & Acromioclavicular & 3 & Abdução, adução (pronação, retração), rotação para cima/para baixo \\
\hline Antebraço & $\begin{array}{l}\text { Cotovelo } \\
\text { Radiulnar }\end{array}$ & $\begin{array}{l}1 \\
1\end{array}$ & $\begin{array}{l}\text { Flexão, extensão, hiperextensão } \\
\text { Pronação, supinação }\end{array}$ \\
\hline Mão & Punho & 2 & Flexão, extensão, hiperextensão, flexão radial, flexão ulnar, circundução \\
\hline Dedos da mão & $\begin{array}{l}\text { Metacarpofalângica } \\
\text { Interfalângica }\end{array}$ & $\begin{array}{l}2 \\
1\end{array}$ & $\begin{array}{l}\text { Flexão, extensão, hiperextensão, abdução, adução, circundução } \\
\text { Flexão, extensão, hiperextensão }\end{array}$ \\
\hline Polegar & $\begin{array}{l}\text { Carpometacarpal } \\
\text { Metacarpofalângica } \\
\text { Interfalângica }\end{array}$ & $\begin{array}{l}2 \\
1 \\
1\end{array}$ & $\begin{array}{l}\text { Flexão, extensão, hiperextensão, abdução, adução, circundução } \\
\text { Flexão, extensão, hiperextensão }\end{array}$ \\
\hline Coxa & Quadril & 3 & $\begin{array}{l}\text { Flexão, extensão, hiperextensão, abdução, adução, hiperadução, adução } \\
\text { horizontal, }\end{array}$ \\
\hline Perna & Joelho & 2 & Flexão, extensão, hiperextensão, rotação med./lat. \\
\hline Pé & $\begin{array}{l}\text { Tornozelo } \\
\text { Intertarsal }\end{array}$ & $\begin{array}{l}1 \\
3\end{array}$ & $\begin{array}{l}\text { Flexão planar, dorsiflexão } \\
\text { Inversão, eversão }\end{array}$ \\
\hline Dedos do pé & $\begin{array}{l}\text { Metatarsofalângica } \\
\text { Interfalângica }\end{array}$ & $\begin{array}{l}2 \\
1\end{array}$ & $\begin{array}{l}\text { Flexão, extensão, abdução, adução, circundução } \\
\text { Flexão, extensão }\end{array}$ \\
\hline
\end{tabular}

Fonte: adaptada de (HAMILL; KNUTZEN, 2012)

\subsection{IMAGEM DIGITAL}

Um sistema de processamento de imagem digitais consiste em quatro etapas 
principais: aquisição, armazenamento, processamento e saída (MARQUES FILHO; VIEIRA NETO, 1999).

A aquisição é a etapa que transforma sinais eletromagnéticos (luz, raio-x, infravermelho entre outros) em sinais elétricos, por um dispositivo sensível a este sinal e outro que converte a informação obtida em dados numéricos digitais armazenáveis.

O armazenamento é realizado em um dispositivo de memória digital, como um HD, um cartão $\mathrm{SD}$ ou um $\mathrm{CD}$, que guarda os sinais obtidos para o processamento propriamente dito.

O processamento é uma etapa exercida por softwares. Neste momento a imagem é transformada de números armazenados em imagem, de forma que possa ser representada por um dispositivo de saída de imagem.

A saída é a etapa de resposta, utiliza dispositivos como monitores ou impressoras para representar visivelmente a imagem processada, cuja qualidade também é medida em pixeis.

Durante a aquisição existe uma conversão de dados analógicos (contínuos) em dados digitais (discretos). A informação obtida pelo dispositivo material, a lente da câmera por exemplo, é analógica, que não pode ser mantida neste formato, pois os dispositivos digitais de armazenamento são discretos. Para converter estes dados é necessário considerar apenas alguns pontos da imagem capturada. Isto ocorre durante a captura na conversão do sinal e é chamada de codificação da imagem.

A imagem analógica é então convertida em pontos discretos, conhecidos como pixeis. A quantidade destes num dispositivo de captura denota a qualidade dele. A figura 12 ilustra este processo.

Figura 12 - Conversão de uma imagem analógica a dados discretos.

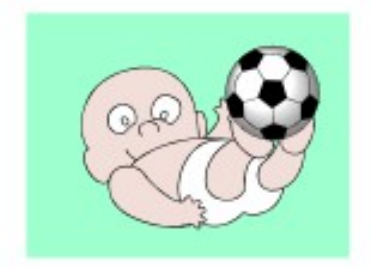

Imagem Contínua

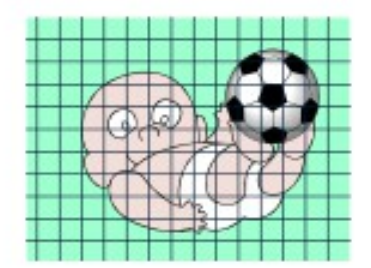

Amostragem

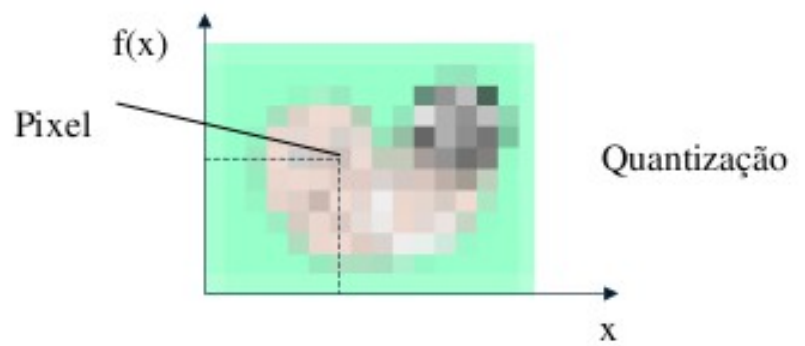

\begin{tabular}{|c|c|c|c|c|c|}
\hline$\ldots$ & $\ldots$ & $\ldots$ & $\ldots$ & $\ldots$ & $\ldots$ \\
\hline 3 & 23 & 63 & 62 & 5 & $\ldots$ \\
\hline 2 & 27 & 43 & 67 & 8 & $\ldots$ \\
\hline 1 & 45 & 32 & 54 & 45 & $\ldots$ \\
\hline 0 & 1 & 2 & 3 & 4 & $\ldots$ \\
\hline
\end{tabular}




\subsubsection{Processamento tridimensional}

Existem diversas formas de processar dados capturados digitalmente em imagens tridimensionais, a seguir, trataremos do método conhecido como Light Coding ${ }^{\mathrm{TM}}$ (Codificação da luz, tradução nossa). Este método foi desenvolvido por Sali e Avraham (2014) em Israel, para empresa PrimeSense ${ }^{\circledR}$ e atualmente pertencente à Apple (ISRAEL, 2013).

Esta técnica consiste na projeção de um padrão de uma única cor, normalmente infravermelha, em conjunto a uma câmera, que captura a mesma cor da projeção, fotografando a projeção refletida por objetos atingidos por ela. Simultaneamente, uma segunda câmera faz capturas coloridas. Ambas as capturas são emitidas em imagens separadas. Finalmente, um processador combina as imagens para obter noções de distância dos objetos filmados, o que gera uma terceira imagem.

Figura 13 - Projeção de um padrão de círculos, captura feita em frequência de luz infravermelha, imagem obtida pelo Kinect

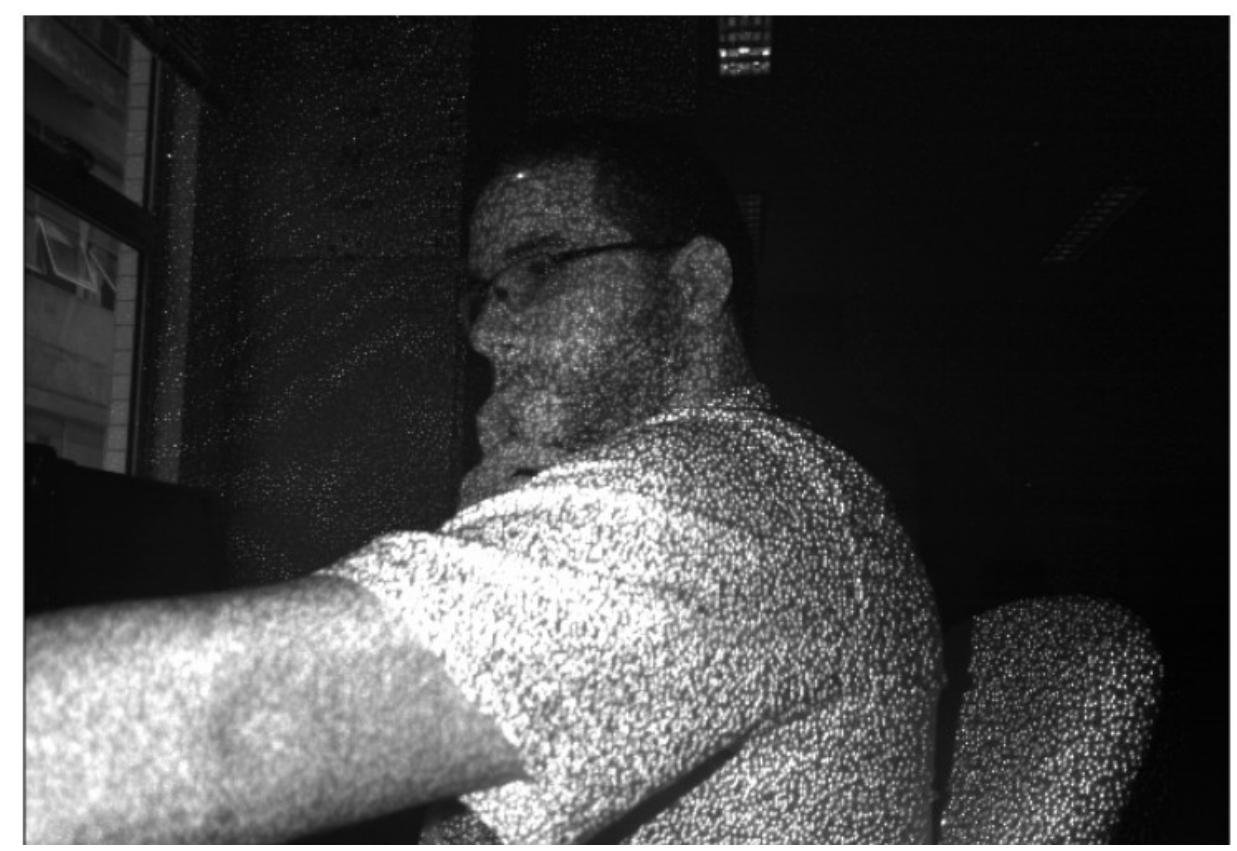

Fonte:(SAMPLES, 2013)

A técnica usada pelo processador é conhecida como Patern-Based Depth Mapping (mapeamento de profundidade baseado em padrões, tradução nossa) e sua patente também pertence à PrimeSense ${ }^{\circledR}$. Um mapa de profundidade é uma matriz numérica em que cada elemento corresponde a um ponto capturado pela imagem. O valor atribuído aos elementos vale a distância entre a superfície que refletiu a projeção e o dispositivo (FREEDMAN et al., 
2008). A imagem capturada pela câmera difere da projeção feita pelo dispositivo devido às formas irregulares do ambiente capturado, ocorrendo deformações no padrão projetado. Em um padrão de pontos como na figura 13, pode-se observar a deformação nos pontos da projeção pela diferença na intensidade luminosa e tamanho relativo entre pontos mais próximos e mais distantes. Estes fatores são utilizados pelo processador para calcular a distância entre os objetos e o dispositivo. 


\section{METODOLOGIA}

A captura e análise de movimentos foi realizada com o desenvolvimento do software para captura de dados com o uso do Kinect, e o desenvolvimento de um segundo software para leitura, análise e representação dos dados obtidos. Ambos os programas foram desenvolvidos na linguagem de programação $\mathrm{C}++$.

Dois programas foram desenvolvidos, um para captura e armazenamento das posições e um para análise cinesiológica dos dados, em ambientes de programação diferentes.

$\mathrm{Na}$ linguagem de programação orientada ao objeto, que foi utilizada para criação deste programa, utiliza-se os termos classes e objetos, neste sentido classe é a definição de variáveis com características e métodos, enquanto um objeto é uma variável do tipo definido. Bibliotecas também tem outro sentido em $\mathrm{C}++$, são arquivos que guardam funções e valores para serem usados por outros programas. Durante a metodologia estas palavras serão utilizadas com estes sentidos.

\subsection{METODOLOGIA DE PROGRAMAÇÃO}

A captura de dados via Kinect é realizada em um computador, configurado com os drivers do hardware, mais as bibliotecas de comunicação com o hardware (middleware), as bibliotecas de desenvolvimento e o ambiente de desenvolvimento (compilador, linguagem de programação).

O trabalho foi desenvolvido utilizando as bibliotecas da empresa PrimeSense, utilizouse o NITE como middleware, o OpenNI como biblioteca de desenvolvimento. Os drivers são fornecidos pela Microsoft e o programa foi desenvolvido no ambiente de programação Microsoft Visual Studio C++ Express. A escolha dessas ferramentas foi devido a sua gratuidade e por apresentar software livre e alta confiabilidade.

Toda a programação da captura dos movimentos foi realizada utilizando as bibliotecas fornecidas pela PrimeSense. O método de instalação foi aplicado de acordo com o apresentado pela empresa.

No fim de 2013 a empresa PrimeSense foi comprada pela Apple, que, em março de 2014, fechou a divisão de software livre para o Kinect. Dessa forma não há mais apoio ao desenvolvimento com essas bibliotecas (KIRIN, 2014). Assim todo o software de captura teve que ser desenvolvido novamente, agora utilizando as bibliotecas que a Microsoft desenvolveu 
e liberou no mercado.

Hoje a instalação do driver, do middleware e da biblioteca básica de desenvolvimento é realizada com um arquivo único por meio de um download direto do site da Microsoft (MICROSOFT, MSDN, 2013), instruções de instalação no apêndice C.

\subsection{PROGRAMA DE CAPTURA}

O programa de captura foi desenvolvido no ambiente de programação Microsoft Visual $C++$ Express 2010, utiliza as bibliotecas inerentes ao Open $G l$ para o retorno visual e as bibliotecas da Microsoft, identificadas como Natural User Interface(Interface natural de usuários, tradução nossa) ou NUI. O usuário pode capturar movimentos por tempo indeterminado, com uma interface de usuário intuitiva com os recursos Windows Forms, do ambiente de programação utilizado.

Com a ferramenta de design do Windows Forms, foram criadas as partes convencionais da interface de usuário (botões, texto, recurso de abrir diretório e controle de tempo) com os elementos predefinidos no ambiente de programação. Suas funções foram definidas com o auxílio desta ferramenta e uso das bibliotecas já citadas.

Seu funcionamento é descrito no fluxograma da Figura 14, em seu desenvolvimento foram criadas funções para manipulação da captura feita e uma classe para o retorno visual (WOOTON, 2006). Os recursos Windows formas não dispõem de janelas OpenGL nativas, por isto foi necessário a definição desta classe.

O acesso ao dispositivo Kinect é feito por uma função definida numa biblioteca separada, inicia seu processo procurando e identificando os dispositivos conectados ao computador, caso não seja encontrado o hardware necessário uma mensagem de erro é exibida. Ao encontrar o Kinect o programa o configura para trabalhar com cores e esqueleto, que são as formas de dados que o aparelho envia ao computador, identificando resolução e variáveis destinadas a receber estes valores.

O programa também acessa o motor do Kinect e ajusta automaticamente sua altura, elevando o ângulo na captura incompleta da cabeça, ou o abaixando se os pés não forem plenamente capturados.

A cada atualização da imagem, que ocorre de acordo com a capacidade do hardware, se mede a quantidade de capturas em um segundo e exibe este valor no campo de "FPS atual", que representa a quantidade de quadros capturados no último segundo, este valor tende a 30 se as configurações do computador atenderem suficientemente as necessidades do dispositivo, 
Figura 14 - Fluxograma das principais funções do programa de captura

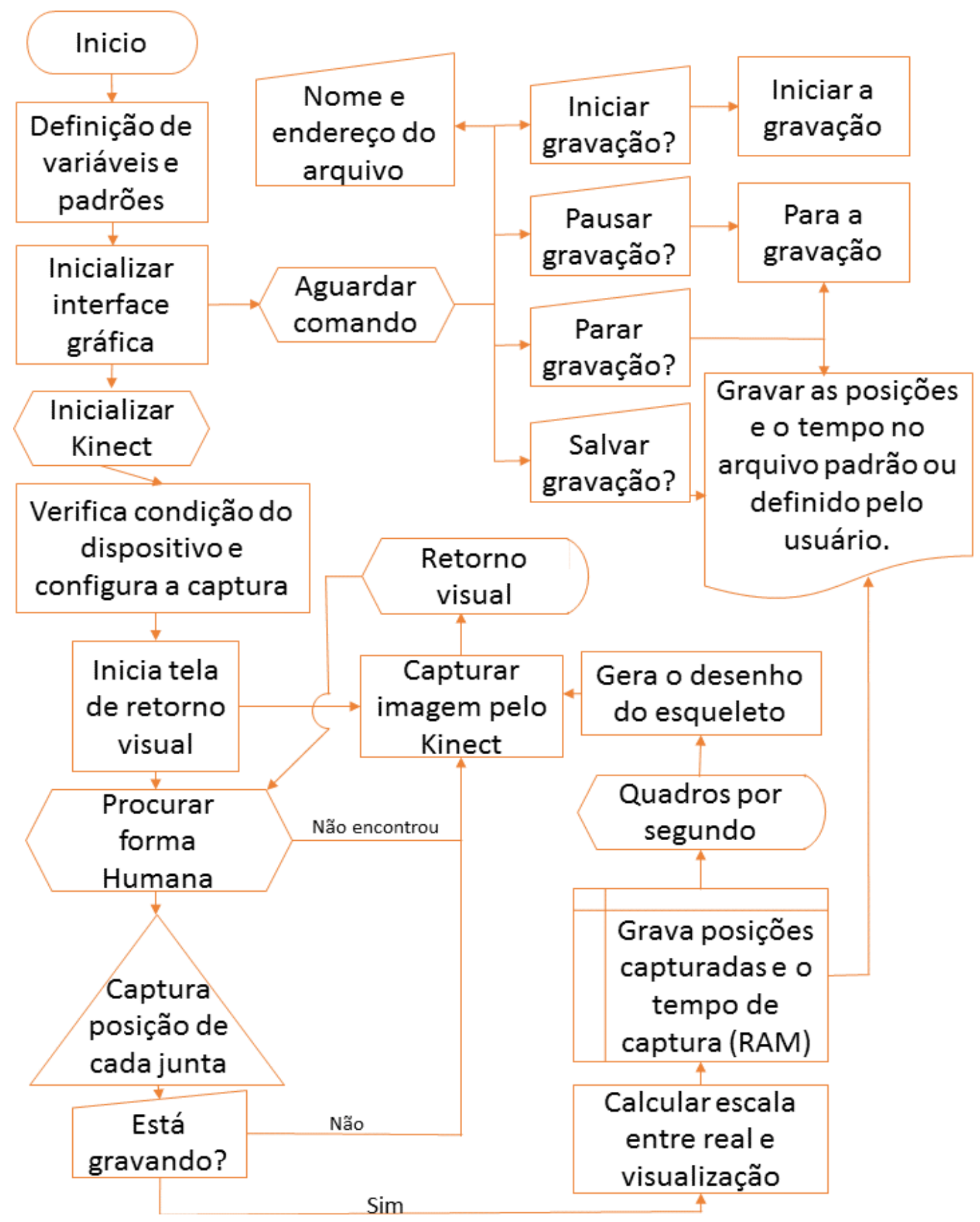

Fonte: Autor

com a luminosidade e distância adequadas, o ajuste de ângulo do motor reduz consideravelmente este valor.

Devido ao funcionamento do Kinect, deve-se evitar ao máximo a luz solar, tanto sobre a pessoa medida quanto sobre o dispositivo, sob luminosidade solar direta a captura tridimensional não funciona. 
Quando iniciada a gravação, o programa armazena na memória volátil do computador em um vetor dinâmico cada quadro capturado, registrando as posições das juntas descritas na Figura 8 e o tempo de captura até então. Apenas quando se envia os comandos de parar ou salvar que este vetor é armazenado em um arquivo, na memória física do computador, com um nome padrão inicial ou na pasta e com o nome que o usuário definir.

Os comandos "parar" e "pausar" diferem apenas em que o primeiro salva o arquivo imediatamente e interrompe o armazenamento na memória volátil, o segundo apenas interrompe o armazenamento. Nenhum deles impede que a captura seja retomada.

\subsubsection{A captura}

Com o recurso da projeção e a câmera infravermelhas, o dispositivo é capaz de medir distâncias de superfícies até ele. O sistema identifica pontos próximos entre si e um algoritmo embarcado reconhece a continuidade de superfícies, ao reconhecer uma forma humana o dispositivo inicia o rastreamento da posição de cada junta.

O programa criado busca esta forma humana num intervalo de tempo prédeterminado, a cada intervalo é iniciado um quadro da captura, as bibliotecas do kit de desenvolvimento de software para Kinect (Kinect SDK, Software Development Kit) identificam-no por "NUI_SKELETON_FRAME", este quadro terá um "esqueleto" relacionado a ele caso uma forma humana seja encontrada, ao chamar a função "NuiSkeletonGetNextFrame", do objeto da classe "INuiSensor", que representa o próprio Kinect.

Devido ao previsível ruído relacionado a esta captura, o kit de desenvolvimento já possui uma função de filtro, chamada por "NuiTransformSmooth", também da classe "INuiSensor". Desta forma o programa dispensa o uso de filtros externos.

Ao encontrar uma forma humana é criado um objeto da classe "NUI_SKELETON_DATA" que guardará as informações do corpo rastreado. Antes de iniciar a coleta dos pontos para gravação se verifica a qualidade do rastreamento, como apenas posição, rastreado e não rastreado (respectivamente: NUI_SKELETON_POSITION_ONLY, NUI_SKELTON_TRACKED e NUI_SKELETON_NOT_TRACKED), o primeiro só obtém a posição de forma geral do corpo, o segundo de cada junta com razoável exatidão, o terceiro indica que nenhuma forma humana foi encontrada.

Cada vez que um corpo é rastreado se incrementa um contador de quadros rastreados, 
e cada segundo se informa quantos foram e reinicia o contador, esta conta é um indicador da qualidade da captura, quando maior o valor melhor, no entanto devido a condições do dispositivo, o número de quadros por segundo (fps) não costuma ultrapassar 30.

Caso a gravação esteja ativada e o corpo rastreado, um vetor dinâmico é incrementado com as posições de cada junta no último momento rastreado, para acessar as juntas se utiliza os seus identificadores com a função "SkeletonPositions[identificador]"do objeto que guarda as informações do corpo. As juntas capturadas estão representadas na figura 8 da página 28.

Tabela 4-Enumeração nas juntas capturadas, seus respectivos índices no algoritmo e seus identificadores na biblioteca do Kinect SDK

\begin{tabular}{|c|c|c|}
\hline Índice & Junta & $\begin{array}{c}\text { Identificador (iniciam com } \\
\text { NUI_SKELETON_POSITION_) }\end{array}$ \\
\hline 0 & Centro do quadril & HIP_CENTER \\
\hline 1 & Coluna, próximo ao centro do tronco & SPINE \\
\hline 2 & Centro dos ombros, ponto médio dos ombros & SHOULDER_CENTER \\
\hline 3 & Cabeça, próximo ao centro dela & HEAD \\
\hline 4 & Ombro esquerdo, próximo ao centro & SHOULDER_LEFT \\
\hline 5 & Cotovelo Esquerdo & ELBOW_LEFT \\
\hline 6 & Pulso esquerdo & WRIST_LEFT \\
\hline 7 & Mão esquerda, próximo ao centro & HAND_LEFT \\
\hline 8 & Ombro direito, próximo ao centro & SHOULDER_RIGHT \\
\hline 9 & Cotovelo direito & ELBOW_RIGHT \\
\hline 10 & Pulso direito & WRIST_RIGHT \\
\hline 11 & Mão direita, próximo ao centro & HAND_RIGHT \\
\hline 12 & Quadril esquerdo, alinhado à coxa e ao joelho & HIP_LEFT \\
\hline 13 & Joelho esquerdo, próximo ao centro & KNEE_LEFT \\
\hline 14 & Tornozelo esquerdo, próximo ao centro & ANKLE_LEFT \\
\hline 15 & Pé esquerdo, próximo à canela & FOOT_LEFT \\
\hline 16 & Quadril direito, alinhado à coxa e ao joelho & HIP_RIGHT \\
\hline 17 & Joelho direito, próximo ao centro & KNEE_RIGHT \\
\hline 18 & Tornozelo direito, próximo ao centro & ANKLE_RIGHT \\
\hline 19 & Pé direito, próximo à canela & FOOT_RIGHT \\
\hline
\end{tabular}




\subsubsection{O retorno visual}

Para o retorno visual com uso do Open $G L$ foi necessário criar uma classe com características inerentes às formas já existentes no Windows Forms, em especial a chamada Native Window, ou seja, janela nativa. Numa janela nativa o OpenGL não apresenta grandes dificuldades de uso, no entanto, dentro de uma forma, muitos passos devem ser seguidos.

Primeiramente, é preciso ter o OpenGL devidamente instalado e pronto para uso em programação, para tanto é preciso ter os arquivos OpenGL32.dll, glu.dll e glut.dll, inseridos na pasta de system do sistema operacional, as bibliotecas opengl.h, glu.h e glut.h na pasta include do ambiente de programação e os arquivos glut32.lib e openg132.lib na pasta Lib do sistema operacional.

Inicialmente é preciso definir o tamanho da forma Open $G L$ e sua posição, assim como a forma na qual ela será inserida, estes valores são salvos em um handle, um manipulador de formas. O handle também recebe informações de estilo: ele não é dependente de outra forma, é visível e compila $O p e n G L$.

Um objeto desta classe precisa de diversas definições do ambiente para OpenGL, uso de textura, tipo de textura, cor básica, profundidade básica, resolução da imagem, tipo de projeção, espaço de projeção, tipo de iluminação, qualidade e tipo de pixel, estes últimos definidos com um objeto da classe PIXELFORMATDESCRIPTOR (WOOTON, 2006).

Gravando ou não, o programa representa as posições das juntas rastreadas no retorno visual, com pontos vermelhos e linhas azuis, no entanto o Kinect informa estas posições em metros com relação ao próprio dispositivo (centro), e a janela OpenGL está em pixeis, a partir do canto superior esquerdo. Para escalonar os dados adquiridos de forma que se sobreponham a imagem já exibida se utiliza um recurso de geometria espacial por semelhança de triângulos (Figura 15)convertendo dados tridimensionais em bidimensionais. 
Figura 15 - Representação da relação entre as distâncias, para conversão em uma imagem bidimensional.

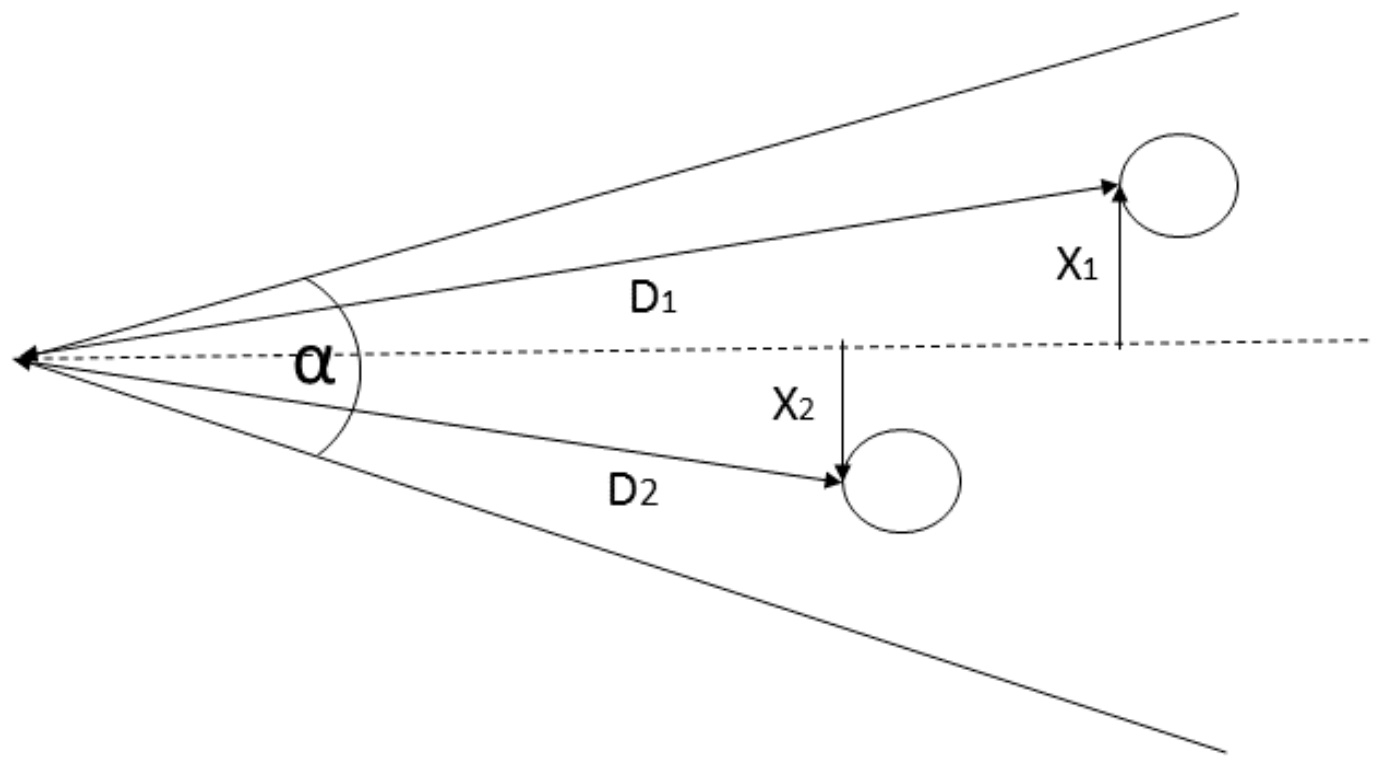

Fonte: Autor

Considerando a largura da imagem em pixeis $L i$, a distância calculada $Z$ que é a projeção de $D_{i}$ na linha tracejada, podemos calcular a amplitude da variação em x de acordo com $\mathrm{Z}$ e o ângulo $\alpha$, tal que:

$$
X_{\min }=Z \times 2 \times \tan (\alpha / 2)
$$

\subsubsection{Salvar captura em arquivos}

Com a captura permitida pelo usuário, o programa incrementa na memória volátil do computador um vetor com os dados obtidos via kinect, no entanto, dados voláteis são apagados assim que o programa é fechado. Para manter os resultados é preciso utilizar a memória rígida do computador ou uma mídia externa ( $\mathrm{cd}$, pen drive, nuvem virtual entre outras).

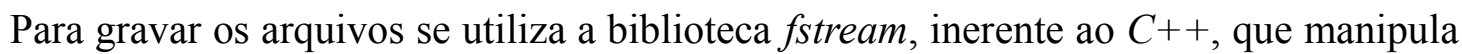
arquivos, para criá-los, destruí-los, lê-los e editá-los. Para acessar o arquivo se cria um objeto da classe $f$ stream, que acessa o arquivo.

O nome do arquivo é definido pelo usuário no campo de edição de linha no programa e a pasta pode ser selecionada com o botão "Mudar Pasta", ao lado deste botão haverá um texto conectado às informações de local e nome para exibir qual o endereço do novo arquivo.

O método open do objeto criado recebe o endereço do arquivo e o tipo de ação que 
efetuará, neste caso é de escrita é indicada pelo identificador ios::out. Caso o arquivo endereçado não exista, o programa o criará automaticamente, caso exista, o anterior será sobrescrito.

Para escrita no arquivo se utiliza a função se saída do objeto, acessada pelo operador $<<$, a qual insere no arquivo cada junta registrada em linha da seguinte forma:

a 1.50452 .00322 .4356

Onde "a" é o identificador da junta que é de apenas um algarismo, por isto, de zero a nove utiliza números e de 10 a 19 , utiliza letras minúsculas. Os números seguintes são a posição da junta nas coordenadas $x, y$ e $z$, respectivamente, separadas por espaço e utiliza o ponto em vez da vírgula para separar as unidades das frações.

Com o identificador " $t$ " o programa registra a diferença temporal entre aquele quadro e o início da captura. Após gravar todas as posições do vetor o arquivo é fechado. Mesmo após salvar o arquivo a captura pode ser reiniciada e nenhum dado se perder, desde que um novo arquivo seja salvo.

\subsubsection{Condições de captura}

Para uma boa captura com o Kinect algumas condições são necessárias, a primeira é a luminosidade, deve-se evitar a luz solar de forma indireta e de forma alguma pode haver incidência de luz solar diretamente sobre o dispositivo ou sobre o usuário. A luz artificial não pode ser excessiva, como uso de refletores ou luzes mais intensas que o necessário para um escritório ou sala de aula por exemplo. Para a captura de movimentos o sistema não precisa de qualquer luz, no entanto o retorno visual depende de luz externa.

A impossibilidade de luz em excesso se dá pela forma de medição feita pelo Kinect, que utiliza projeção de luz infravermelha, a luz solar também possui o espectro luminoso desta frequência, portanto ele torna a malha de pontos (Figura 13, página 34) em uma única mancha desta cor.

A segunda condição é manter o espaço de captura o mais livre possível de móveis, paredes e pessoas, o ideal é que o usuário fique isolado dentro do espaço de captura, mas caso este precise do auxílio de outra pessoa, a auxiliar deve ser apenas uma e ficar sempre atrás ou ao lado do usuário, caso passe entre o usuário e o dispositivo, o rastreamento será perdido, assim é necessário reiniciar o programa. O espaço de captura é a região em forma de trapézio à frente do dispositivo (Figura 16). 
Figura 16 - Vista superior do espaço de captura do Kinect

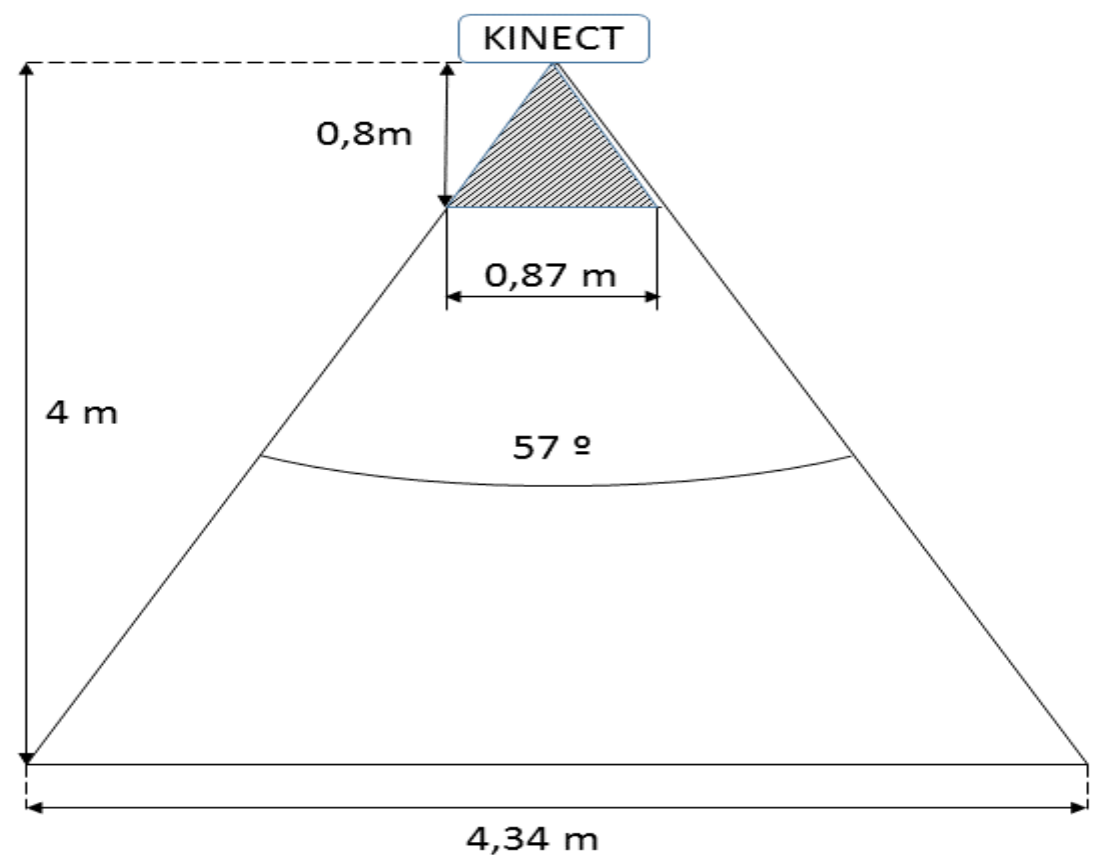

Fonte: Adaptada de:(JANA, 2012)

A terceira condição é que todo o corpo do usuário seja capturado pelo Kinect, o que pode ser verificado pelo retorno visual, o próprio programa ajustará o ângulo de inclinação do dispositivo se os pés ou a cabeça do usuário não esteja sendo rastreada, se ambos não estiverem visível ao aparelho, o usuário deve afastar-se dele.. Por isto, pessoas mais altas devem ficar mais longe do aparelho, sem exceder os quatro metros do espaço de captura.

\subsection{PROCESSAMENTO DE DADOS}

Para o processamento dos dados obtidos pelo programa de captura foi desenvolvido um software utilizando a ferramenta QtCreator, que é uma SDK para produção rápida de programas com interface gráfica convencional. O fluxograma da figura 17 representa o funcionamento do programa.

\subsubsection{Leitura}

Nesta etapa ele pode acessar o programa de captura, ler e interpretar os arquivos gerados por ele, gerar gráficos de ângulo, velocidade ou aceleração para cada junta, gerar um modelo tridimensional do que foi capturado, filtrar os dados para reduzir os efeitos de ruído e salvar arquivos modificados. 
Para calcular a velocidade se utiliza o princípio da derivada discreta, a diferença de posição absoluta entre duas capturas adjacentes multiplicadas pela taxa de captura, que é o inverso do tempo entre elas. Semelhantemente se calcula a aceleração, com a única diferença de que em vez de comparar as posições se comparam as velocidades adjacentes.

Figura 17 - Fluxograma do programa de leitura e processamento

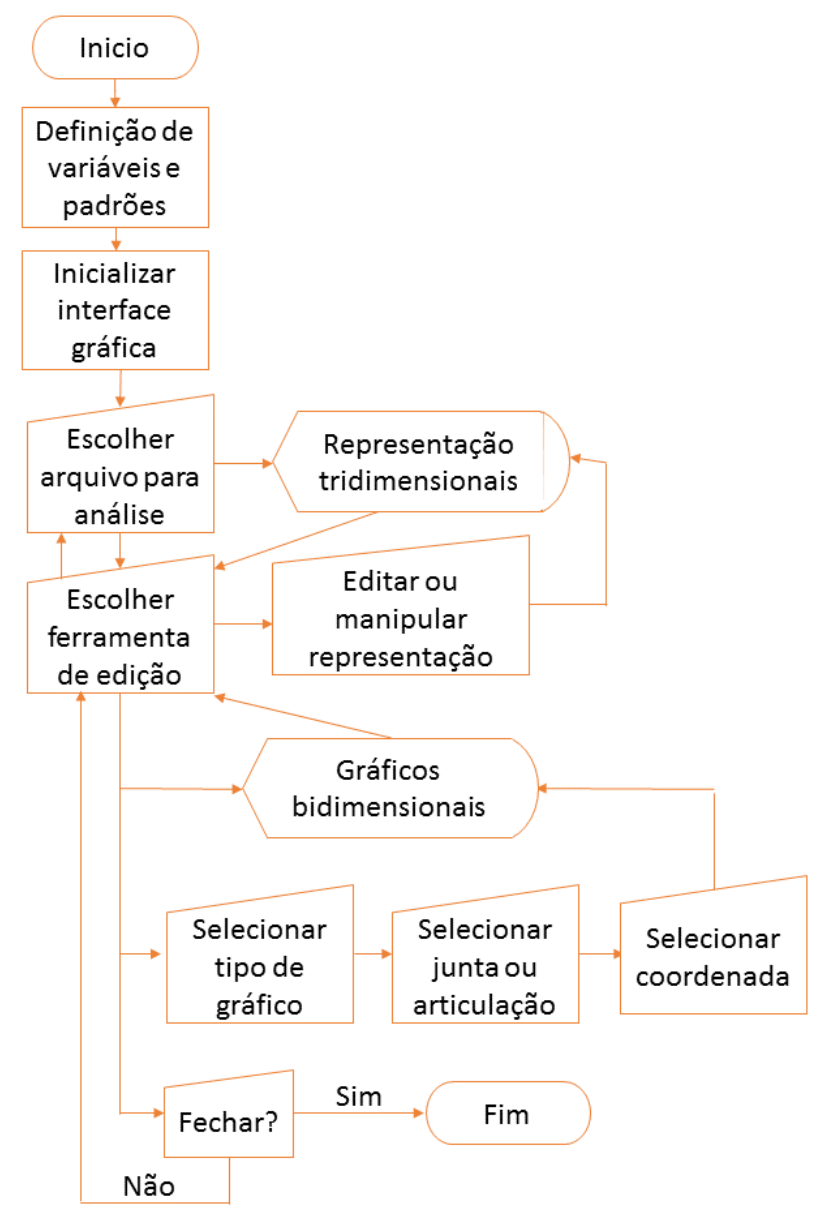

Fonte:Autor

\subsubsection{Cálculo de ângulos}

Para calcular o ângulo de uma junta se faz necessário de três pontos adjacentes: Para o ângulo do joelho precisa-se também do pé e do quadril, para o quadril precisa-se do joelho e do torso ou do outro lado do quadril, para os ombros precisa-se do pescoço e do cotovelo adjacente, para os cotovelos se utiliza também as mãos e os ombros.

O Principio é o mesmo para todos os ângulos. Como exemplo, tomemos o cotovelo. Formando dois vetores, a partir das coordenadas, ambos do cotovelo para os adjacentes: 


$$
\begin{gathered}
\text { Mão }=M=\left(m_{x}, m_{y}, m_{z}\right) \\
\text { Cotovelo }=C=\left(c_{x}, c_{y}, c_{z}\right) \\
\text { Ombro }=O=\left(o_{x}, o_{y}, o_{z}\right) \\
\text { Antebraço }=B=M-C=\left(m_{x}-c_{x}, m_{y}-c_{y}, m_{z}-c_{z}\right)=\left(a_{x}, a_{y}, a_{z}\right) \\
\text { Braço }=A=O-C=\left(o_{x}-c_{x}, m_{y}-c_{y}, m_{z}-c_{z}\right)=\left(b_{x}, b_{y}, b_{z}\right)
\end{gathered}
$$

Tendo definido estes vetores, teremos um ângulo entre eles.

Figura 18 - Representação dos vetores e o ângulo entre eles.

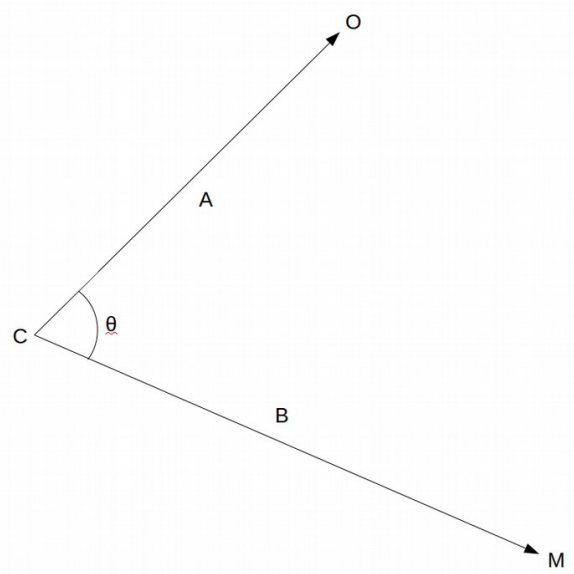

Fonte: Autor

Com base na lei dos cossenos (ANTON; RORRES, 2002) que diz:

$$
\langle A, B\rangle=\square A \square \square B \square \cos \theta
$$

$\mathrm{Na}$ qual $<\mathrm{A}, \mathrm{B}>$ significa o produto internos entres os vetores $\mathrm{A}$ e $\mathrm{B}$. Em seguida conclui-se:

$$
\theta=\arccos \left(\frac{\langle A, B\rangle}{\square A \llbracket \square B \square}\right)
$$

Assim, os ângulos são calculados.

\subsubsection{Visualização}

Para gerar as visualizações, utiliza-se a classe QGLWidget, que é o correspondente ao Open $G L$ nativa à plataforma $\mathrm{Qt}$, de acordo com a necessidade de cada ponto do programa.

\subsubsection{Gráfico 2D}

Para gerar o gráfico bidimensional, é preciso primeiro gerar o ambiente de visualização OpenGL, definir cor de fundo, cor da linha, escopo de visualização (espaço 
vetorial que é exibido na tela), entre outras aplicações inerentes a toda apresentação deste tipo. Para que os dados sejam exibidos dentro do escopo é preciso escalonar os dados, de forma que se adequem bem à imagem.

Utilizando um escopo entre -1 e 1 nas três coordenadas, é preciso normalizar os dados, ou seja, dividir pelo módulo no maior elemento do vetor de captura. Gerando um novo vetor de dados entre - 1 e 1 . A normalização é feita encontrando o maior elemento absoluto do vetor e dividindo todos os outros elementos pelo seu valor absoluto, para o eixo vertical desta visualização, que pode representar qualquer coordenada dos dados apresentados. O eixo horizontal representa o tempo, como varia de -1 a 1 , temos um intervalo de duas unidades, para preencher este espaço, a posição inicial do vetor de estar em -1 e a final em 1, o calculo da posição horizontal de cada ponto é:

$$
x=\left(\frac{\text { índice }}{\text { total de pontos }}-1\right) \times 2
$$

Em sincronia com a representação tridimensional, este gráfico é percorrido por uma reta vertical, representando o momento em que a representação se encontra.

\subsubsection{Gráfico 3D}

Com uso de recursos das primitivas do OpenGL e as posições registradas no arquivo lido, foram feitas funções para representar os membros e as juntas, as juntas com esferas construídas de linhas (GL_LINE_STRIP) em torno das juntas com um raio variável de acordo com o zoom. Os membros são representados com cilindros construídos de triângulos preenchidos (GL_TRIANGLE_STRIP). O modificador STRIP, indica que o último ponto de uma figura será o primeiro da seguinte. Com linhas também se representou um canto de parede para auxiliar na percepção de profundidade

A representação conta com a rotação em torno dos três eixos ortogonais, controlados por caixas se seleção numérica (QSpinBox). Para rotacionar sem interferir nos dados originais, a QGLWidget copiar todos os pontos lidos e os altera, utilizando matrizes de transformação todos os pontos. Ela também conta com translação e escalonamento(zoom), de forma semelhante à rotação (Tabela 5). O recurso de translação é utilizado na opção centralizar, na qual se pode escolher uma junta e coloca-la no centro da representação até que outra junta seja selecionada como centro. 
Tabela 5 - Matrizes de transformação vetorial

\begin{tabular}{|c|c|c|c|c|c|c|c|c|}
\hline \multicolumn{9}{|c|}{ Matrizes de transformação de rotação (rotacionais) } \\
\hline \multicolumn{3}{|c|}{$X$} & \multicolumn{3}{|c|}{$\mathrm{Y}$} & \multicolumn{3}{|c|}{$\mathrm{Z}$} \\
\hline 1 & 0 & 0 & $\cos (\theta)$ & 0 & $\operatorname{sen}(\theta)$ & $\cos (\theta)$ & $\operatorname{sen}(\theta)$ & 0 \\
\hline 0 & $\cos (\theta)$ & $\operatorname{sen}(\theta)$ & 0 & 1 & 0 & $\cos (\theta)$ & $-\operatorname{sen}(\theta)$ & 0 \\
\hline 0 & $-\operatorname{sen}(\theta)$ & $\cos (\theta)$ & $-\operatorname{sen}(\theta)$ & 0 & $\cos (\theta)$ & 0 & 0 & 1 \\
\hline \multicolumn{4}{|c|}{ Fator de escalonamento (FE) } & \multicolumn{5}{|c|}{ Matriz de translação } \\
\hline \multicolumn{4}{|c|}{$[x, y, z] \times F E$} & \multicolumn{5}{|c|}{$[x, y, z]+[d x, d y, d z]$} \\
\hline
\end{tabular}

Fonte: (ANTON; RORRES, 2002)

\subsubsection{Leitura do arquivo}

Neste programa o acesso ao arquivo se deu pelo uso da classe QTextStream e QFile nativos ao $Q t$, o objeto da segunda classe abre o arquivo selecionado por uma tela de escolha gerada pelo sistema operacional. Com o arquivo aberto, o objeto da primeira classe lê o arquivo linha a linha, separando seus valores pelos espaços, o primeiro valor é o identificador, que indica de que junta se trata, de acordo com o programa de captura, então salva seus valores em um vetor alocado segundo a quantidade de pontos existentes no arquivo.

Assim que a leitura é concluída o programa gera os retornos visuais na representação tridimensional, no gráfico das posições do centro do quadril (primeiro item do vetor) na coordenada x e numa linha que indica a quantidade de quadros naquele arquivo. 


\section{RESULTADOS}

Os programas desenvolvidos podem capturar e analisar movimentos de forma rápida, necessitando apenas de um computador com eles, o dispositivo, energia para ambos e um local aberto com pouca luz solar.

Seu custo de aquisição é baixo, o dispositivo pode ser encontrado por menos de R\$ 100,00 na internet (EBAY, 2015), normalmente as instituições de ensino já contam com computadores em maior parte de suas salas de aula, dispensando o custo de obter este aparelho. Restando apenas o custo do software, ainda indefinido. Não é difícil encontrá-lo em lojas virtuais, lojas de informática ou jogos, até mesmo em supermercados, auxiliando seu acesso ao público.

Com a captura de 20 juntas distribuídas pelo corpo, o sistema proposto tem uma boa varredura sobre o usuário, dos pés à cabeça, o que permite o estudo em membros inferiores e superiores, assim como momentos amplos. No entanto, movimentos rápidos não são bem capturados por este sistema.

Com dimensões de $28 \mathrm{~cm} \times 7 \mathrm{~cm} \times 7 \mathrm{~cm}$, e menos de $1 \mathrm{~kg}$ (ACTION GAMES, 2011), o Kinect é facilmente carregado em uma mochila ou bolsa, acompanhado de quase $4 \mathrm{~m}$ de fios para alimentação e fluxo de dados, o sistema pode ser transportado e posicionado com facilidade e adaptabilidade às condições do ambiente.

\subsection{PROGRAMA DE CAPTURA}

O programa de captura possui um uso bastante intuitivo com uma interface gráfica simples e retorno visual (Figura 19), o qual indica o quão bem a captura está sendo executada, pela quantidade de quadros por segundo (FPS) e pela cor da representação dos membros, que ficam verdes se não estiverem sob o rastreamento adequado.

\subsection{PROGRAMA DE LEITURA E PROCESSAMENTO}

Este sistema transforma o movimento que é capturado qualitativamente de forma humana pela visão, em números que é a forma que os computadores registram tudo, para então converter estes números novamente em imagens, com ferramentas para que visualmente, um humano os entenda quantitativamente. Este é um passo importante na análise de movimento para auxiliar no aprendizado e na quantificação dos dados. 
Figura 19 - Programa de captura de movimentos em funcionamento.

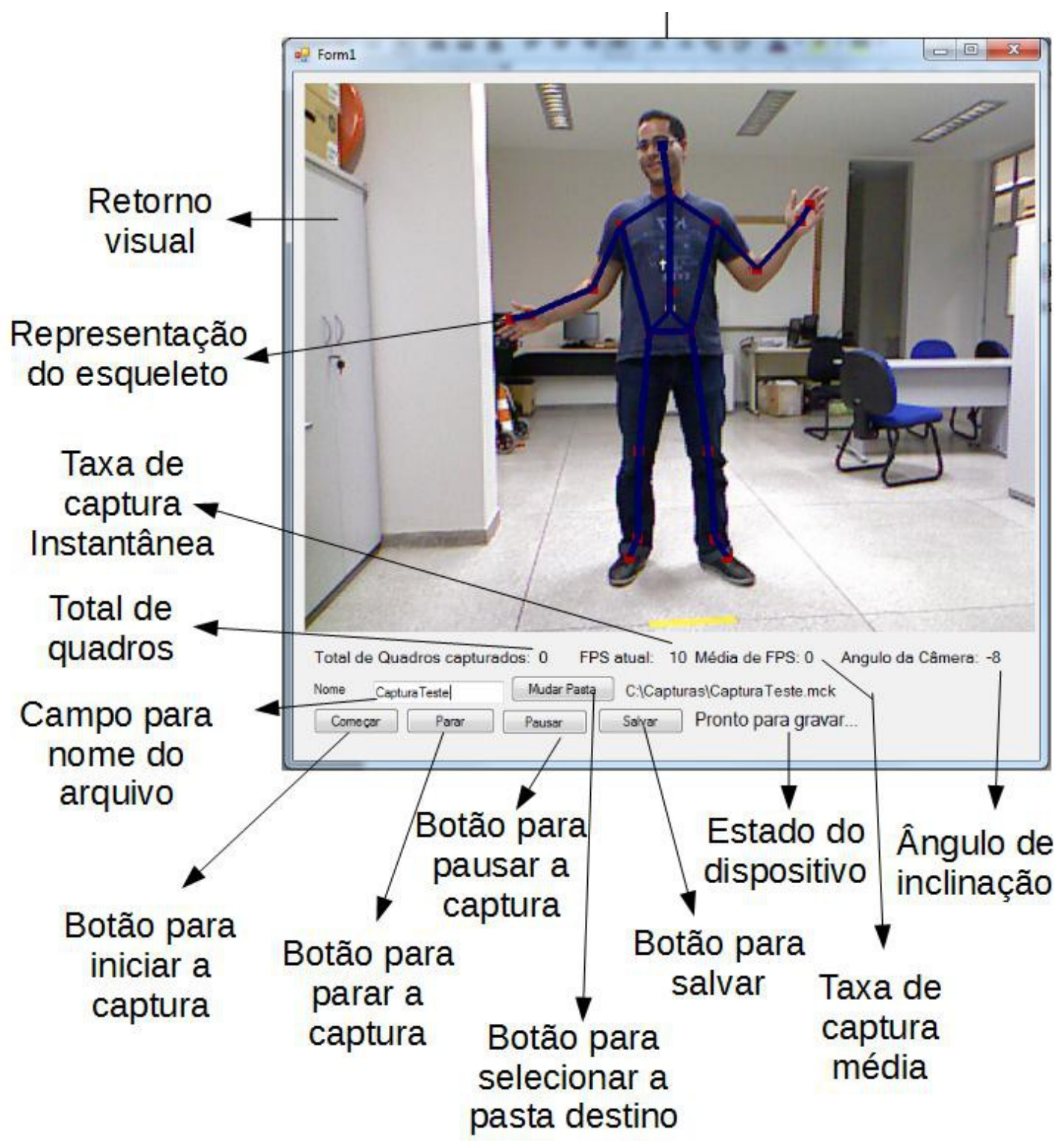

Fonte: Autor

$\mathrm{Na}$ figura 20 pode-se observar a interface de usuário do programa de análise e processamento de dados, apresentando os gráficos das posições na coordenada ' $\mathrm{x}$ ' de ambas a mãos, a representação tridimensional está rotacionada em $70^{\circ} \mathrm{em}$ torno do eixo vertical e a representação está centralizada na junta do centro dos quadris. 
Figura 20 - Interface do programa de análise e processamento de dado

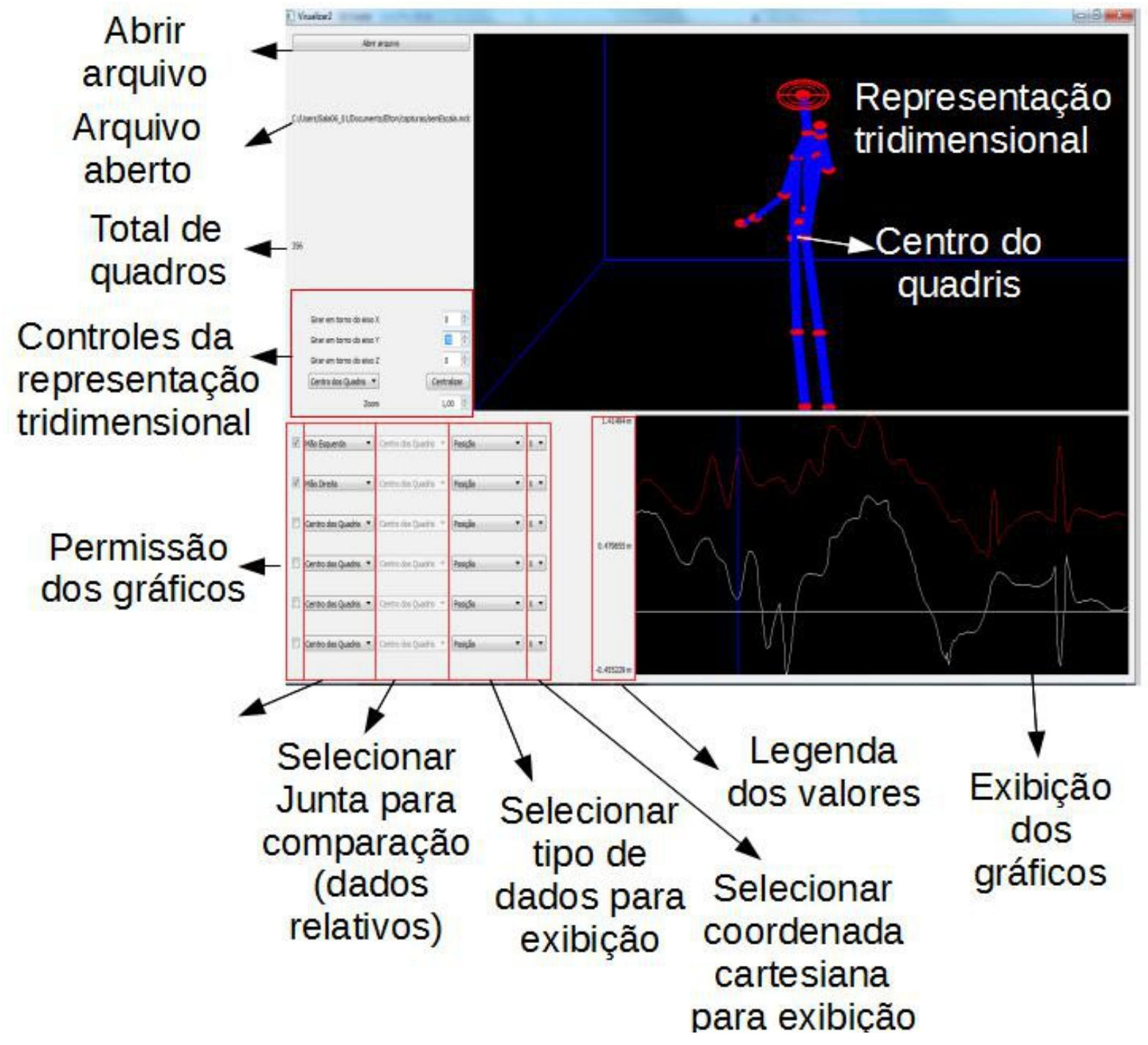

Fonte Autor

Este trabalho com o Kinect repercutiu em publicações em dois congressos nacionais CBEB 2012 e CONEM 2012, (MOURA, 2012), um congresso internacional (ESB 2012) com uma publicação em revista ((DE ALBUQUERQUE et al., 2012)). Os artigos estão em anexo neste trabalho. 


\section{CONSIDERAÇÕES FINAIS}

Dentre os objetivos do trabalho, a escolha do equipamento é a mais importante, pois define a próxima etapa no desenvolvimento do trabalho. Foram realizados estudos e comparações entre os vários mecanismos e sistemas no mercado e se optou pelo sensor Kinect 360. Este sensor apresenta vantagens em relação a mobilidade, ao custo, entre outras em relação aos diferentes sensores encontrados. Foi observado que no desenvolvimento de sistemas de captura de movimentos 3D o mercado é muito dinâmico e já existem hardwares mais avançados, como o Kinect One e o Real Sense (Intel) além de outros dispositivos com o mesmo princípio de funcionamento e novas tecnologias para mapeamento 3D. No Kinect One, o princípio de funcionamento é o mesmo do anterior, mas o hardware foi aprimorado. Pela tabela 6 podemos comprovar a superioridade do novo hardware, por isto se o trabalho fosse iniciado hoje, o Kinect One seria o dispositivo utilizado.

Tabela 6 - Comparação entre os sensores Kinect para XBox 360 e para XBox One

\begin{tabular}{|l|l|l|}
\hline \multicolumn{1}{|c|}{ Característica } & \multicolumn{1}{c|}{ Kinect 360 } & \multicolumn{1}{c|}{ Kinect One } \\
\hline Campo de captura & $57,5^{\circ}$ horizontal, $43,5^{\circ}$ vertical & $70^{\circ}$ horizontal, $60^{\circ}$ vertical \\
\hline Resolução colorida & $640 \times 480$ pixeis & $1920 \times 1080$ pixeis \\
\hline Resolução de profundidade & $320 \times 240$ pixeis & $512 \times 424$ pixeis \\
\hline Intervalo entre capturas & $90 \mathrm{~ms}$ & $60 \mathrm{~ms}$ \\
\hline Custo & $69,95 \mathrm{USD}$ & $111,49 \mathrm{USD}$ \\
\hline
\end{tabular}

Fontes: (XBOX, 2013) e (AMAZON, 2014)

Dessa forma o uso do Kinect pode parecer obsoleto, porém eficaz. Baseado no conhecimento sobre a evolução do hardware, desde o início do projeto já se pensou em dividir o sistema de captura e análise em dois programas diferentes. Assim, o uso de um hardware mais moderno, exige somente uma alteração no programa de captura e o uso do programa de análise não será prejudicado.

Sendo assim, o programa para análise de movimentos foi dividido e desenvolvido em duas etapas: de captura e de processamento. Como para a instalação do Kinect é necessária a licença de uso do Microsoft SDK e não permite a comercialização do programa desenvolvido com ele, sendo assim faz-se necessário a aquisição de uma licença comercial ou distribuir apenas o código fonte para compilação. Porém o programa de análise dos dados foi desenvolvido com o QtCreator que possui licença livre, não proibindo a venda do programa 
desenvolvido nele, ainda que hoje busque-se distribuí-lo também livremente, versões futuras poderão ser pagas. Desta forma, os softwares podem ser distribuídos sem fins lucrativos.

Por isto, mesmo com os avanços do hardware, o programa não perde a funcionalidade, pois somente o programa de captura será modificado ou desenvolvido em outra plataforma para outro hardware.

\subsection{PERSPECTIVAS FUTURAS}

O próximo passo deste projeto é testar o sistema em análises clínicas, com projetos que já estão sendo desenvolvidos dentro do LAIS/UFRN. Utilizando o software junto a outras técnicas já desenvolvidas para sua validação. Por fim, pretende-se implementar um sistema para utilizar o Kinect para Xbox One e o Real Sense da Intel, que é mais moderno e com um hardware mais robusto. Com o novo equipamento se pretende obter mais precisão e qualidade dos resultados. 


\section{BIBLIOGRAFIA}

ACTION GAMES. Xbox 3604 GB Slim + Kinect $\mid$ XBOX $360 \mid$ Console $\mid$ ActionGame.com.br - Games e Informática em Geral. Comercial. Disponível em: $<\mathrm{http}: / / \mathrm{www}$.actiongame.com.br/produtos_descricao.asp? lang=pt_BR\&codigo_produto=3362>. Acesso em: 6 dez. 2011.

AMAZON. Amazon.com: Online Shopping for Electronics, Apparel, Computers, Books, DVDs \& more. Disponível em: <http://www.amazon.com/s/ref=nav_search_go?url=searchalias\%3Daps\&field-keywords=kinect $>$. Acesso em: 31 ago. 2014.

ANTON, Howard; RORRES, Chris. Álgebra linear com aplicações. 8. ed. Porto Alegre: Bookman, 2002.

ASCENSION, Technology Corporation. 3D Guidance driveBAY - Ascension Technology Corporation. Disponível em: <http://www.ascension-tech.com/medical/driveBAY.php $>$. Acesso em: 1 jun. 2014a.

ASCENSION, Technology Corporation. 3D Guidance trakSTAR - Ascension Technology Corporation. Disponível em: $<$ http://www.ascension-tech.com/medical/trakSTAR.php $>$. Acesso em: 1 jun. 2014b.

ASCENSION, Technology Corporation. Ascension Technology Corporation - 3D Guidance, Surgical navigation, Minimally invasive, 3D Ultrasound, Image-guided procedures, Localization, Tracking, Magnetic and optical sensors, Medical guidance, 3D Digitizer. Comercial. Disponível em: <http://www.ascension-tech.com/>. Acesso em: 1 jun. 2014c.

ASCENSION, Technology Corporation. Ascension Technology Product Brochure: MotionStar - motionstar.pdf. Disponível em:

$<$ http://www.mindflux.com.au/products/ascension/motionstar.pdf $>$. Acesso em: 1 jun. 2014.

ASCENSION, Technology Corporation. Sensor options. . EUA: [s.n.]. Disponível em: $<$ http://www.ascension-tech.com/medical/pdf/TrakStarSensor.pdf $>$. Acesso em: 30 maio 2014. , 2014

BAKER, Richard. The history of gait analysis before the advent of modern computers. Gait \& Posture, v. 26, n. 3, p. 331-342, set. 2007. Acesso em: 17 ago. 2014.

BÍBLIA, Português. Bíblia do Peregrino - Edição de Estudos. 3. ed. São Paulo: Paulus, 2011.

BORGHESE, N. Alberto. Motion Capture Passive markers and video-based techniques. . Universidade de Milano: [s.n.]. Disponível em:

$<$ http://homes.di.unimi.it/borghese/Teaching/DigitalAnimation/Slides/L_08_MoCap_II_Siste miMarkerPassivi.pdf>. Acesso em: 11 jun. 2014. , 2005

BRAUN, Marta. Étienne-Jules Marey. Disponível em: $<$ http://www.answers.com/topic/tienne-jules-marey>. Acesso em: 8 maio 2014.

BROOKS, A L; CZAROWICZ, A. Markerless motion tracking: MS Kinect and Organic Motion OpenStage. . Laval, França: [s.n.]. Disponível em: 
$<$ http://www.icdvrat.reading.ac.uk/2012/papers/ICDVRAT2012_SP05_Brooks_Czarowicz.pd f>. Acesso em: 12 jun. 2014. , 2012

CAMERON, James. - The Making of Terminator 2 - YouTube. . [S.1.]: TriStar Pictures. Disponível em: $<$ https://www.youtube.com/watch? $\mathrm{v}=\mathrm{gLwUX} 11 \mathrm{rr} 3 \mathrm{M}>$. Acesso em: 13 maio 2014a. , 3 jul. 1991

CAMERON, James. O Exterminador do Futuro 2: O Julgamento Final. . [S.1.]: TriStar Pictures. , 3 abr. 1991b

CARSE, Bruce et al. Affordable clinical gait analysis: An assessment of the marker tracking accuracy of a new low-cost optical 3D motion analysis system. Physiotherapy, jun. 2013. Disponível em: <http://linkinghub.elsevier.com/retrieve/pii/S0031940613000266>. Acesso em: 31 out. 2013.

DE ALBUQUERQUE, Alessandro et al. KINECT SENSOR USED AS A SUPPORT TOOL IN CLINICAL ANALYSIS. Journal of Biomechanics, v. 45, p. S304, jul. 2012. Acesso em: 29 ago. 2014.

EBAY. PlayStation Eye | eBay. Disponível em: <http://www.ebay.com/sch/i.html? trksid=p2050601.m570.11313.TR11.TRC1.A0.H0.XPlayStation+Eye\&_nkw=PlayStation+E ye\&_sacat $=0 \&$ _from $=$ R40 $>$. Acesso em: 12 jun. 2014.

EBAY, Brasil. kinect $\mid$ eBay. Vendas. Disponível em: $<$ http://www.ebay.com/sch/i.html? nkw $=$ kinect\&_sacat $=0 \& \_$from $=$R $40>$. Acesso em: 4 mar. 2015.

FEINBERG, Ashley. Classic Disney Animations And Their Real-Life Counterparts. Blog. Disponível em: $<$ http://www.gizmodo.com.au/2013/04/classic-disney-animations-and-theirreal-life-counterparts/>. Acesso em: 8 maio 2014.

FIFTH, Dimension Technologies. Ascension MotionStar Wireless ${ }^{\circledR} 2$. Comercial. Disponível em: <http://www.5dt.com/products/imotionstar_w_01.html $>$. Acesso em: 1 jun. 2014.

FREEDMAN, Barak et al. Depth mapping using projected patterns. . [S.1: s.n.]. Disponível em: <http://www.google.com/patents/US20080240502?hl=pt-BR>. Acesso em: 22 ago. 2014. , 2 out. 2008

GOMIDE, João Vitor Boechat et al. Captura de Movimentos e Animação de Personagens em Jogos. . Belo Horizonte - MG: [s.n.]. Disponível em:

$<$ http://laplace.dcc.ufmg.br/npdi/uploads/bd254485-3879-77ef.pdf $>$. Acesso em: 17 jan. 2012. , 2011

GOUVINHAS, André Dinis; FANTASIA, Jonatas Franchi. SISTEMAS DE CAPTURA E SIMULAÇÃO DE MOVIMENTOS HUMANOS. 2008. 5 f. Trabalho de conclusão de curso USP, São Paulo, 2008. Disponível em:

$<$ http://143.107.106.66/sites/pmr.poli.usp.br.euniversidade.com.br/files/ARTIGO \%20Gouvinhas_Jonatas.pdf $>$.Acesso em: 5 jun. 2014.

HALLIDAY, David; RESNICK, Robert; WALKER, Jearl. Fundamentos de fisica. volume 1. [S.l: s.n.], 2011. Disponível em: <http://alltitles.ebrary.com/Doc?id=10839595>. Acesso em: 
18 ago. 2014.

HAMILL, Joseph; KNUTZEN, Kathleen M. Bases biomecanicas do movimento humano. 3. ed. São Paulo (SP): Manole, 2012.

HILAL, Isam et al. D3.2. Technical Report on Data Collection Procedure ANNEX I. , Virtual Animation of the Kinematics of the Human for Industrial, Educational and Research Purposes.RP, $\mathrm{n}^{\circ}$ D3.2. Bruxelas: [s.n.], 2002. Disponível em:

$<$ http://www.ulb.ac.be//project/vakhum/public_dataset/Doc/VAKHUM-1-

Data_Collection_Procedure.pdf $>$. Acesso em: 21 ago. 2014.

HOFFMANN, Christoph. Superpositions: Ludwig Mach and Étienne-Jules Marey's studies in streamline photography. Studies in History and Philosophy of Science Part A, v. 44, n. 1, p. 111, mar. 2013. Acesso em: 17 ago. 2014.

IMMERSION, Corporation. Polhemus: Motion Tracking Case Study - Immersion Haptic Workstation for Position and Orientation Tracking. Disponível em:

$<$ http://polhemus.com/case-study/detail/immersion-case-study-the-haptic-workstationpolhemus-fastrak-used-for-posit>. Acesso em: 21 maio 2014.

INITION. CyberGlove Systems | Inition. Comercial. Disponível em:

$<$ http://www.inition.co.uk/opinion/cyberglove-systems/>. Acesso em: 5 jun. 2014.

ISRAEL, Shel. Forbes. Why Apple Bought PrimeSense, 25 nov. 2013. Disponível em: $<$ http://www.forbes.com/sites/shelisrael/2013/11/25/why-would-apple-buy-primesense/>. Acesso em: 13 jun. 2014.

JANA, Abhijit. Kinect for Windows SDK Programming Guide. Birmingham: Packt Pub., 2012. Disponível em: < http://public.eblib.com/EBLPublic/PublicView.do?ptilD=1108354>. Acesso em: 19 ago. 2014.

KAUR, Kal. Motion Capture Sensor Systems. . Reino Unido: [s.n.], 10 ago. 2012. Disponível em: $<$ http://www.azosensors.com/article.aspx?ArticleID=43>.

KAZEROONI, H.; CHU, A.; STEGER, R. That Which Does Not Stabilize, Will Only Make Us Stronger. The International Journal of Robotics Research, v. 26, n. 1, p. 75-89, jan. 2007. Acesso em: 9 jun. 2011.

KIRIN, Peter. “Open” Kinect Tools Go Closed and Dead, Limiting Artist and Hacker Options; Call for Help. Create Digital Motion. [S.l: s.n.]. Disponível em:

$<$ http://createdigitalmotion.com/2014/02/open-kinect-tools-go-closed-and-dead-limitingartist-and-hacker-options-call-for-help/>. Acesso em: 29 ago. 2014. , 28 fev. 2014

LAPORTE, Yves. Etienne-jules marey, founder of the graphic method. Comptes Rendus de l'Académie des Sciences - Series III - Sciences de la Vie, v. 321, n. 5, p. 351-354, maio 1998. Acesso em: 18 ago. 2014.

LEFFMANN, Henry. The invention of the motion picture. Journal of the Franklin Institute, v. 207, n. 6, p. 825-828, jun. 1929. Acesso em: 18 ago. 2014. 
LOPES, E.G. et al. DESENVOLVIMENTO DE UM SENSOR DINÂMICO PARA PROTESES/ORTESES INTELIGENTES UTILIZANDO UM IPMC PRODUZIDO POR PLASMA. . São Paulo: [s.n.]. Disponível em:

$<$ http://www.abmbrasil.com.br/utilitarios/editor2.0/UserFiles/File/Alessandra_66o.Congresso/ congresso_abm.pdf $>$. Acesso em: 5 jun. 2014. , 2011

MAISON, Jordan. News Bits: Mortal Kombat, Taken 2, Lindsay Lohan, Dark Tower, Xerxes, and more!. Blog. Disponível em: <http://www.cinelinx.com/movie-news/item/990-news-bitsmortal-kombat-taken-2-lindsay-lohan-dark-tower-xerxes-and-more.html $>$. Acesso em: 11 jun. 2014.

MARQUES FILHO, Oge; VIEIRA NETO, Hugo. Processamento digital de imagens. Rio de Janeiro (RJ): BRASPORT, 1999.

MEASURAND. Measurand | ShapeHand. Comercial. Disponível em: $<$ http://www.shapehand.com/gallery.html $>$. Acesso em: 5 jun. 2014.

MEDIA, Computing Group. The Media Computing Group : Guide to the Vicon Motion Capturing System. Disponível em: $<$ https://hci.rwth-aachen.de/guide_vicon_old $>$. Acesso em: 12 jun. 2014.

METAMOTION. Gypsy 7 Electro-Mechanical Motion Capture System. Disponível em: $<$ http://www.metamotion.com/gypsy/gypsy-motion-capture-system.htm>. Acesso em: 10 jun. 2014.

METAMOTION. Gypsy Motion capture system technology explained. Disponível em: $<$ http://www.metamotion.com/gypsy/gypsy-motion-capture-system-mocap.htm>. Acesso em: 30 maio 2012a.

METAMOTION. Magnetic Motion Capture Systems. Disponível em: $<$ http://www.metamotion.com/motion-capture/magnetic-motion-capture-1.htm>. Acesso em: 30 maio $2012 b$.

METAMOTION. Optical Motion Capture Systems. Disponível em: $<$ http://www.metamotion.com/motion-capture/optical-motion-capture-1.htm $>$. Acesso em: 11 jun. 2014.

MICROSOFT. Interaction Space. Documentação. Disponível em: $<$ http://msdn.microsoft.com/en-us/library/hh973071.aspx>. Acesso em: 19 ago. 2014.

MICROSOFT. Kinect for Windows Sensor Components and Specifications. Documentação. Disponível em: <http://msdn.microsoft.com/en-us/library/jj131033.aspx>. Acesso em: 19 ago. 2014.

MICROSOFT. NUI_SKELETON_POSITION_INDEX Enumeration. Disponível em: $<$ https://msdn.microsoft.com/en-us/library/nuiskeleton.nui_skeleton_position_index.aspx $>$. Acesso em: 3 mar. 2015.

MICROSOFT, MSDN. Kinect for Windows SDK. Disponível em: $<$ http://www.microsoft.com/en-us/download/details.aspx?id=40278>. Acesso em: 29 ago. 
2014.

MICROSOFT, Robotics Developer Studio. Kinect Sensor. Disponível em:

$<$ http://msdn.microsoft.com/en-us/library/hh438998.aspx>. Acesso em: 6 dez. 2011.

MOTION, Organic. Markerless Motion Capture Designed for Animators - Animation Software - OpenStage 2 - Organic Motion. Disponível em:

$<$ http://www.organicmotion.com/mocap-for-animation/>. Acesso em: 12 jun. 2014.

MOTIONWERX. Gypsy7(US).indd - MotionWerxAnimazoo_GYPSY7_Brochure. Disponível em: <http://www.motionwerx.com/MotionWerxAnimazoo_GYPSY7_Brochure>. Acesso em: 2 jun. 2014.

MOURA, Elton. DESENVOLVIMENTO DE UM SISTEMA DE CAPTURA MOVIMENTOS DE BAIXO CUSTO PARA AUXILIAR O DESENVOLVI - MENTO DE EQUIPAMENTOS DE AUXILIO A LOCOMOÇÃO. . São Luís, MA: [s.n.]. , ago. 2012

MUYBRIDGE, Eadweard. The attitudes of animals in motion. Journal of the Franklin Institute, v. 115, n. 4, p. 260-274, abr. 1883. Acesso em: 18 ago. 2014.

OLIVEIRA, Vinicius Machado De et al. Influência do gradiente de inclinação na pronação subtalar em corrida submáxima. Acta Ortopédica Brasileira, v. 21, n. 3, p. 163-166, jun. 2013. Acesso em: 21 ago. 2014.

PHASESPACE, Motion Capture. PhaseSpace Motion Capture | Products : Impulse X2 Motion Capture Solution. Disponível em:

$<$ http://www.phasespace.com/impulse_motion_capture.html $>$. Acesso em: 12 jun. 2014.

PHOENIX, Technologies Inc. What is Motion Capture? | PTI. Disponível em:

$<$ http://www.ptiphoenix.com/what-is-motion-capture/>. Acesso em: 8 ago. 2014.

POLHEMUS, Innovation in Motion. Polhemus Fastrak. Disponível em:

$<$ http://www.polhemus.com/motion-tracking/all-trackers/fastrak/>. Acesso em: 21 maio 2014a.

POLHEMUS, Innovation in Motion. Polhemus G4. Comercial. Disponível em:

$<$ http://polhemus.com/motion-tracking/all-trackers/g4>. Acesso em: 16 maio 2014b.

POLHEMUS, Innovation in Motion. Polhemus Liberty. Disponível em:

$<$ http://polhemus.com/motion-tracking/all-trackers/liberty>. Acesso em: 21 maio 2014c.

POLHEMUS, Innovation in Motion.

Polhemus_Tracking_Performance_Comparison_Chart.pdf. Comercial. Disponível em: $<$ http://polhemus.com/_assets/img/Polhemus_Tracking_Performance_Comparison_Chart.pdf >. Acesso em: 25 maio 2014.

QUALISYS, Motion Capture Systems. Hardware - Oqus - Qualisys Motion Capture Systems. Disponível em: < http://www.qualisys.com/products/hardware/>. Acesso em: 11 jun. 2014. 
QUALISYS, Motion Capture Systems. Long Range Active Markers - Qualisys Motion Capture Systems. Disponível em: <http://www.qualisys.com/products/accessories/activemarkers/long-range/>. Acesso em: 12 jun. 2014a.

QUALISYS, Motion Capture Systems. Passive markers - Reflective markers - Qualisys Motion Capture Systems. Disponível em:

$<$ http://www.qualisys.com/products/accessories/passive-markers/>. Acesso em: 11 jun. 2014b.

QUALISYS, Motion Capture Systems. Short Range Active Markers - Qualisys Motion Capture Systems. Disponível em: <http://www.qualisys.com/products/accessories/activemarkers/short-range/>. Acesso em: 12 jun. 2014c.

ROBERTS, Randy. The Making of Brilliance the Sexy Robot. . [S.1: s.n.]. Disponível em: $<$ https://www.youtube.com/watch?v=HZY5_ZzRdbk>. Acesso em: 31 out. 2013., 1985

RODRIGUEZ-MARTIN, Daniel et al. SVM-based posture identification with a single waistlocated triaxial accelerometer. Expert Systems with Applications, v. 40, n. 18, p. 7203-7211, dez. 2013. Acesso em: 18 ago. 2014.

RONDINELLA, L.F. Muybridge's motion pictures. Journal of the Franklin Institute, v. 208, n. 3, p. 417-420, set. 1929. Acesso em: 17 ago. 2014.

SALI, Erez; AVRAHAM, Assaf. THREE-DIMENSIONAL MAPPING AND IMAGING. . Savyon: [s.n.]. , 6 maio 2014

SAMPLES, Kinect SDK. InfraredBasics-WPF. [S.1.]: Microsoft, 2013.

SARAIVA, Roberto. Engenharia da natureza - Superinteressante. Notícias. Disponível em: $<$ http://super.abril.com.br/ecologia/engenharia-natureza-620356.shtml $>$. Acesso em: 8 ago. 2014.

SCURI, Antonio Escaño. Fundamentos da Imagem Digital. 1999. 95 f. PUC-Rio, Rio de Janeiro, 1999. Disponível em: <http://www.google.com.br/url?

$\mathrm{sa}=\mathrm{t} \& \mathrm{rct}=\mathrm{j} \& \mathrm{q}=\&$ esrc $=\mathrm{s} \&$ source $=$ web $\& \mathrm{~cd}=9 \& \mathrm{sqi}=2 \& \mathrm{ved}=0 \mathrm{CEEQFjAI} \&$ url $=\mathrm{http} \% 3 \mathrm{~A} \% 2 \mathrm{~F}$

$\% 2$ Fwww.inf.ufes.br\%2F thomas\%2Fgraphics\%2Fwww\%2Fapostilas

$\% 2 F C I V 2801$ ScuriImgDigital.pdf\&ei=20SdU-

HAOfHnsAT05YKIAg\&usg=AFQjCNGUaVzEwWgPTf0_QN4kRk2E8OZKBA\&sig2=pngv 0UGpQ6T9vL1SWxpo2Q\&bvm=bv.68911936,d.cWc $>$.

SENZTECH. 3DSuit Motion Capture System. Comercial. Disponível em:

$<$ http://www.senztech.cc/showpros.aspx?proid=2>. Acesso em: 11 jun. 2014.

SIGAL, Leonid. Lecture-3-MarkerBasedMocap.pdf. . [S.1: s.n.]. Disponível em: $<$ http://www.cs.cmu.edu/ yaser/Lecture-3-MarkerBasedMocap.pdf $>$. Acesso em: 12 jun. 2014. , 2012

SMUGMUG. Muybridge. Disponível em: <http://www.muybridge.org>. Acesso em: 8 maio 2014.

SONY, Computer Entertainment America LLC. PlayStation $® E y e$ Camera $\mid P S 3^{T M}$ 
Accessories - PlayStation ${ }^{\circledR}$. Comercial. Disponível em:

$<$ http://us.playstation.com/ps3/accessories/playstation-eye-camera-ps3.html $>$. Acesso em: 12 jun. 2014.

SOUVR, Company. 3DSuit PosiTrac_Capture Suits_SouVR. Disponível em: $<$ http://en.souvr.com/product/201106/8101.html>. Acesso em: 11 jun. 2014.

SOUVR, Company. Ascension 3D Guidance driveBAY_Magnetic_SouVR. Comercial. Disponível em: $<$ http://en.souvr.com/product/200805/1349.html>. Acesso em: 1 jun. 2014a.

SOUVR, Company. Ascension 3D Guidance trakSTAR_Magnetic_SouVR. Comercial. Disponível em: $<$ http://en.souvr.com/product/200805/1350.html>. Acesso em: 1 jun. 2014b.

ST, Life.augmented. INEMO-M1 iNEMO system on board - STMicroelectronics. Disponível em: < http://www.st.com/web/en/catalog/sense_power/FM89/SC1448/PF253162>. Acesso em: 10 jun. 2014.

STURMAN, David J. A Brief History of Motion Capture for Computer Character Animation. Disponível em:

$<$ http://www.siggraph.org/education/materials/HyperGraph/animation/character_animation/m otion_capture/history1.htm>. Acesso em: 8 maio 2014.

SURVR. Measurand ShapeTape /ShapeAnimator_Capture Suits_SouVR. Comercial. Disponível em: <http://en.souvr.com/product/200712/265.html>. Acesso em: 5 jun. 2014.

SYNERTIAL, An Animazzo Company. Full Body Suits Archives - Synertial. Comercial. Disponível em: <http://www.synertial.com/product-category/full-body-suits/>. Acesso em: 10 jun. 2014a.

SYNERTIAL, An Animazzo Company. IGS-180 Motion Capture Suit | Mocap Suit |Synertial. Disponível em: $<$ http://www.synertial.com/product/igs-180-full-body-motion-capture-systemcopy/>. Acesso em: 10 jun. 2014b.

TRACKLAB. Ascension driveBay. Comercial. Disponível em:

$<$ http://tracklab.com.au/object/magnetic/ascension-drivebay>. Acesso em: 30 maio 2014.

VARADARANJAN, Suba. Motion Capture History and Pipeline. . Ohio: [s.n.]. Disponível em: <http://accad.osu.edu/ varadara/Class1.pdf $>$. Acesso em: 8 maio 2014. , 2002

VICON, Motion Systems 1td. Vicon | Markers and Suits. Comercial. Disponível em: $<$ http://www.vicon.com/System/Markers>. Acesso em: 12 jun. 2014.

VICON, Motion Systems ltd. Vicon | Systems. Comercial. Disponível em: $<$ http://www.vicon.com/System/Bonita $>$. Acesso em: 16 maio 2014.

VIRTUAL REALITIES. FASTRAK - Virtual Reality Motion Tracker. Comercial. Disponível em: $<$ http://www.vrealities.com/products/motion-trackers/fastrak>. Acesso em: 21 maio 2014a.

VIRTUAL REALITIES. LIBERTY LATUS - Virtual Reality Motion Tracker. Disponível em: 
$<$ http://www.vrealities.com/products/motion-trackers/liberty-latus $>$. Acesso em: 21 maio $2014 \mathrm{~b}$.

VIRTUAL REALITIES. LIBERTY - Virtual Reality Motion Tracker. Comercial. Disponível em: $<$ http://www.vrealities.com/products/motion-trackers/liberty>. Acesso em: 21 maio $2014 c$.

WOOTON, Benjamim. Creating an OpenGL view on a Windows Form - CodeProject. Tutorial. Disponível em: <http://www.codeproject.com/Articles/16051/Creating-an-OpenGLview-on-a-Windows-Form>. Acesso em: 27 fev. 2015.

WORLD, Computer Graphics. Computer Graphics World - Tools of the Trade. Comercial. Disponível em: <http://www.cgw.com/Publications/CGW/2006/Volume-29-Issue-11-Nov2006-/Tools-of-the-Trade.aspx>. Acesso em: 1 jun. 2014.

WU, Ge et al. ISB recommendation on definitions of joint coordinate system of various joints for the reporting of human joint motion - part I: ankle, hip, and spine. Journal of Biomechanics, v. 35, n. 4, p. 543-548, abr. 2002. Acesso em: 20 ago. 2014.

XBOX. Xbox One. Disponível em: <http://support.xbox.com/pt-BR/browse/xboxone/system/Manuals\%20and\%20Specs>. Acesso em: 31 ago. 2014.

XSENS, Technologies. MVN-BIOMECH-leaflet.pdf. Disponível em: $<$ http://www.Xsens.com/wp-content/uploads/2013/12/MVN-BIOMECH-leaflet.pdf $>$. Acesso em: 10 jun. 2014. 


\section{LISTA DE SIGLAS}

MP: Megapixels, tamanho da imagem em milhões de pixels

fps: Frame per second, do inglês, quadros por segundo, semelhante a Hertz, usado para frequência de imagens.

Hz: Hertz, evento por segundo, frequência.

SDK: Software Development Kit, pacote de desenvolvimento de programas, recursos necessário para desenvolver um software.

IPMC: Ionic Polymer-Metal Composite, Composito polimérico-metálico iônico, tradução nossa. Compósito capaz de reagir eletricamente a estímulos mecânicos e vice-versa.

MEMS: Micro Electronics-Mechanized Systems, Micro sistemas eletrônicosmecanizados, tradução. 


\section{GLOSSÁRIO}

. Análise de movimento: Análise de uma movimentação seja qualitativa ou quantitativamente.

. Captura de movimentos: Registrar uma movimentação em imagens ou dados numéricos ao longo de um período.

. Côndilo: Saliência, ou ponta dos ossos da canela presentes na junta do joelho.

. Dispositivo de captura de movimento: Equipamento utilizado para realizar uma captura de movimentos.

. Espira: É um componente eletrônico formado por um condutor conectado a si mesmo em forma circular

Grau de liberdade: Cada grau de liberdade denota a capacidade de um corpo moverse em uma única direção, seja por translação ou por rotação.

. Maléolo: Saliência, ou ponta dos ossos da canela presentes na junta do tornozelo.

. Método de captura de movimento: Técnica utilizada para capturar movimentos.

. Ortogonal: Que faz ângulo reto $\left(90^{\circ}\right)$.

. Pixel: Unidade mínima que compõe uma imagem digital.

. Rede Neural: Algoritmo composto por equações de muitas variáveis, as quais mudam de acordo com a informação captada, em busca de adaptar o código para melhor interagir com dados futuros. O processo de adaptação é chamado de aprendizagem ou treinamento.

. Software embarcado: Software que é processado dentro de um dispositivo ou periférico, em vez de um computador propriamente dito.

. Sistema de captura de movimento: Conjunto formado por ao menos um dispositivo de captura de movimentos e uma forma de análise de movimentos. 


\section{APÊNDICES}

\section{APÊNDICE A - HISTÓRICO DA CAPTURA DE MOVIMENTOS}

Os registro mais antigos de captura de movimento são do fotografo inglês Eadweard Muybridge (1830-1903) e do francês, físico, inventor, fotógrafo, médico e físiologista Etienne-Jules Marey (1830-1904) (VARADARANJAN, 2002), que buscaram estudar os movimentos através de fotos sequenciais em meados de 1860 .

O Muybridge iniciou a captura de movimento para analisar a movimentação de animais, utilizou diversas câmeras, posicionadas ao longo de sua trajetória, ativadas por cordas, pelo próprio movimento, eram tiradas diversas fotos e posteriormente utilizadas para análise de movimentos, também utilizou este sistema em humanos. Criou o primeiro reprodutor de vídeo, o Zoopraxisoscópio (RONDINELLA, 1929), consistia em um disco giratório com diversas imagens em que o observador observava apenas uma por vez e elas eram giradas, mudando a imagem vista frequentemente (SMUGMUG, 2014).

Figura 21 - Captura de movimentos de um bisão em movimento, feita por Eadweard Muybridge.

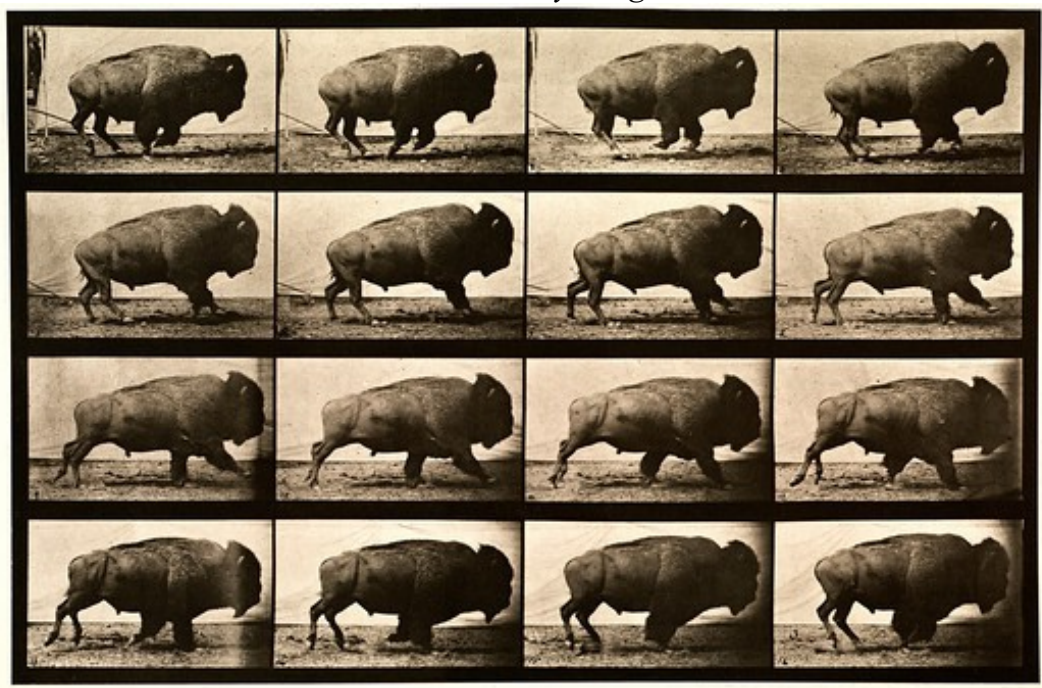

Fonte: (SMUGMUG, 2014)

Marey no entanto, iniciou seu estudo em seres humanos, para tanto, desenvolveu uma câmera fotográfica que tirava fotos em sequência (Figura 22), este método chamado de Cronofotografia (BRAUN, 1992), era uma filmadora primitiva, chamada de câmera fuzil.

Estes pesquisadores foram contemporâneos e o trabalho de um influenciou o do outro, chegaram a se conhecer pessoalmente em 1881 e ambos foram os precursores da captura de movimento. 
Figura 22 - Camera fuzil de Étienne-Jules Marey.

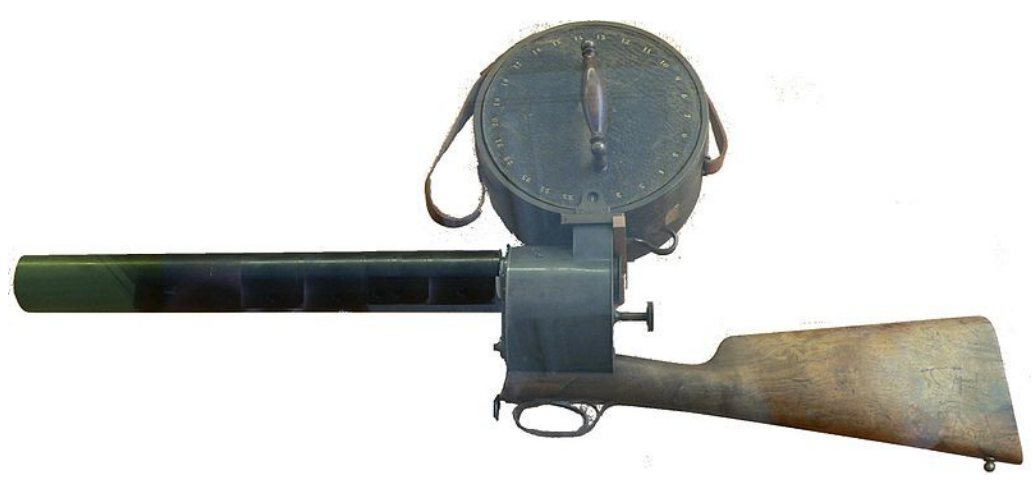

Fonte: (BRAUN, 1992)

Posteriormente, o cinema passou a utilizar captura de movimentos para animar personagens, diversos filmes da Walt Disney ${ }^{\circledR}$ utilizaram capturas de movimento para melhor animar os personagens, o primeiro filme com este método foi "A Branca de Neve" de 1937 (Figura 23) o método da empresa consistia em filmar atores reais e os utilizar como modelos para os desenhos (STURMAN, 1993).

Figura 23 -"A branca de neve" foi o primeiro filme a utilizar captura de movimentos.

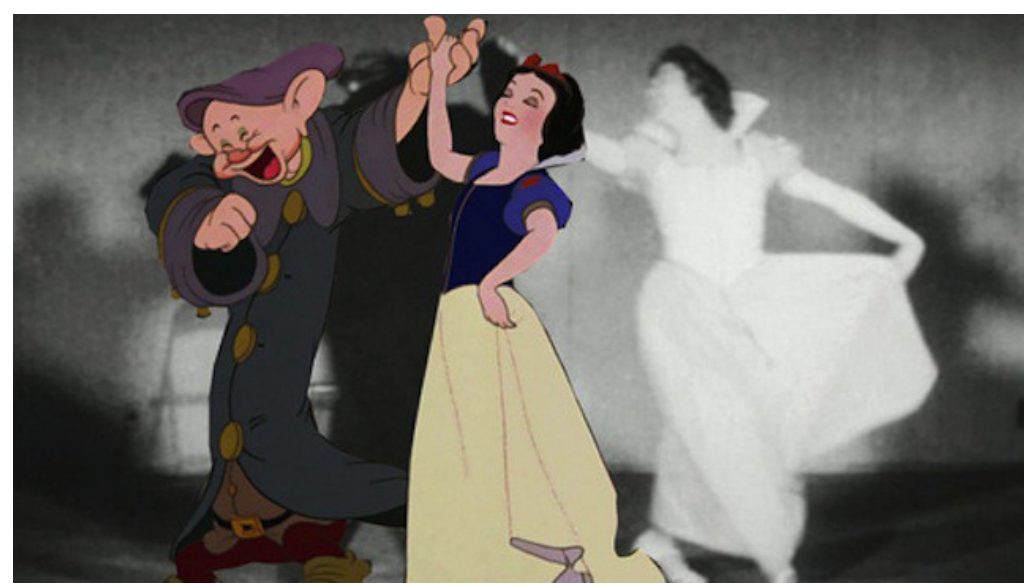

Fonte: (FEINBERG, 2013)

A partir dos anos 80 a indústria de entretenimento assumiu a captura de movimentos para animar personagens completamente digitais, para comerciais, filmes, jogos, seriados entre outras funções (STURMAN, 1993) .

Como exemplos de pioneirismo na captura de imagens para animar personagens digitais (Figura 24) temos o comercial de comida enlatada "Brilliance" (ROBERTS, 1985), criado por Robert Abel e associados, este trabalho utilizou captura de imagem de pontos na pele da atriz e animou um personagem criado computacionalmente. 
Figura 24 - "The Sexy Robot", primeiro personagem completamente digital animado por captura de movimentos.

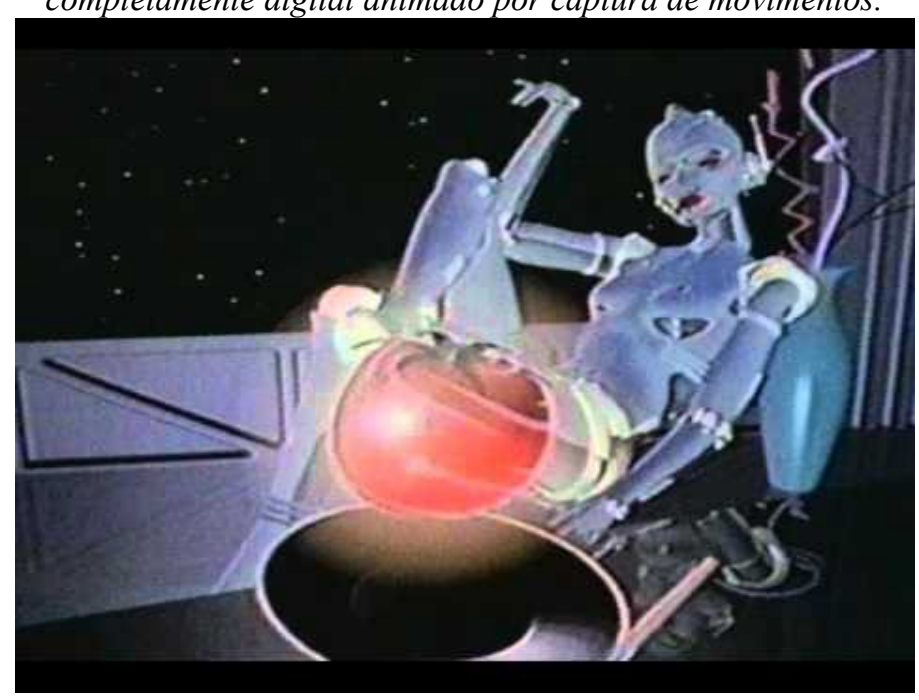

Fonte: (ROBERTS, 1985)

Outro exemplo a ser lembrado é o filme "O Exterminador do futuro 2" (Terminator 2: Judgement day) (CAMERON, 1991b), a animação de um personagem parte líquido parte sólido (Figura 25) garantiu ao filme o Oscar de efeitos especiais.

Figura 25 - Personagem T-1000, do Filme" Terminator 2: Judgement day", primeiro filme a combinar personagens digitais com atores reais.

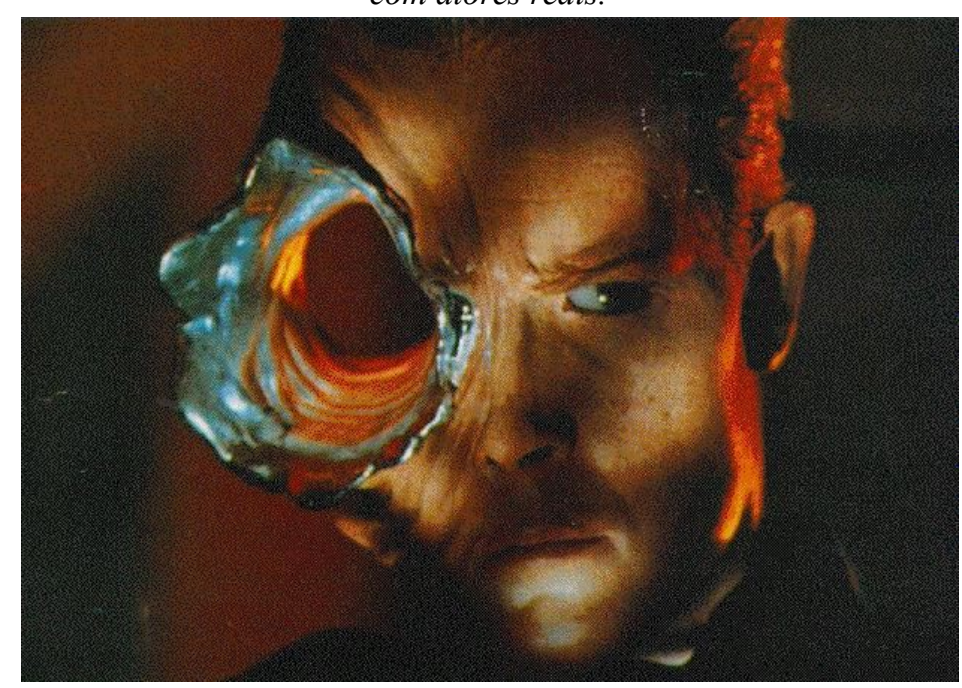

Fonte: (CAMERON, 1991a) 


\section{APÊNDICE B - SISTEMAS DE CAPTURA DE MOVIMENTO}

Todo sistema de captura consiste em módulo de sensoriamento (dispositivo), módulo de análise (software) e dados de movimento (armazenamento). Os diversos sistemas são classificados de acordo com seu módulo de sensoriamento (GOMIDE et al., 2011), em quatro tipos: magnético, eletromecânico, inercial e ótico.

\section{B.1 SISTEMAS MAGNÉTICOS}

\section{B.1.1 Polhemus}

Esta empresa fornece diversos sistemas de capturas de movimentos com dispositivos magnéticos:

\section{B.1.1.1 G4}

Este sistema portátil e sem fio (Figura 26) é oferecido pela empresa em um kit por USD \$ 5.250,00 mais USD \$ 5.995,00 de adicionais, além da licença de software, os quais são diversos e é possível encontrar até mesmo freewares (POLHEMUS, 2014b).

Figura 26-Dispositivo de aquisição G4.

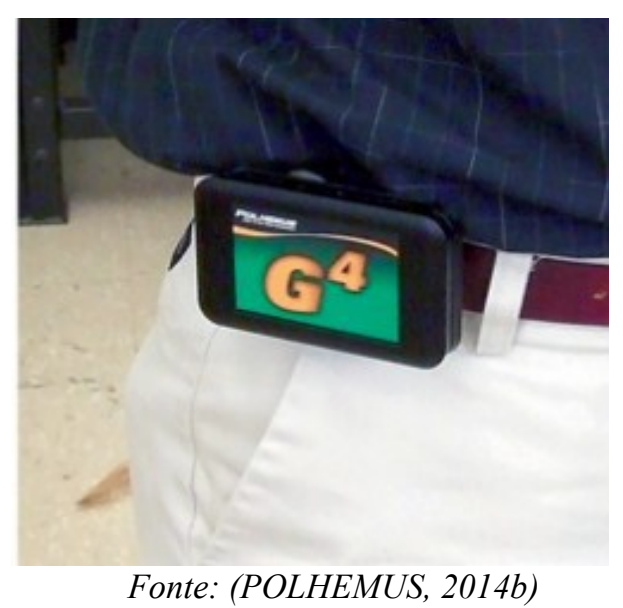

\section{B.1.1.2 Liberty}

Este sistema é o mais rápido e exato entre os dispositivos oferecidos pela empresa, recebe os dados de posição e orientação a cada $3,5 \mathrm{~ms}$, em seis graus de liberdade. $\mathrm{O}$ pacote 
básico inclui capacidade para quatro sensores simultâneos, podendo ampliar até 16. Sua versão sem fio, chamada Liberty Latus (Figura 27) pode utilizar até 12 sensores, com uma frequência de captura de $188 \mathrm{~Hz}$ até 8 sensores, e $94 \mathrm{~Hz}$ acima disto (POLHEMUS, 2014c).

Seu preço na versão com fío pode variar de USD \$ 7.955,00 até USD \$19.595,00 (VIRTUAL REALITIES, 2013c), enquanto sem fio custa de USD \$ 12.845,00 até USD \$ 20.345,00 (VIRTUAL REALITIES, 2013b).

Figura 27 - Sistema de aquisição de dados de sensore magnéticos Polhemus Liberty.

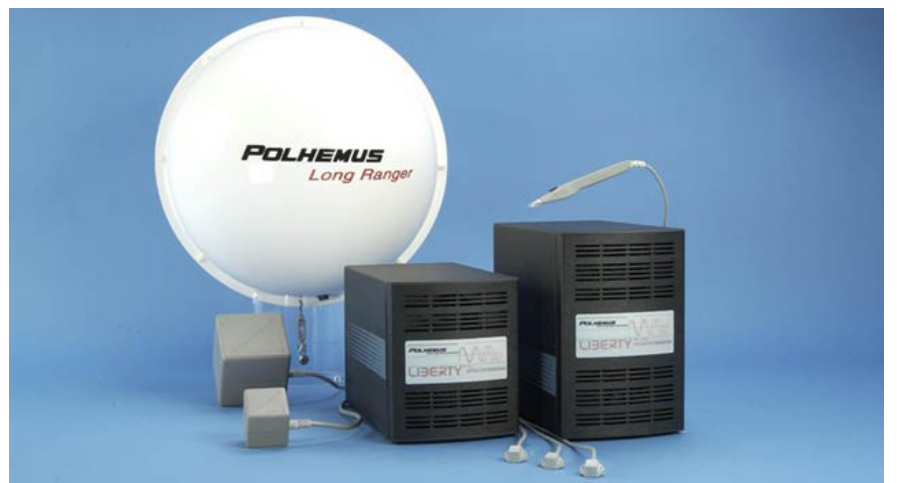

Fonte (POLHEMUS, 2014c)

\section{B.1.1.3 Fastrak}

É o dispositivo (Figura 28) mais vendido da empresa, pelo seu preço e praticidade, seu sistema informa a posição do corpo e não do sensor, como em outros sistemas. Pode usar até quatro sensores, porém a taxa de captura é reduzida, $120 \mathrm{~Hz}$ para um sensor, $60 \mathrm{~Hz}$ para dois sensores, $40 \mathrm{~Hz}$ para três sensores e $30 \mathrm{~Hz}$ para quatro sensores (POLHEMUS, 2014a). Seu custo varia de USD \$ 6.350,00 a USD \$ 7.850,00 (VIRTUAL REALITIES, 2013a).

Figura 28 - Uso do sistema Fastrak para controlar um dispositivo de realidade virtual.

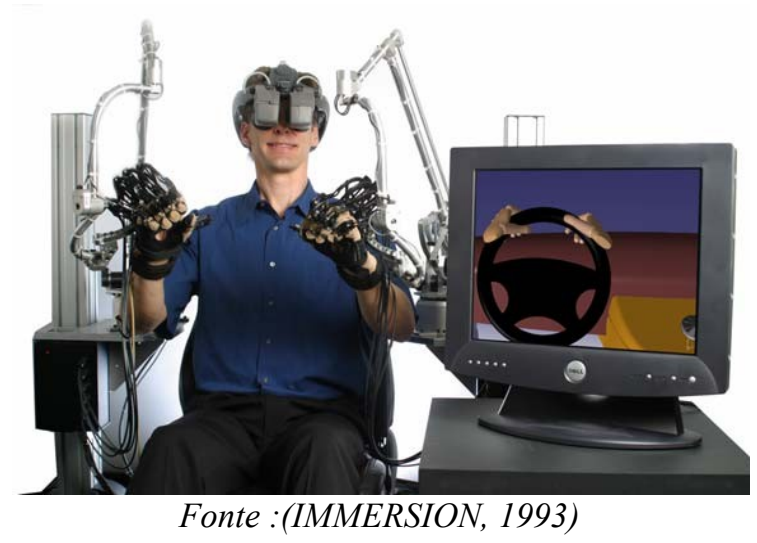


Tabela 7 - Comparativo de sistemas da empresa Polhemus

\begin{tabular}{llllll}
\hline Sistema & Taxa de & Alcance* & Número de & \multicolumn{2}{c}{ Resolução } \\
\cline { 5 - 6 } & Captura[Hz] & & sensores & Posição & Ângulo \\
\hline Fastrak & $120 / 60 / 40 / 30$ & 3 ou $6,1 \mathrm{~m}$ & $1 / 2 / 3 / 4$ & $0,76 \mathrm{~mm}$ & $0,15^{\circ}$ \\
\hline Liberty & 240 & 3 ou $6,1 \mathrm{~m}$ & 1 a 16 & $0,76 \mathrm{~mm}$ & $0,15^{\circ}$ \\
\hline Liberty & 188 até 8 sensores & 18 ou $37 \mathrm{~m}$ (Sem & 1 a 12 & $2,54 \mathrm{~mm}$ & $0,50^{\circ}$ \\
Latus & 94 de 9 a 12. & fio $)$ & & & \\
\hline G4 & 120 & $0,61 / 1,22 / 1,83 \mathrm{~m}$ & 1 a 3 & $2,0 \mathrm{~mm}$ & $0,50^{\circ}$ \\
\hline
\end{tabular}

Fonte: (POLHEMUS, 2013).

\section{B.1.1.4 Ascention}

Esta empresa oferece sensores passivos (Tabela 8) diversos para várias aplicações, com diferentes tamanhos, formatos e custos (ASCENSION, 2014), para capturas de corpo inteiro o mais indicado é o modelo 800 (Tabela 9).

Tabela 8-Opções de sensores da empresa Ascention Technology

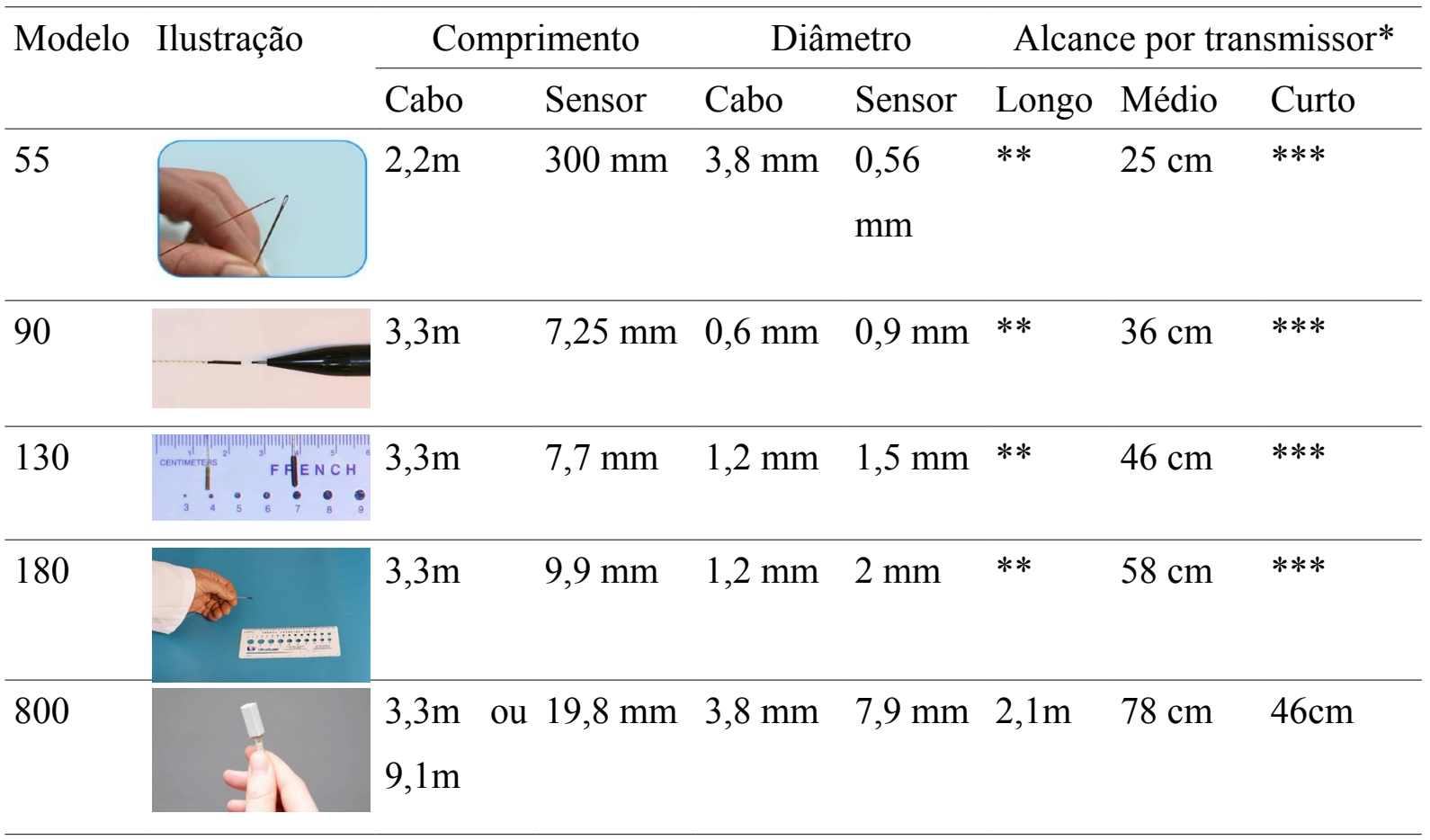

Fontes: (ASCENSION, 2014) e (TRACKLAB, 2013).

*O funcionamento do sensor depende do transmissor utilizado, sensores menores tendem a possuir uma 
precisão maior.

** O transmissor de longo alcance só funciona com o sensor modelo 800.

*** O alcance do transmissor de curto alcance necessita da consulta do fabricante para ser conhecido, a depender a aplicação e atualização.

Tabela 9 - Atribuições dos transmissores da empresa Ascention.

\begin{tabular}{|c|c|c|c|}
\hline Alcance & Curto $($ até $46 \mathrm{~cm})$ & Médio (até $78 \mathrm{~cm})$ & Longo $($ até $2,1 \mathrm{~m})$ \\
\hline Imagem & & & \\
\hline Dimensões & $6,3 \times 4,6 \times 5,2(\mathrm{~cm})$ & $9,6 \mathrm{~cm}(\mathrm{Cubo})$ & $30,5 \mathrm{~cm}($ Cubo $)$ \\
\hline
\end{tabular}

Fonte:(ASCENSION, 2014)

\section{B.1.1.5 DriveBay}

Este sistema possui um receptor de dados montado no computador como um drive de cd (Figura 29), pode receber dados de 1 a 4 sensores simultaneamente, com taxa de captura entre 240 a $420 \mathrm{~Hz}$, sua coleta de dados é resistente a metais condutores. Funciona com emissores de médio e longo alcance.

Indicado para aplicações médicas (ASCENSION, 2013a). Seu preço varia de acordo com o transmissor e sensores, de USD \$ 3.540,00 até USD \$ 6.145,00 (SOUVR, 2014a).

Figura 29 - Posição do equipamento no gabinete do computador.

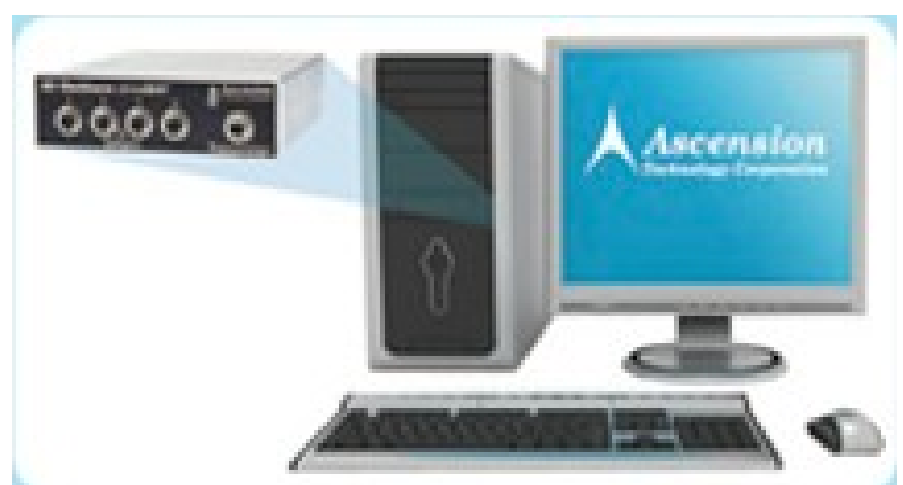

Fonte:(ASCENSION, 2013b) 


\section{B.1.1.6 TrakStar}

O TrakStar (Figura 30) é uma versão melhorada do DriverBay, muito semelhantes externamente, porém o TrakStar funciona com até 16 sensores e também com o emissor de longo alcance, sendo assim mais indicado para uso de biomecânica (ASCENSION, 2013b).

Seu custo varia de acordo com a quantidade de sensores e o tipo de transmissor, entre USD \$ 4.797,00 até USD \$ 7.663,00 (SOUVR, 2014b).

\section{Figura 30 - Receptor TrakStar e um Transmissor de curto} alcance.

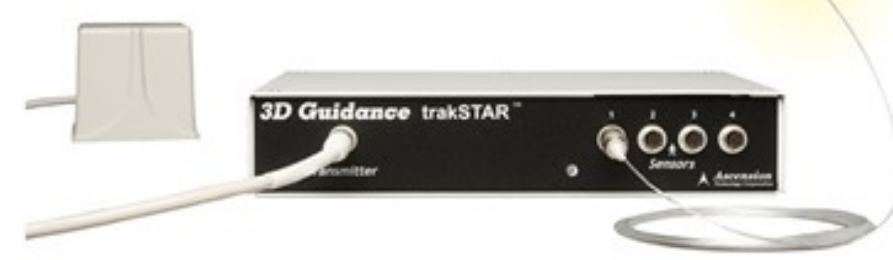

Fonte: Adaptado de:(ASCENSION, 2013b)

\section{B.1.1.7 MotionStar}

Este sistema (Figura 32) lançado em 1998, já foi utilizado para animar diversos personagens digitais como Lara Croft (Figura 31) do jogo Tomb Raider, da Eidos Interactive (ASCENSION, 2000), é indicado para captura de corpo inteiro como para animação de personagens e estudos biomecânicos. Utiliza até dois emissores de longo alcance, até 18 sensores, em duas pessoas simultaneamente, captura em até $144 \mathrm{~Hz}$ (FIFTH, 2012).

preço de sua versão com fios varia de USD \$29.000,00 a USD \$ 35.000,00, sem fio pode variar de USD \$ 59.000,00 até USD \$ 88.000,00 (WORLD, 2014).

Tabela 10 - Comparação entre os produtos da empresa Ascension.

\begin{tabular}{cccccc}
\hline Sistema & Taxa de & Alcance & Número de & \multicolumn{2}{c}{ Exatidão } \\
\cline { 5 - 6 } & captura & & sensores & Posição & ângulo \\
\hline DriveBay & $240 \mathrm{a} 420 \mathrm{~Hz}$ & Até $78 \mathrm{~cm}$ & 1 a 4 & $1,4 \mathrm{~mm}$ & $0.5^{\circ}$ \\
\hline TrakStar & 240 a $420 \mathrm{~Hz}$ & Até $2,1 \mathrm{~m}$ & 1 a 16 & $1,4 \mathrm{~mm}$ & $0.5^{\circ}$ \\
\hline MotionStar & Até $144 \mathrm{~Hz}$ & Até $3,05 \mathrm{~m}$ & 1 a 18 & $7.65 \mathrm{~mm}$ & $0,5^{\circ}$ \\
\hline
\end{tabular}

Fonte: (ASCENSION, 2013c) 
Figura 31 - Cena da personagem Lara Croft no jogo Tomb Raider.

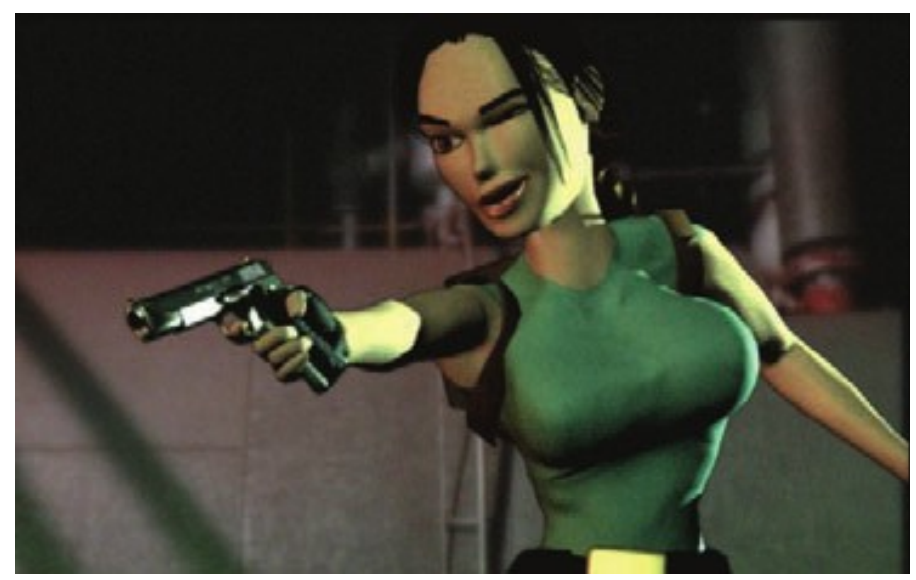

Fonte: (ASCENSION, 2000)

Figura 32 - Exemplo de animação produzida pelo MotionStar.

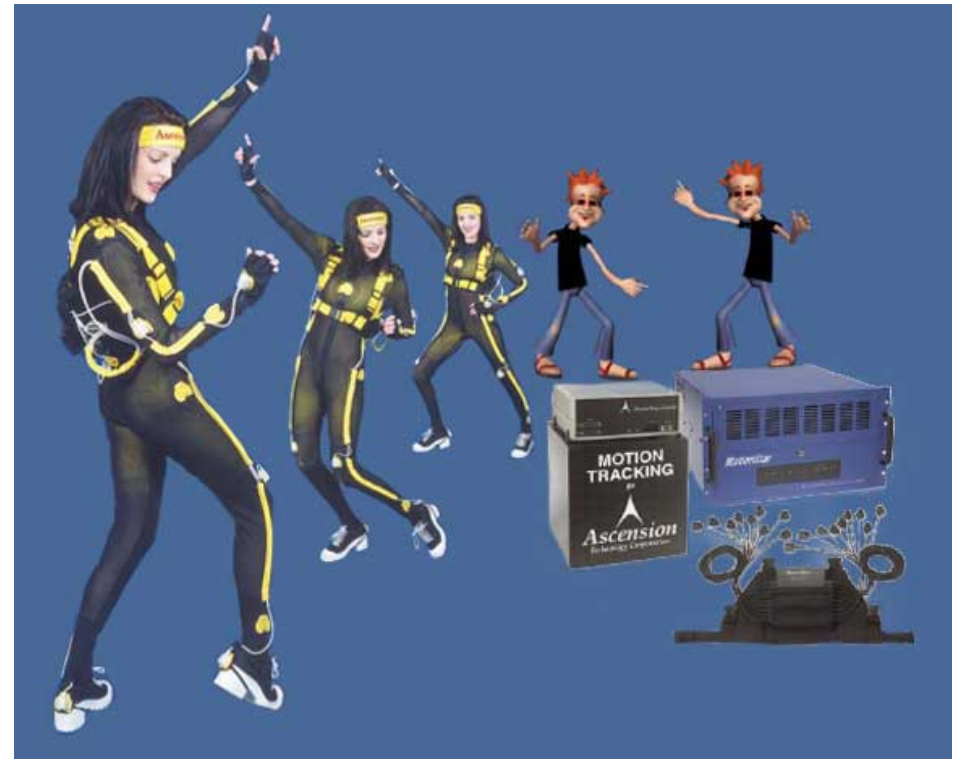

Fonte:(ASCENSION, 2000)

\section{B.2 SISTEMAS ELETROMECÂNICOS}

\section{B.2.1 Animazoo Gypsy 7}

Este sistema da empresa hoje chamada Synertial tem versões para o corpo inteiro (Figura 33) e para tronco com membros superiores, utiliza potenciômetros em 14 juntas para capturar os movimentos, com a exatidão de um oitavo de grau a $120 \mathrm{~Hz}$, contém controles 
para capturar movimentos das mãos e transmissão de dados por fio. Pode custar de USD \$ 7.995,00 (METAMOTION, 2014) a USD \$ 16.100 (METAMOTION, 2012a).

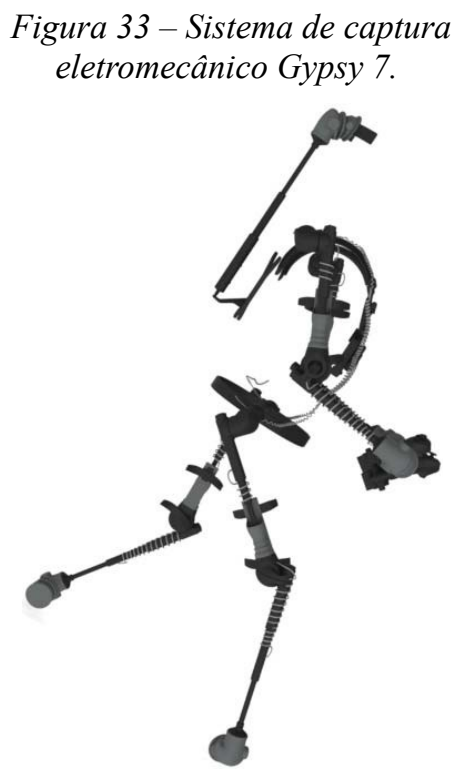

Fonte:(MOTIONWERX, [S.d.])

\section{B.2.2 CyberGlove}

Este dispositivo, cuja versão mais recente é CyberGlove III (Figura 34), faz uso de fitas sensitivas que variam de resistência elétrica com o movimento, para capturar detalhadamente os movimentos da mão. Contém 22 sensores, faz capturas a $100 \mathrm{~Hz}$ e cada luva custa USD \$ 12.995,00 (INITION, 2014).

Figura 34 - CyberGlove, equipamento eletromecânico para capturar movimentos da mão.

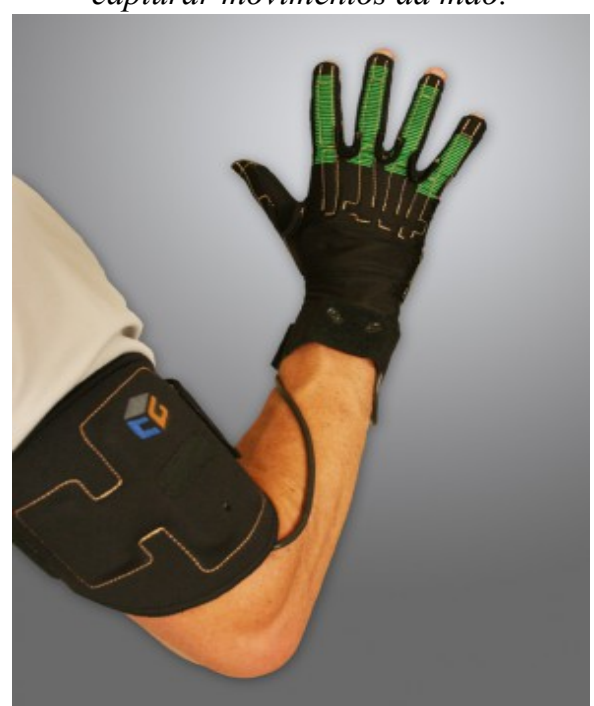

Fonte:(INITION, 2014) 


\section{B.2.2.1 Measurand ShapeTape}

Este sistema utiliza de fitas (Figura 35) com sensores baseados em fibra óptica para capturar movimentos, são bastante leves e portáteis, porém, possuem um processamento de dados bastante complexo para fazer análises biomecânicas, pois o que se obtém é o formato da fita, não do corpo (MEASURAND, 2009).

A fita pode ser torcida, comprimida, esticada, dobrada, isto a torna muito versátil e tem uma resolução de $0,3 \mathrm{~mm}$ de posição e 0,5 graus de inclinação a $110 \mathrm{~Hz}$. Seu preço varia de USD \$ 4.550.00 a USD \$ 15.275,00 (SURVR, 2014).

Figura 35 - Aplicação de Measurand Shapehand

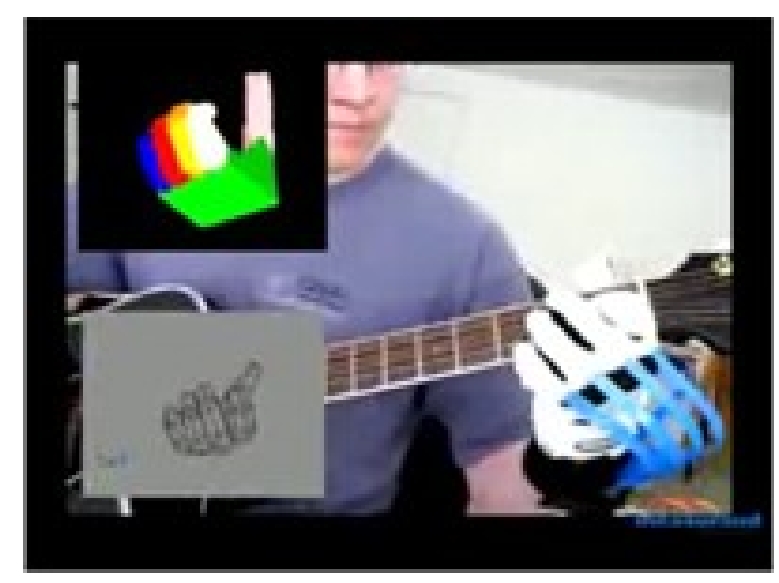

Fonte:(MEASURAND, 2009)

\section{B.3 SISTEMAS INERCIAIS}

\section{B.3.1 Synertial}

Esta empresa fornece sistemas inerciais, denominados pela sigla IGS (Figura 37), com quatro versões. Tem forma de traje e funcionamento semelhante entre si, com variações na quantidade de transmissores e qualidade dos dados (SYNERTIAL, 2013a). Todos os IGS necessitam de pelo menos 7 minutos de preparação. Podem perceber uma aceleração até duas vezes a da gravidade. 
Tabela 11 - Comparação entre dispositivos IGS

\begin{tabular}{|c|c|c|c|c|c|}
\hline \multicolumn{2}{|c|}{ Característica } & IGS $-150 \mathrm{c} /$ fios & IGS $-150 \mathrm{~s} /$ fios & IGS - 180 & IGS-180i \\
\hline \multicolumn{2}{|c|}{$\begin{array}{c}\text { Tempo de } \\
\text { bateria }\end{array}$} & $\mathrm{N} / \mathrm{A}$ & $2,5 \mathrm{~h}$ & $2 \mathrm{~h}$ & $1,5 \mathrm{~h}$ \\
\hline \multicolumn{2}{|c|}{$\begin{array}{l}\text { Quantidade de } \\
\text { sensores }\end{array}$} & 15 & 15 & 17 & 21 \\
\hline \multicolumn{2}{|c|}{$\begin{array}{l}\text { Sensores } \\
\text { opcionais }\end{array}$} & nenhum & nenhum & 1 & 4 \\
\hline \multicolumn{2}{|c|}{ Alcance } & $7 \mathrm{~m}$ & $30 \mathrm{~m}$ & $50 \mathrm{~m}$ & $50 \mathrm{~m}$ \\
\hline \multicolumn{2}{|c|}{ Processamento } & $\begin{array}{c}\text { Computador por } \\
\text { USB }\end{array}$ & Un. integrada & Un. Integrada & $\begin{array}{c}\text { Un. Integrada ou } \\
\text { USB }\end{array}$ \\
\hline \multicolumn{2}{|c|}{ Taxa de captura } & $500 \mathrm{~Hz}$ & $500 \mathrm{~Hz}$ & $500 \mathrm{~Hz}$ & $500 \mathrm{~Hz}$ \\
\hline \multirow{3}{*}{$\begin{array}{l}\text { Precisão } \\
\text { angular }\end{array}$} & $\mathrm{X}$ & $1,5^{\circ}$ & $1,5^{\circ}$ & $0,2^{\circ}$ & $0,2^{\circ}$ \\
\hline & $\mathrm{Y}$ & $1,5^{\circ}$ & $1,5^{\circ}$ & $1^{o}$ & $1^{o}$ \\
\hline & Z & $2^{o}$ & $2^{o}$ & $1^{\mathrm{o}}$ & $1^{o}$ \\
\hline \multicolumn{2}{|c|}{ Preço } & USD \$ 24.000,00 & USD $\$ 31.500,00$ & USD \$ 50.400,00 & USD \$ 68.500,00 \\
\hline
\end{tabular}

Fonte: (SYNERTIAL, 2013).

\section{B.3.2 Ubisense 3DSuit}

Este sistema é semelhante ao IGS da Synertial quanto ao funcionamento, possui 20 sensores para todo o corpo, anexados a um traje (Figura 36), necessita de um computador para processamento de dados e uma taxa de captura de $100 \mathrm{~Hz}$. Precisão de $1^{\mathrm{o}}$ de giro em torno do eixo vertical e $0,5^{\circ}$ em torno dos eixos horizontais. Seu sinal sem fio é emitido por ondas de rádio a $915 \mathrm{MHz}$, alcance de $1.000 \mathrm{~m}(\mathrm{SENZTECH}, 2014)$. Porém a área de captura é limitada devido o emissor do sinal, o pacote para uma área de $10 \mathrm{~m}$ por $10 \mathrm{~m}$ custa USD \$ 9.094,00 e o pacote para $30 \mathrm{~m}$ por $30 \mathrm{~m}$ custa USD \$15.594,00 (SOUVR, 2013). 
Figura 36 - Traje 3DSuite da empresa Ubisense.

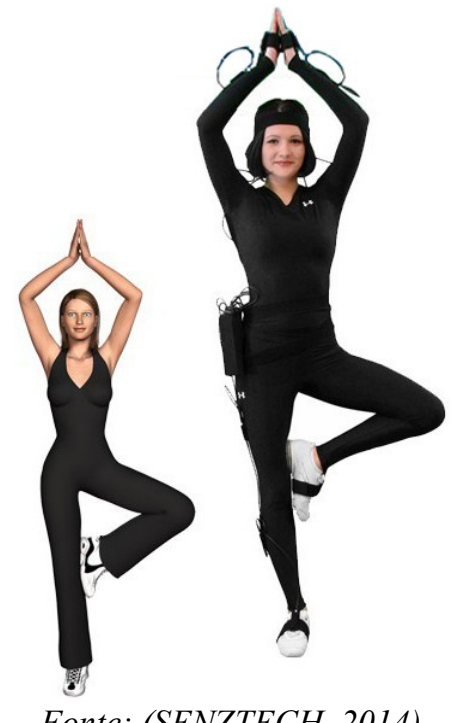

Fonte: (SENZTECH, 2014)
Figura 37 - Traje de captura de movimentos IGS180.

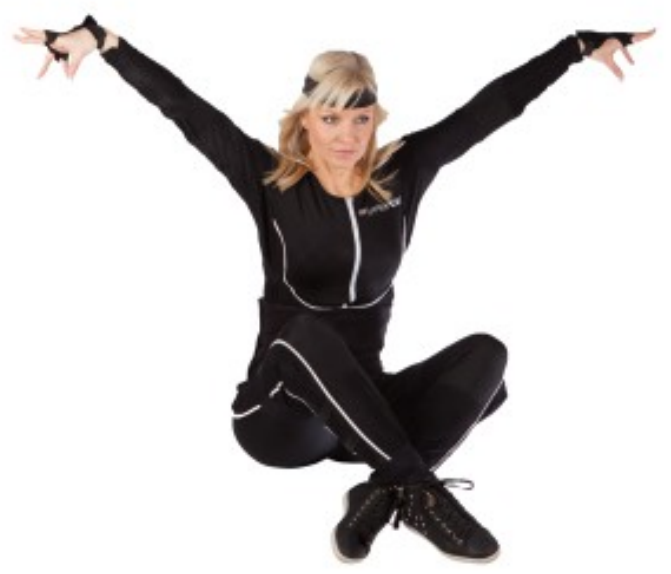

Fonte: (SYNERTIAL, 2013b)

\section{B.3.3 Xsens MVN Biomech}

Este sistema tem um funcionamento semelhante ao anterior, sensores inerciais anexados a um traje (Figura 38), este possui 17 sensores, um grande alcance de $150 \mathrm{~m}$, não possui fios, pode iniciar a captura em menos de dez minutos, sua taxa de captura é selecionável para definição de quantidade de dados, entre 120, 100, 80 ou $60 \mathrm{~Hz}$. Esta informação coletada pode ser exportada para outros sistemas nas taxas de 120, 100, 60, 50, 40, 30, 25 ou $24 \mathrm{~Hz}$ (XSENS, 2014).

Sua bateria pode durar até 3 horas e tem uma precisão de $0,5^{\circ}$ nas três direções e reconhece acelerações até 18 vezes a gravidade, seu kit completo custa USD \$48.000,00

\section{B.3.4 STMicroelectronics iNEMO}

Este sistema (Figura 39) é promovido pela empresa ST, a qual é fornecedora de MEMS, este possui de dez a quinze sensores, os quais possuem 9 graus de liberdade, três para posição, três para orientação, três para posicionamento magnético, em relação a um campo magnético natural ou artificial (ST, 2013). O sistema captura dados a aproximadamente $70 \mathrm{~Hz}$ e com precisão de $0,5^{\circ}$. 


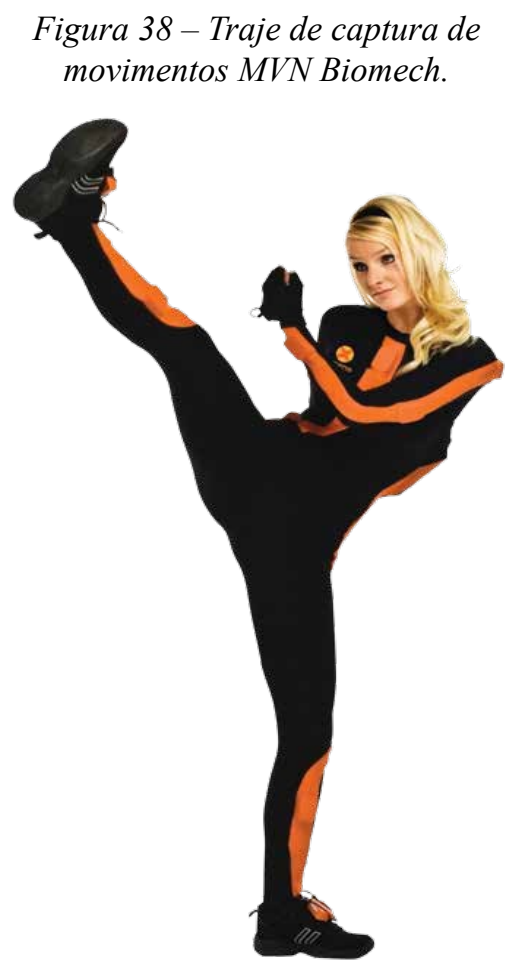

Fonte:(XSENS, 2014)
Figura 39 - Sistema de captura iNEMO da empresa $S T$.

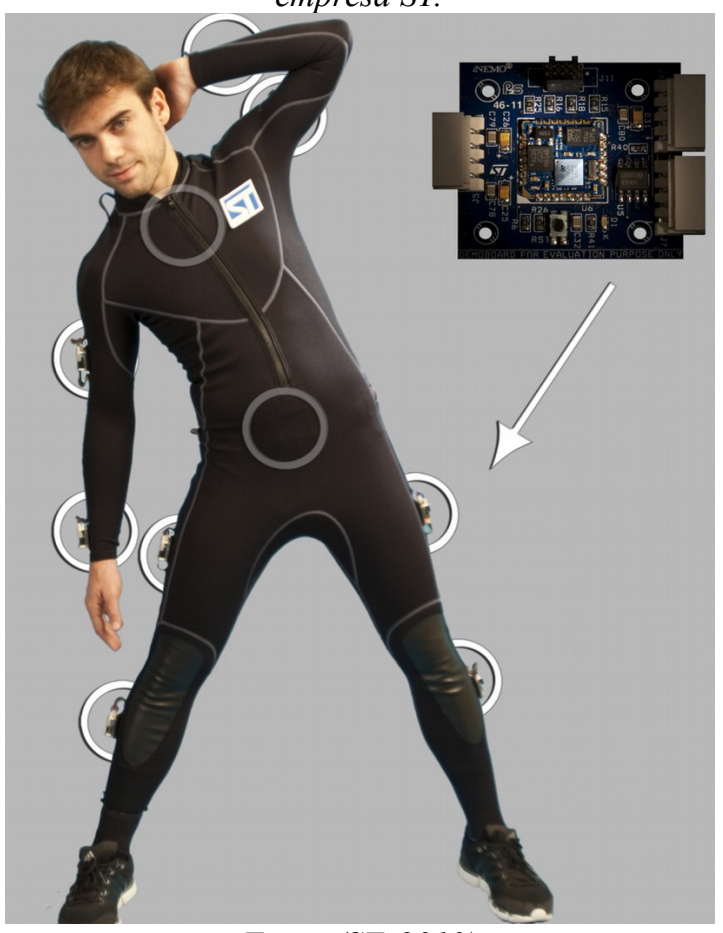

Fonte:(ST, 2013)

\section{B.4 MÉTODOS ÓTICOS}

\section{B.4.1 Sistemas óticos com marcadores passivos}

Este é provavelmente o método mais utilizado na indústria cinematográfica (MAISON, 2011) (Figura 40), com uma diversidade de marcadores passivos para atender as diversas necessidades da captura (Tabela 12). Por exemplo a empresa Qualisys oferece marcadores de diversos tamanhos rígidos ou leves, à prova de água, em forma de fita adesiva e fixável por velcro (QUALISYS, 2013b).

Os marcadores passivos são reflexivos, por isso aparecem em destaque nas filmagens (Figura 41), logo são mais facilmente isolados computacionalmente, permitindo uma análise como menor influência externa, ainda que dificultada por objetos reflexivos. 
Figura 40 - Ator Andy Serkis, interpretando o personagem Gollum para o filme "The Hobbit" de 2012, é visível o grande número de marcadores passivos no seu corpo e rosto.

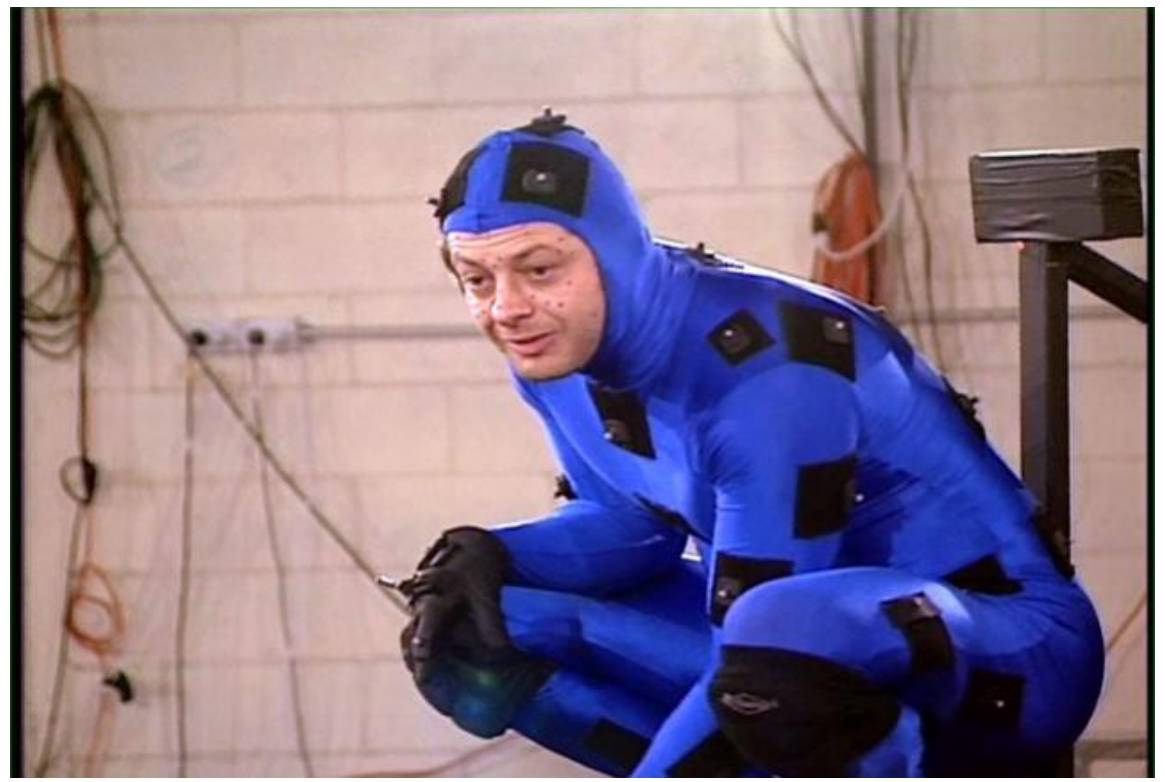

Fonte: (MAISON, 2011)

Figura 41 - Comparação da mesma cena capturada com ilulminação normal e com captura de alto contrasate, realçando os marcadores reflexivos.

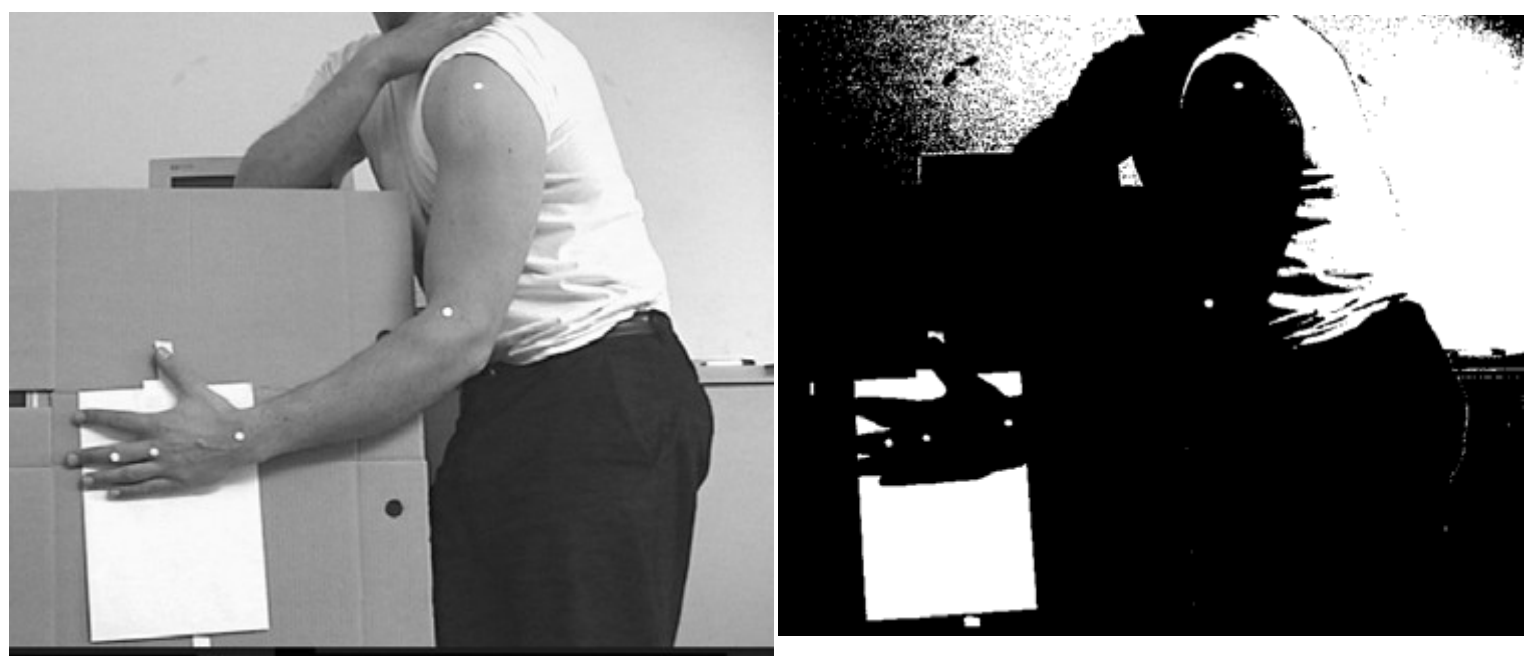

Fonte:(BORGHESE, 2005) 
Tabela 12 - Características dos marcadores passivos da empresa Qualisys.

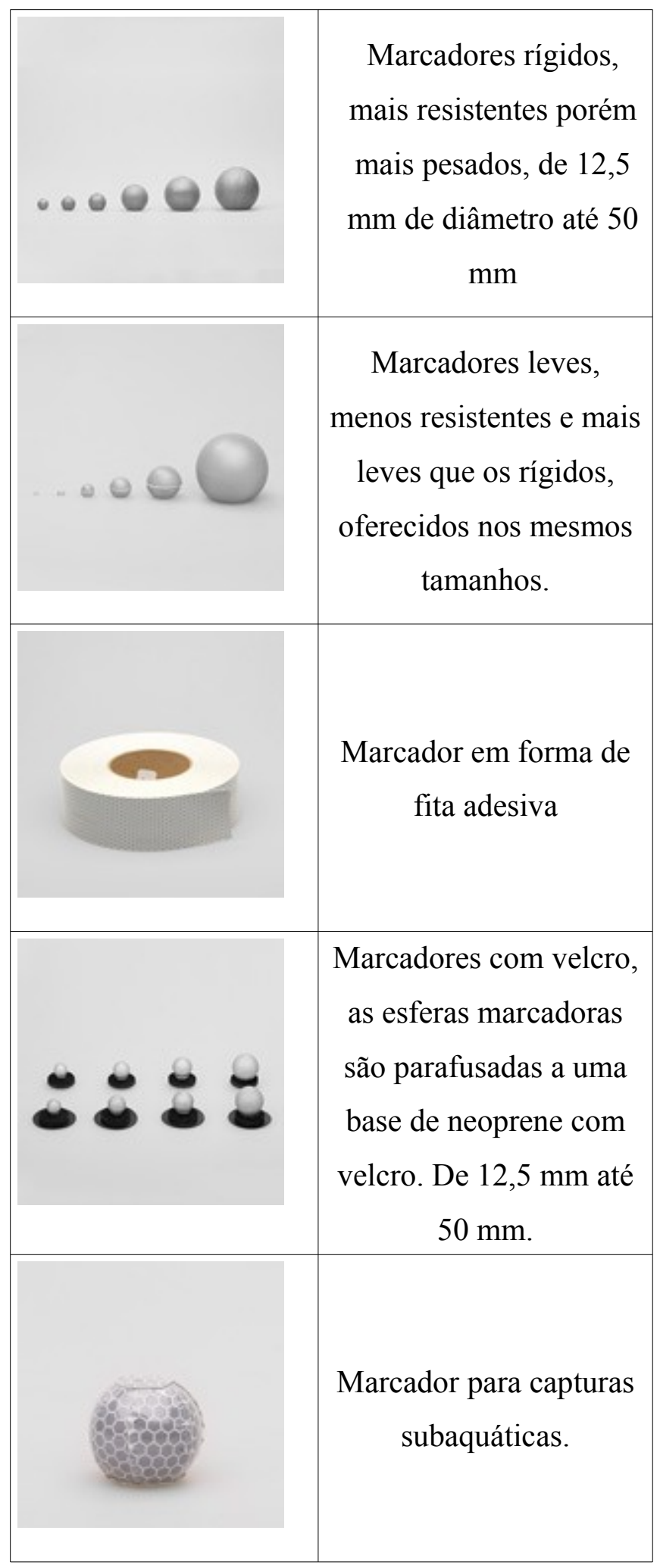

Fonte:(QUALISYS, 2013). 
Estes sistemas utilizam diversas câmeras, e por métodos computacionais comparam-se as imagens de cada câmera acerca do mesmo marcador para então formar um sistema de coordenadas tridimensional para os marcadores (METAMOTION, 2011).

\section{B.4.1.1 Qualisys}

Esta empresa dispõe à venda câmeras que capturam e emitem uma faixa específica de luz, que é refletida pelos marcadores cujas posições são capturadas. Suas câmeras são denominadas Oqus e possuem diversas versões, os modelos $M R I$ são compatíveis com ressonância magnética.

As câmeras modelo UnderWater (do inglês: subaquática, tradução nossa) são à prova de água e recomendada para capturas imersas, sua capacidade de captura é semelhante a série Oqus básica. Os modelos Oqus $F X$ são voltados para aplicações de resposta instantânea, com processamento em tempo real. O modelo Video é feito para captura dos marcadores e do vídeo ao mesmo tempo, capaz de gravar em HD. A taxa de captura é máxima quando a resolução é mínima (QUALISYS, 2014).

Tabela 13 - Comparativo entre as diversas câmeras da empresa Qualisys

\begin{tabular}{|c|c|c|c|c|c|c|c|}
\hline \multirow[t]{2}{*}{ Imagem } & \multirow[t]{2}{*}{ Nome } & \multirow[t]{2}{*}{ Série } & \multicolumn{2}{|c|}{ Modo normal } & \multicolumn{2}{|c|}{$\begin{array}{c}\text { Modo de alta } \\
\text { velocidade }\end{array}$} & \multirow{2}{*}{$\begin{array}{c}\text { Taxa de captura } \\
\text { máxima } \\
(\mathrm{fps} / \mathrm{Hz})\end{array}$} \\
\hline & & & MP & fps & MP & fps & \\
\hline & \multirow{4}{*}{ Oqus } & 1 & 0,3 & 250 & N/A & N/A & 1000 \\
\hline & & $3+$ & 1,3 & 500 & 0,3 & 1750 & 10000 \\
\hline & & 4 & 3 & 480 & N/A & N/A & 10000 \\
\hline & & 5 & 4 & 180 & 1 & 360 & 10000 \\
\hline & \multirow{3}{*}{ Oqus MRI } & 1 & 0,3 & 250 & $\mathrm{~N} / \mathrm{A}$ & N/A & 1000 \\
\hline & & 3 & 1,3 & 500 & $\mathrm{~N} / \mathrm{A}$ & N/A & 1000 \\
\hline & & 5 & 4 & 180 & $\mathrm{~N} / \mathrm{A}$ & N/A & 1000 \\
\hline & \multirow{4}{*}{$\begin{array}{c}\text { Oqus } \\
\text { Underwater }\end{array}$} & 1 & 0,3 & 250 & N/A & N/A & 1000 \\
\hline & & 3 & 1,3 & 500 & 0,3 & 1750 & 10000 \\
\hline & & 4 & 3 & 480 & $\mathrm{~N} / \mathrm{A}$ & $\mathrm{N} / \mathrm{A}$ & 10000 \\
\hline 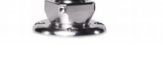 & & 5 & 4 & 180 & 1 & 360 & 10000 \\
\hline
\end{tabular}




\begin{tabular}{|c|c|c|c|c|c|c|c|}
\hline \multirow[t]{2}{*}{ Imagem } & \multirow[t]{2}{*}{ Nome } & \multirow[t]{2}{*}{ Série } & \multicolumn{2}{|c|}{ Modo normal } & \multicolumn{2}{|c|}{$\begin{array}{l}\text { Modo de alta } \\
\text { velocidade }\end{array}$} & \multirow{2}{*}{$\begin{array}{l}\text { Taxa de captura } \\
\text { máxima } \\
(\mathrm{fps} / \mathrm{Hz})\end{array}$} \\
\hline & & & MP & fps & MP & fps & \\
\hline & \multirow{2}{*}{ Oqus FX } & 1.3 & 1,3 & 500 & 0,3 & 1750 & 10000 \\
\hline & & 4 & 4 & 180 & 1 & 360 & 10000 \\
\hline \multirow{4}{*}{ 024: } & \multirow{4}{*}{ Oqus Video } & \multicolumn{6}{|c|}{$\begin{array}{l}\text { Neste modelo, o modo normal é de transmissão imediata, o } \\
\text { de alta velocidade coleta de dados para análise posterior. }\end{array}$} \\
\hline & & Full HD & 2 & 24 & 2 & 337 & 1000 \\
\hline & & $0,5 \mathrm{MP}$ & 0,5 & 87 & 0,5 & 665 & 1000 \\
\hline & & VGA & 0,3 & 120 & 0,3 & 750 & 1000 \\
\hline
\end{tabular}

Fonte: (QUALISYS, 2014).

\section{B.4.2 Vicon}

A empresa Vicon também dispõe de uma grande variedade de marcadores passivos, os quais são fixados aos trajes de captura, seus diâmetros variam entre 3, 4, 6,35, 9,5, 14, 19 e 25 $\mathrm{mm}$, estes são vendidos em pacotes de 50 para $3 \mathrm{~mm}$ e 10 para os demais, os preços dos pacotes variam entre $€ 67,00$ e $€ 270,00$ (MEDIA, 2011), incluem máscaras e gorros como pode-se ver na figura 42 (VICON, 2013).

Figura 42 - Usuário com diversos marcadores e algumas câmeras Vicon ao fundo.

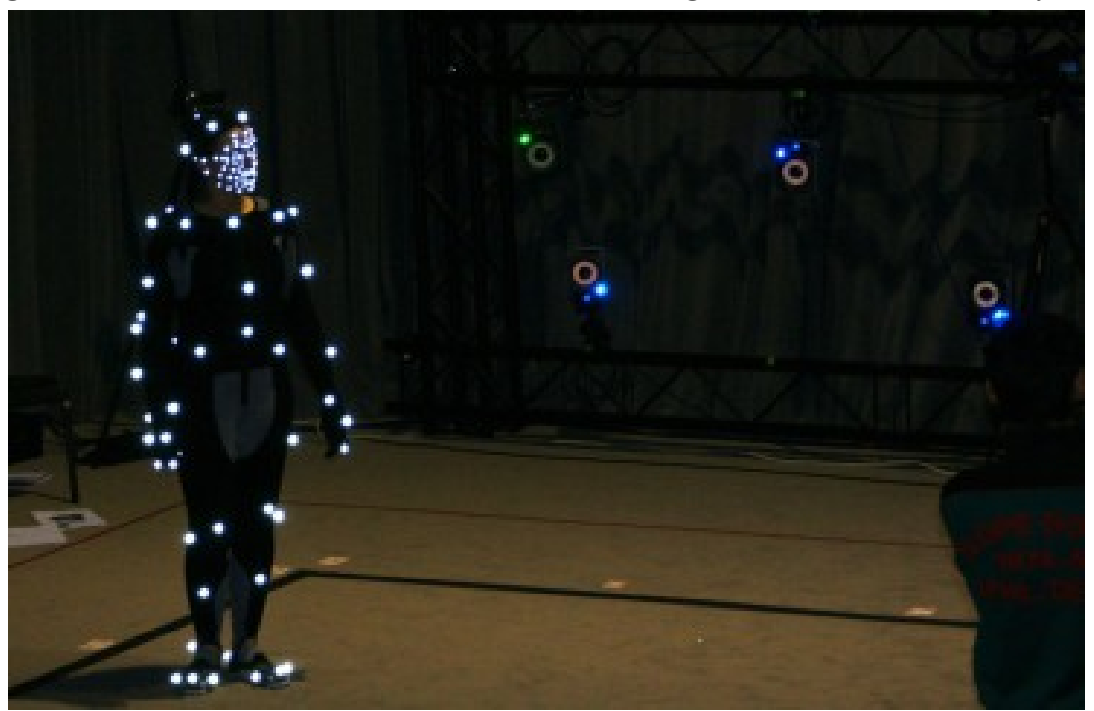

Fonte:(VICON, 2013) 
A tabela 14 dispõe de informações relevantes acerca das câmeras desta empresa, cujo funcionamento é semelhante aos modelos anteriores (VICON, 2014).

Tabela 14 - Características das câmeras da empresa Vicon.

\begin{tabular}{|c|c|c|c|c|c|}
\hline Imagem & Série & Modelo & $\begin{array}{l}\text { Resolução } \\
\text { (MP) }\end{array}$ & $\begin{array}{c}\text { Taxa de captura } \\
\text { (fps) }\end{array}$ & $\begin{array}{l}\text { Preço por } \\
\text { câmera }\end{array}$ \\
\hline \multirow{7}{*}{$+\infty$} & \multirow{5}{*}{$\mathrm{T}$} & 160 & 16.0 & 120 & N/A \\
\hline & & $40 \mathrm{~S}$ & 4.0 & 515 & N/A \\
\hline & & $20 \mathrm{~S}$ & 2.0 & 690 & N/A \\
\hline & & $10 \mathrm{~S}$ & 1.0 & 1000 & N/A \\
\hline & & 10 & 1.0 & 250 & N/A \\
\hline & & B10 & 1.0 & 250 & N/A \\
\hline & & B3 & 0.3 & 240 & N/A \\
\hline
\end{tabular}

Fonte: (VICON, 2014)

\section{B.5 SISTEMAS ÓTICOS COM MARCADORES ATIVOS}

Estes sistemas também utilizam câmeras combinadas para capturar marcadores, porém, estes são emissores de luz, dispensando a necessidade de reflexão, livrando-se de objetos reflexivos indesejados. Isto reduz na câmera a necessidade de emissão luminosa, ainda que os marcadores necessitem de alimentação por bateria ou cabos (SIGAL, 2012).

Assim como os marcadores passivos, este sistema também sofre influência de luz externa, podem dificultar ou impossibilitar a captura de movimentos. Também necessitam de calibração de forma semelhante aos passivos.

\section{B.5.1 PhaseSpace}

Esta empresa oferece sistemas de captura com marcadores ativos, o Impulse $2 x$ (Figura 43) e Improv, ambos baseados em marcadores de LED do mesmo tipo, mas câmeras diferentes entre si. Os marcadores podem manter-se com suas baterias por até 4 horas. As câmeras do 
Impulse $2 x$ tem uma resolução de 12 MP e 960 fps, o Improv também captura a 12 MP mas a 240 fps (PHASESPACE, 2013).

Figura 43 - Sistema de captura ótico com marcadores ativos PhaseSpace Impulse $2 x$.

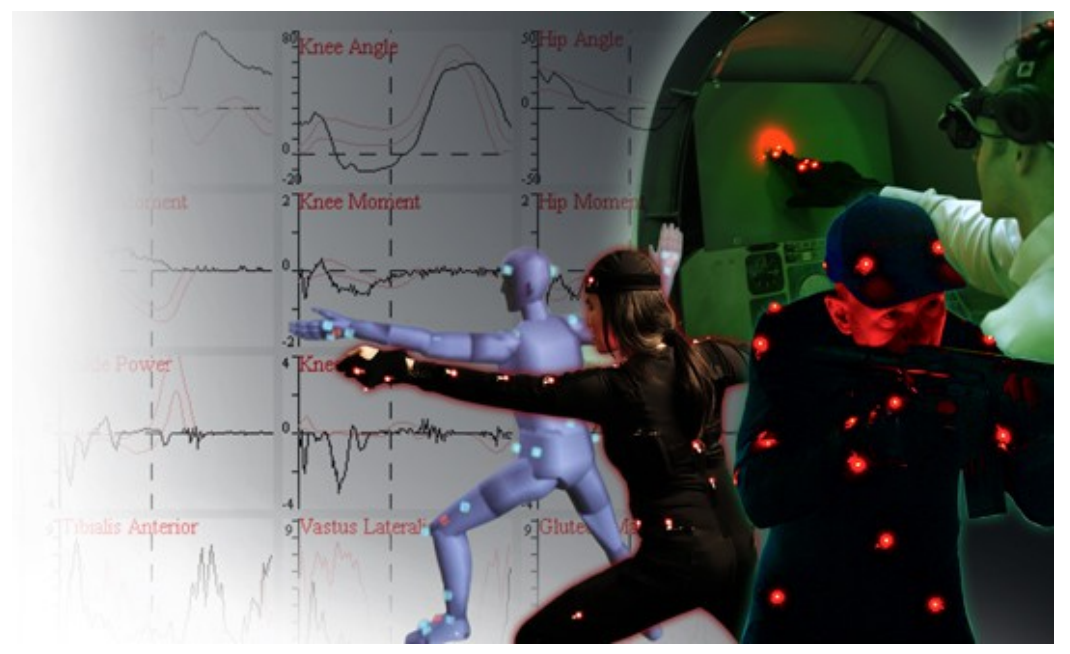

Fonte: (PHASESPACE, 2013).

\section{B.5.2 Qualisys}

Esta empresa também trabalha com marcadores ativos, em dois tipos, de longo ou de curto alcance (Figura 44), seu marcador de longo alcance é capaz de fazer medições a mais de $100 \mathrm{~m}$ de distância, a 200 fps. Os marcadores de curto alcance têm um sistema que permite fazer a captura de mais de 100 emissores a 500 fps (QUALISYS, 2013c).

Figura 44 - Marcadores ativos da Qualisys, longo alcance à esquerda e curto à direita.
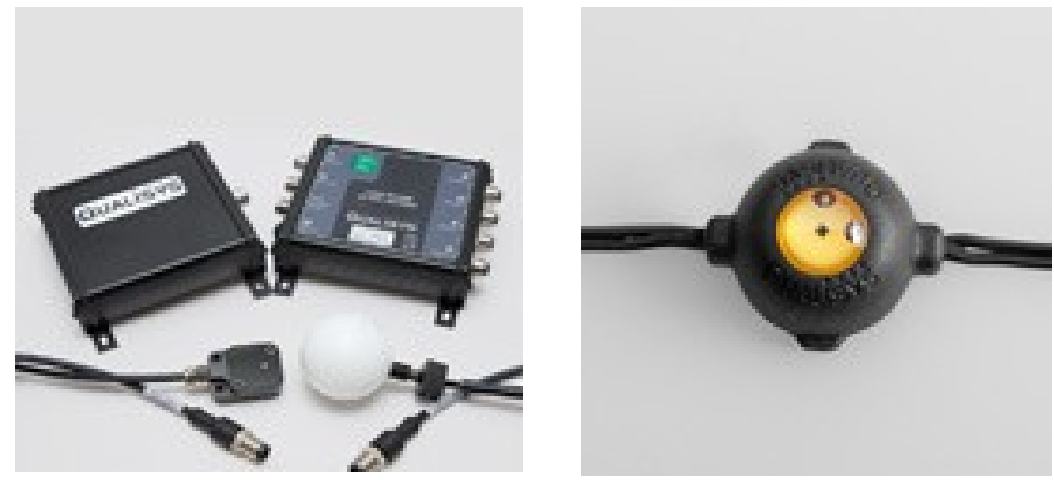

Fonte: (QUALISYS, 2013b) 


\section{B.6 SISTEMAS ÓTICOS SEM MARCADORES}

Estes sistemas, na verdade, são técnicas que não exigem muito dos equipamentos, mas bastante dos softwares de processamento. Uma grande vantagem destes sistemas é não necessitar de fixar qualquer tipo de dispositivo no usuário, nem de trajes especiais. $\mathrm{O}$ que torna bastante prático para aplicações mais corriqueiras.

\section{B.6.1 Organic Motion}

Esta empresa oferece três sistemas de captura: para uso clínico, para uso didático ou produção de animações (Figura 45) e um último para simulações e interações em tempo real para treinamento militar.

Seus sistemas utilizam de 8 a 24 câmeras, com frequência de captura entre 80 e 160 $\mathrm{Hz}$ e processamento de dados, responsável por reconhecer o corpo humano, por isto seu tempo de preparo é curto. Seu preço varia de USD \$ 40.000,00 a USD \$ 80.000,00 (BROOKS; CZAROWICZ, 2012).

Figura 45 - Sistema de captura OrganicMotion e resposta em tempo real.

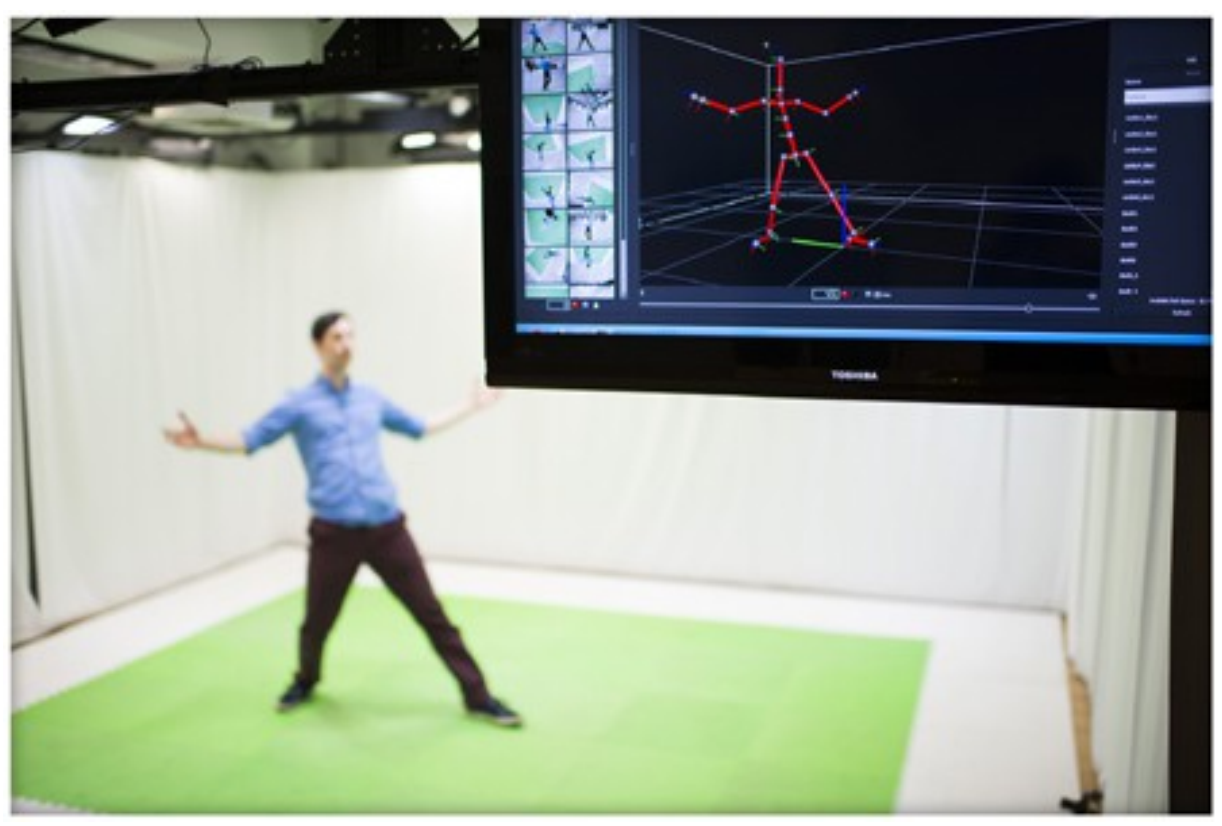

Fonte: (MOTION, 2013) 


\section{B.6.2 Sony PlayStation Eye}

Este dipositivo (Figura 46) é um periférico do console PlayStaion 3, possui uma câmera colorida com resolução de $0,3 \mathrm{MP}$ a 60 fps ou 0,07 MP a 120 fps, também é capaz de reconhecer alguns gestos e diversos comandos para os jogos em execução (SONY, 2014). Possui microfones para capturar comandos vocais. Pode ser encontrada por menos de R\$ 50,00 (EBAY, 2014).

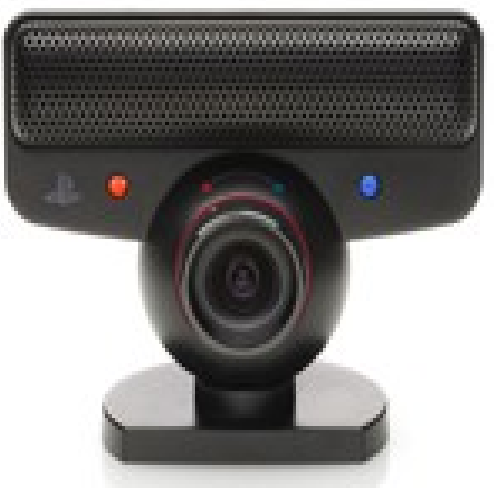

Figura 46 - PlayStation Eye, dispositivo de captura de movimento sem marcadores da Sony. Adaptada de: (SONY, 2014) 


\section{APÊNDICE C - MANUAL DE INSTALAÇÃO DO KINECT}

\section{C.1 USAR O PROGRAMA DESENVOLVIDO}

Para que o programa desenvolvido possa ser utilizado em um computador é necessário instalar o Kinect SDK na versão 1.8, e o dispositivo Kinect para Xbox 360, encontrada no endereço http://www.microsoft.com/en-us/download/details.aspx?id=40278. Com o sistema operacional Windows 7, 8 ou 8.1.

Para instalar certifique-se de que o Kinect esteja desconectado do computador, caso haja algum outro pacote de drivers ou SKD para Kinect instalado, certifique-se de desinstalar, pois pode haver incompatibilidades.

Ao terminar a instalação, ele recomendará a instalação do Kinect for Windows Developer Toolkit, da página http://www.microsoft.com/enus/download/details.aspxid=40276, o qual é interessante apenas para desenvolvedores, ele inclui alguns aplicativos exemplares, que podem ser usados para testar a instalação do Kinect inicialmente.

Após a instalação, o Kinect pode ser conectado ao computador e à energia elétrica simultaneamente, pode-se verificar se o computador o reconheceu através do gerenciador de dispositivos, ele deve ser reconhecido pelo aplicativo como apresentado da figura 47.

\section{C.2 DESENVOLVER APLICATIVOS PARA KINECT}

Para desenvolver aplicativos para Kinect, utiliza-se o Microsoft Visual Studio, primeiro deve-se criar um projeto e ao selecionar o arquivo principal, editar as preferências dele da seguinte forma: Selecionar a opção na barra de índices Project $>$ \{nome do projeto\} Properties, na janela aberta, selecionar o nó Configuration Properties $>\{$ A linguagem usada $\}>$ General, definir a caixa de opções Configuration como All Configurations, então no campo Additional Include Directories acrescentar "\$(KINECTSDK10_DIR)|inc", no nó Linker>General, no campo Additional Library Directories acresentar "\$(KINECTSDK10_DIR)|lib|x86", no nó Linker>Input, no campo Additional Dependencies acrescentar kinect10.lib;, utilize também a biblioteca NuiApi.h 
Figura 47 - Gerenciador de Dispositivos reconhecendo corretamente um Kinect conectado ao computador

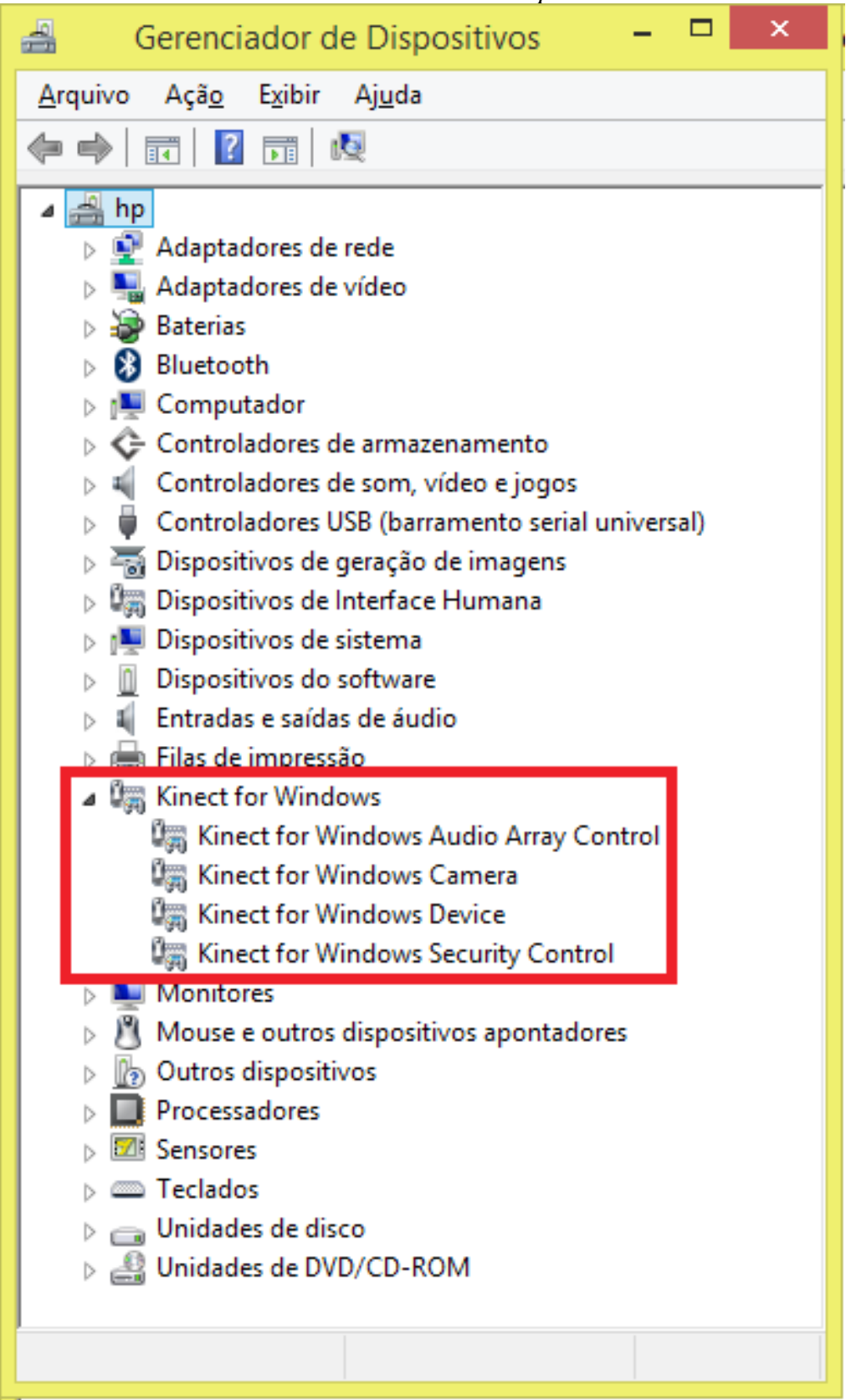

Fonte: Autor 
ANEXOS

ANEXO A ARTIGO PUBLICADO NO CBEB 2012

\title{
DESENVOLVIMENTO DE UM SISTEMA DE CAPTURA MOVIMENTOS DE BAIXO CUSTO DESTINADO A PROJETOS DE EQUIPAMENTOS DE AUXILIO A LOCOMOÇÃO
}

\author{
E. G. X. Moura*, D. A. P. Nagem** e L. de A. Mendes** \\ *Departamento de Engenharia Mecânica/UFRN, Natal, Brasil \\ **Departamento de Engenharia Biomédica/UFRN, Natal, Brasil \\ eltongilx@gmail.com \\ nagem@ufrnet.br \\ mendes.luciana.a@gmail.com
}

\begin{abstract}
A incapacidade de caminhar é motivo de diversos prejuízos para a vida de um humano, sua capacidade locomotora é comprometida, seu organismo não funciona como deveria e é bastante prejudicial à autoestima do deficiente. Este trabalho buscar desenvolver um software para uso do Microsoft Kinect com o uso da API OpenNI, capaz promover um sistema de captura de movimentos e determinação dos parâmetros da caminhada para apoiar projetos de equipamentos de auxilio a locomoção. Sendo assim a etapa inicial do desenvolvimento de um equipamento para que um indivíduo com locomoção comprometida usufrua dos benefícios da caminhada, ganhar mais independência e autoestima e integrar-se à sociedade.
\end{abstract}

Palavras-chave: Kinect, Reabilitação, Marcha, Captura de Movimentos.

Introdução

Existe uma grande quantidade de pessoas com problemas de locomoção [1], representam $6,7 \%$ da população brasileira. Esta ausência de locomoção na forma natural implica diversas 
complicações sociais, fisiológicas e psicológicas [2].

Equipamentos diversos são utilizados para aumentar a mobilidade. Equipamentos que permitem uma mobilidade mais próxima de uma pessoa sem dificuldades locomotivas são as órteses e próteses são em maioria muito caros. Para desenvolver estes equipamentos, fazem-se necessários estudos minuciosos da movimentação humana. Dispositivos como esses causam grandes benefícios aos usuários: emocionais, profissionais, sociais e fisiológicos como melhor circulação, a prevenção de escaras e do atrofiamento da musculatura [3].

Para capturar movimentos humanos existem alguns métodos disponíveis, desenvolvidos principalmente para animação de personagem computadorizados para cinema, televisão e jogos. Para transformar os movimentos em dados digitais, utilizam-se sistemas de sensores, entre eles estão: os sistemas mecânicos, magnéticos e ópticos

Atualmente os equipamentos encontrados no mercado atualmente são muito caros, impossibilitando seu uso terapêutico em pequenas clínicas que necessitem deste tipo de sistema, exigem minuciosas calibrações e o uso de marcadores que requerem treinamento prévio para uso devido, além de serem grandes e dificilmente reposicionados [4].

\section{Kinect}

O Kinect, inicialmente chamado de "project Natal", trata-se de um sensor óptico de movimento. Produzido pela Microsoft em parceria com a Prime Sense, como acessório do vídeo game Xbox 360, para jogos sem o convencional controle.

Com ele e possível utilizar gestos e voz como comandos, com o objetivo de atender a um mercado menos convencional de jogadores [5]. Pode ser encontrado no mercado brasileiro a partir de $\mathrm{R} \$ 300,00[6]$.

\section{Hardware}

O Kinect e um aparelho consideravelmente pequeno (Figura 1), composto por:

Uma câmera RGB (Red,Green,Blue): esta e uma câmera comum, semelhante a uma webcam usada para reconhecimento facial e construção do ambiente visualizado pelo periférico.

Um emissor e um receptor infravermelho: o emissor cobre um espaço à frente, entre 800 
$\mathrm{mm}$ e $4000 \mathrm{~mm}$ [7], os quais utilizam o método óptico, para obter um ambiente tridimensional.

Um motor de inclinação: capaz de girar o aparelho para adaptar-se a altura entre ele e os usuários. Tendo função de ajuste apenas.

Um conjunto de microfones: com um grupo de microfones que capta sons de diversas direções, calcula a posição da origem, reduz ruídos, e reconhece a voz de diversos jogadores simultaneamente [8].

Led: um emissor de luz com cor variável para exibir o status do Kinect,

Microchip de sistema: responsável pela sincronia dos demais hardwares e contem dados de reconhecimento do corpo humanoide.

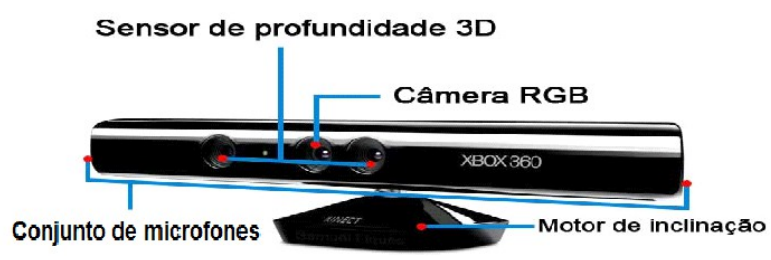

Figura 1 Sensor Kinect e seu hardware [9]

\section{Software}

O software do Kinect foi desenvolvido pela Microsoft [10] e é essencial para o hardware. Ao ativa-lo pela primeira vez, ele lê condições do ambiente e configura o espaço viável para captura de dados de imagem e mapeamento tridimensional. O aparelho é capaz de rastrear o corpo (Figura 2), de cada usuário, mapeia-os em reprodução digital em forma de estrutura de esqueleto, ainda analisa detalhes faciais.

A análise e o processamento de inúmeras capturas de humanos foram capazes de garantir a maquina um algoritmo de reconhecimento. Ele foi produzido para trabalhar com pessoas em aparências muito distintas, em idade, altura, peso, roupas, de forma que reduzisse assim a chance de alguém não ser reconhecido como humano [11]. 


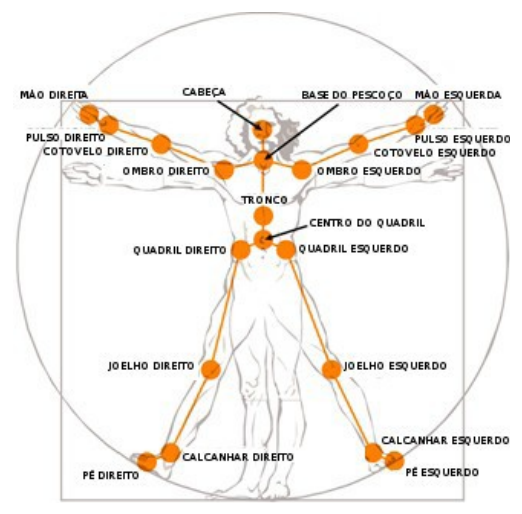

Figura 2 Juntas Conhecidas pelo Kinect [12].

Detém software aberto e disponibilizado pela própria Microsoft, entre outras SDK`s que foram produzidas paralelamente, com licença livre e versões para Linux e Mac. Este fator possibilita o uso acadêmico e recreativo por desenvolvedores de software, para diversas aplicações.

\section{Metodologia}

Este trabalho desenvolve um método de captura e processamento de imagens para capturar dados da movimentação do corpo humano. Para tal fim, desenvolve-se um software para captura de dados com o uso do Kinect; realizaram-se testes e o desenvolvimento de um segundo software para leitura, análise e representação dos dados obtidos. Ambos os programas foram desenvolvidos na linguagem de programação $\mathrm{C}++$.

\section{Captura}

A captura de dados via Kinect é feita em um computador com bibliotecas do OpenNI e funções do middleware NITE. Por meio de um software desenvolvido na SDK Microsoft Visual Studio $C++2010$ Express capaz de receber informações do hardware e transcrevê-las de forma numérica em um arquivo que armazena as informações coletadas. O software funciona da seguinte forma:

I. Recebe um numero de quadros a serem capturados.

II. Conecta o hardware e software, preparando o Kinect para trabalhar em conjunto com o 
computador.

III. Define os parâmetros de captura e rastreamento, como modo de definição do "esqueleto".

IV. Preparado o ambiente de captura, acessa-se o arquivo de texto que receberá os dados capturados.

V. Arquivo, software e hardware prontos, inicia-se a busca por formas humanas.

VI. Após reconhecer um humano, inicia-se a etapa de calibração, na qual se identifica pontos chave do corpo.

VII. Após a calibração do usuário, inicia-se o ciclo de captura para todo o corpo.

\section{Testes}

Para testar a funcionalidade do sistema desenvolvido, foram feitos diversos testes sendo a maioria deles com movimentações aleatórias feitas durante a programação, apenas para testar a captura e a compilação do programa.

Os testes principais são feito no Laboratório de Analise da Movimentação Humana no departamento de Fisioterapia da UFRN, sob a supervisão da fisioterapeuta Dra Luciana de Andrade Mendes, aferindo o caminhar de um voluntario (Figura 3).

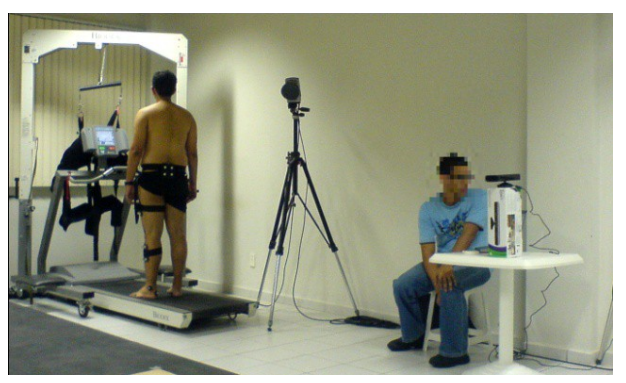

Figura 3 Teste em Esteira com voluntario no laboratório de analise da movimentação humana

O sistema proposto precisou de cerca de 30 segundo para calibração e não utiliza marcadores presos ao corpo. O software operou a captura por 60 segundos.

\section{Interface Gráfica}

Desenvolve-se uma interface com a SDK da Nokia, QtCreator, seu desenvolvimento buscou a simplicidade de uso e o rápido acesso as funções disponíveis, com uma aparência 
amigável e fácil instalação. É voltada para uso no sistema operacional Windows 7.

\section{Leitura e analise dos dados}

Um segundo software foi desenvolvido para leitura do arquivo gerado pelo primeiro e uso destes dados. Neste software foi implementada uma interface gráfica para uso mais intuitivo, que acessa os arquivos gerados pelo primeiro e dos dados contidos.

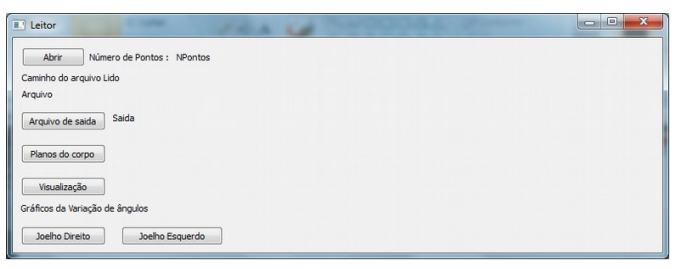

Figura 4 Interface Gráfica inicial do programa proposto

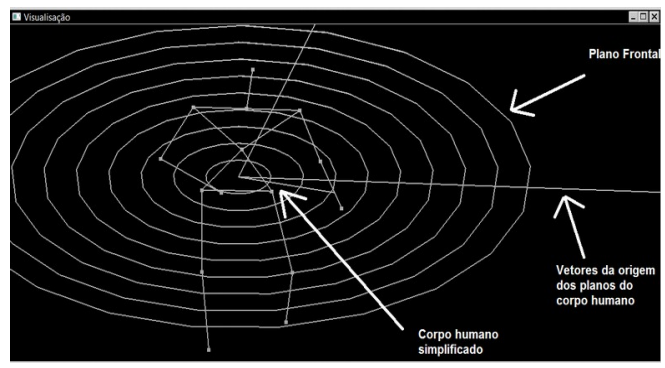

Figura 5 Visualização da movimentação capturada pelo Kinect e gerada pelo programa proposto

\section{Agradecimentos}

Agradeço aos professores, especialmente Márcio Valério pelo convite e Carlos Magno por ter me concedido o embasamento para realizar este trabalho: ao Laboratório de Análise da Marcha Humana na UFRN; ao Hospital Universitário Onofre Lopes(HUOL) pelo espaço e aos integrantes do Laboratório de Inovação Tecnológica em Saúde(LAIS) e do antigo Laboratório de Acessibilidade Integrada(LAI) pelo apoio e companheirismo.

7

\section{Referências}

[1]IBGE (2010) " SALA DE IMPRENSA :: CENSO DEMOGRÁFICO: RESULTADOS PRELIMINARES DA AMOSTRA" IN: "IBGE :: INSTITUTO BRASILEIRO DE GEOGRAFIA E ESTATÍSTICA,” 2010. DISPONÍVEL EM: 
HTTP://WWW.IBGE.GOV.BR/HOME/

PRESIDENCA/NOTICIAS/NOTICIA_VISUALIZA.PHP?

ID_NOTICIA=2018\&ID_PAGINA=1. ACESSO EM: 29 MAI. [2] Greve, J. (2001)

Diagnóstico e tratamento da lesão da medula espinal, 1a ed. São Paulo SP: Roca,.

[3] Hocoma, "Patient Stories," In: Hocoma We move you, 2007. Disponível em: http://www.hocoma. com/en/patients/lokomat-therapie/patient-stories/. Acesso: 21 jun. 2011].

[4] Gomide, J. V. B, Flam,. D. L., de Queiroz, D. P., Araújo , A. de A., (2011) "Captura de Movimentos e Animação de Personagens em Jogos," Belo Horizonte - MG.

[5]Prada, R. , (2010) “Kinect: o Projeto Natal finalmente ganha vida!," In: Tecmundo. Disponível em: http://www.tecmundo.com.br/4413-kinect-o-projeto-natal-finalmente-ganhavida-.htm. Acesso: 06 dec. 2011].

[6] Ebit, (2011) "Controle para Videogame," Shopping Ebit, 2011.. Disponível em: http://shopping.ebit. com.br/prod_unico?id=10117\&idu=302749\&pos=1. Acesso: 07 dec. 2011.

[7]Microsoft, R. D. S.(2011) “Kinect Sensor," In: Kinect Sensor. Disponível em: http://msdn. microsoft.com/en-us/library/hh438998.aspx. Acesso: 06 dec. 2011.

[8]McCowan, I.(2010) "Microphone Arrays," In: Microphone Arrays. Disponível em: http://www. idiap.ch/ mccowan/arrays/arrays.html. Acesso: 06 dec. 2011.

[9] Youbot, S. (2011) “KUKA youBot Store,” In: Youbot store. Disponível em: http://youbotstore.com/drivers/7/software.aspx. Acesso: 06 dec. 2011.

[10] Schramm, M., (2010) "Kinect: The company behind the tech explains how it works | Joystiq," Joystiq. Disponível em: http://www.joystiq. com/2010/06/19/kinect-how-it-worksfrom-the-company-behind-the-tech/. [Acesso: 06 dec. 2011].

[11] Kuchinska, S.,(2010) "Scientific American," In: Microsoft's Hands-Free Answer to the Nintendo Wii Good-bye, controller: an Xbox upgrade reads natural gestures.

[12] RAITEN, S. (2011) "KINECT - GETTING STARTED - BECOME THE INCREDIBLE HULK - SHAI RAITEN,”. DISPONÍVEL EM: HTTP://BLOGS.MICROSOFT.CO.IL /BLOGS/SHAIR/ARCHIVE/2011/06/17/KINECTGETTING-STARTED-BECOME-THE-INCREDIBLE-HULK.ASPX. ACESSO: 08 DEC. 2011. 
ANEXO B ARTIGO PUBLICADO NO CONEM 2012

\title{
DESENVOLVIMENTO DE UM SISTEMA DE CAPTURA MOVIMENTOS DE BAIXO CUSTO DESTINADO A PROJETOS DE EQUIPAMENTOS DE AUXILIO A LOCOMOÇÃO
}

\begin{abstract}
Elton Gil Xavier Moura, eltongxm@hotmail.com ${ }^{1}$
Danilo Alves Pinto Nagem, nagem@ufrnet.br ${ }^{2}$

'Universidade Federal do Rio Grande do Norte, Rua Francisco Ferreira Neves, 1023, Bairro Monte Castelo, 59146-180, Parnamirim-RN

${ }^{2}$ Universidade Federal do Rio Grande do Norte, Centro de Tecnologia, Departamento de Engenharia Biomédica,.Campus Universitário, Lagoa Nova, 59072-970, Natal-RN

Resumo: A incapacidade de caminhar é motivo de diversos prejuizos para a vida de um humano, sua capacidade locomotora é comprometida, seu organismo não funciona como deveria e é bastante prejudicial à autoestima do deficiente. Este trabalho buscar desenvolver um software para uso do Microsoft Kinect com o uso da API OpenNI, capaz promover um sistema de captura de movimentos e determinação dos parâmetros da caminhada para apoiar projetos de equipamentos de auxilio a locomoção. Sendo assim a etapa inicial do desenvolvimento de um equipamento para que um indivíduo com locomoção comprometida usufrua dos beneficios da caminhada, ganhar mais independência e autoestima e integrar-se à sociedade
\end{abstract}

Palavras-chave: Kinect, Rehabilitação,Marcha, Captura de Movimentos

\section{INTRODUÇÃO}

Dados do CENSO 2000 reportam que havia 7,9 milhões de pessoas com dificuldade de locomoção no Brasil (IBGE, 2000), representando 4,67\% da população brasileira, a OMS estima que em media $2 \%$ da população dos países que não estão em guerra possua alguma deficiência motora (OMS, 1997). Estes dados não foram atualizados em 2010, mas acredita-se que este valor absoluto tenha aumentado. Esta ausência de locomoção na forma natural implica diversas complicações sociais, fisiológicas e psicológicas (GREVE, 2001).

Equipamentos como muletas, cadeiras de rodas, órteses e próteses são utilizados para aumentar a mobilidade, estes equipamentos são em maioria muito caros, aqueles que permitem uma mobilidade mais próxima de uma pessoa sem dificuldades locomotivas são as órteses e próteses que são sempre muito caras. Para desenvolver estes equipamentos se fazem necessários estudos minuciosos da movimentação humana. Para fazê- 
lo de forma barata e prática existe a necessidade de um equipamento pequeno, móbil e barato para captura e medição de parâmetros relacionados à movimentação humana.

Dispositivos como estes causam grandes benefícios aos usuários, físicos e emocionais, como sentir que pode caminhar novamente. Existem, também, benefícios profissionais e sociais, como para atletas com próteses e a perda da limitação imposta pelas cadeiras de rodas. No uso fisioterapêutico, com máquinas que ajudam aos paraplégicos a simular uma caminhada, tem impactos fisiológicos como melhor circulação, a prevenção de escaras e do atrofiamento da musculatura (HOCOMA, [S.d.]).

Uma órtese ativa, também chamada de exoesqueleto de reabilitação (EKSO BIONICS, 2011), alia o ganho de mobilidade ao tratamento fisioterapêutico, dando mais independência e saúde ao usuário. Para desenvolver um dispositivo como este é necessário profundo conhecimento da marcha humana, projetos mecânicos, programação de sistemas embarcados e aspectos econômicos envolvidos.

Para capturar movimentos humanos existem alguns métodos disponíveis, desenvolvidos principalmente para animação de personagem computadorizados para cinema, televisão e jogos. Para transformar os movimentos em dados digitais utilizam-se sistemas de sensores, entre eles estão: os sistemas mecânicos tratam-se de conjuntos de sensores aplicados às vestimentas; sistemas magnéticos que utilizam emissores eletromagnéticos em um campo elétrico para medir sua posição; assim como sistemas ópticos, que prendem marcadores reflexivos na pessoa medida e capturam a posição deles com diversas câmeras devidamente calibradas para determinar a posição deles.

Os equipamentos encontrados no mercado atualmente são muito caros impossibilitando seu uso terapêutico em pequenas clínicas que necessitem deste tipo de sistema, exigem minuciosas calibrações e o uso de marcadores que requerem treinamento prévio para uso devido, além de serem grandes e dificilmente reposicionados (GOMIDE et al., 2011).

A captura de movimentos é importante para o diagnóstico de doenças relacionadas à má coordenação da movimentação, sendo assim capaz de comparar numericamente padrões de movimento entre paciente e modelo. No entanto o deslocamento dos pacientes para uma clínica com porte o suficiente para possuir um destes equipamentos pode ser custoso e complicado dependendo das condições do paciente. Para evitar estes transtornos, se faz necessário um sistema portátil e barato de medição de movimentos.

\section{CARACTERÍSTICAS DO EQUIPAMENTO}

\subsection{Processamento tridimensional}

É possível se obter um mapeamento de um espaço tridimensional por meio de processamento de imagens bidimensionais, como é feito pelo método de padrões de projeção (FREEDMAN et al., 2010). Este método utiliza um projetor de luz e uma câmera para captar a imagem projetada em um espaço (Figura 48).

A imagem projetada será deformada devido ao volume dos objetos no espaço medido, essa deformação tem um comportamento dependente apenas da projeção e do formato da região na qual ela é projetada. Tendo a projeção conhecida, pois ela é definida pelo emissor, pode-se utilizar a diferença entre a projeção esperada e a 
medida.

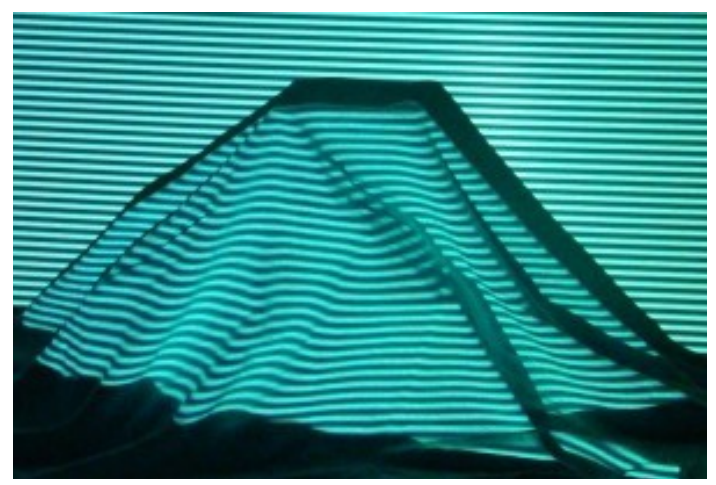

Figura 48 Deformação da imagem projetada. Fonte : adaptada de QUEIROZ, 2010.

O padrão utilizado pode variar, é usual se encontrar listras, pontos (Figura 49), círculos, elipses, quadrados, entre outros, mas é crucial que o algoritmo esteja preparado para trabalhar com o padrão usado. Assim, câmera, projetor e algoritmo devem trabalhar em conjunto (SPEKTOR et al., 2010).

Com o padrão conhecido, sabe-se onde cada ponto da projeção deveria estar e uma câmera, devidamente posicionada em relação ao projetor, pode "enxergar" toda a projeção. A mudança de distâncias entre os elementos do padrão e a deformação deles serve como indicador de superfícies inclinadas em relação ao projetor, assim como a variação de tamanho deles indica distâncias. Pois, quanto mais longe está a superfície projetada e o projetor, maior o elemento do padrão (HALLIDAY et al., 2009). Este método mede o quanto os pixeis ocupados pelo elemento do padrão varia em relação ao esperado de seu formato.

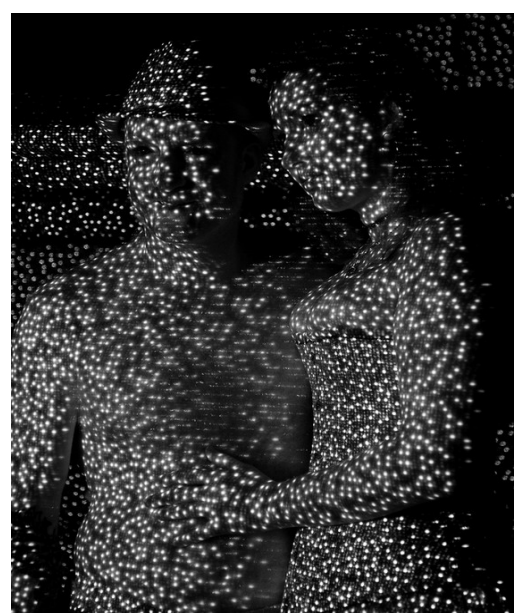

Figura 49 Amostra do mapeamento de um casal utilizando um padrão de círculos. Fonte: adaptado de LEAF, 2010.

\subsection{Kinect}


O Kinect, inicialmente chamado de "project Natal", trata-se de um sensor óptico de movimento. Produzido pela Microsoft em parceira com a Prime Sense como acessório do vídeo game Xbox 360, para jogos sem o convencional controle. Com ele é possível utilizar gestos e voz como comandos, com o objetivo de atender a um mercado menos convencional de jogadores (PRADA, 2010). Pode ser encontrado no mercado brasileiro a partir de $\mathrm{R} \$ 300,00$ (EBIT, 2011).

\subsubsection{Hardware}

O Kinect é um aparelho consideravelmente pequeno (Figura 50), com as dimensões de $7 \mathrm{~cm}$ de altura, $7 \mathrm{~cm}$ de espessura e $27 \mathrm{~cm}$ de largura, com a forma de uma barra horizontal presa a uma base (ACTION GAMES, 2011), e composto por:

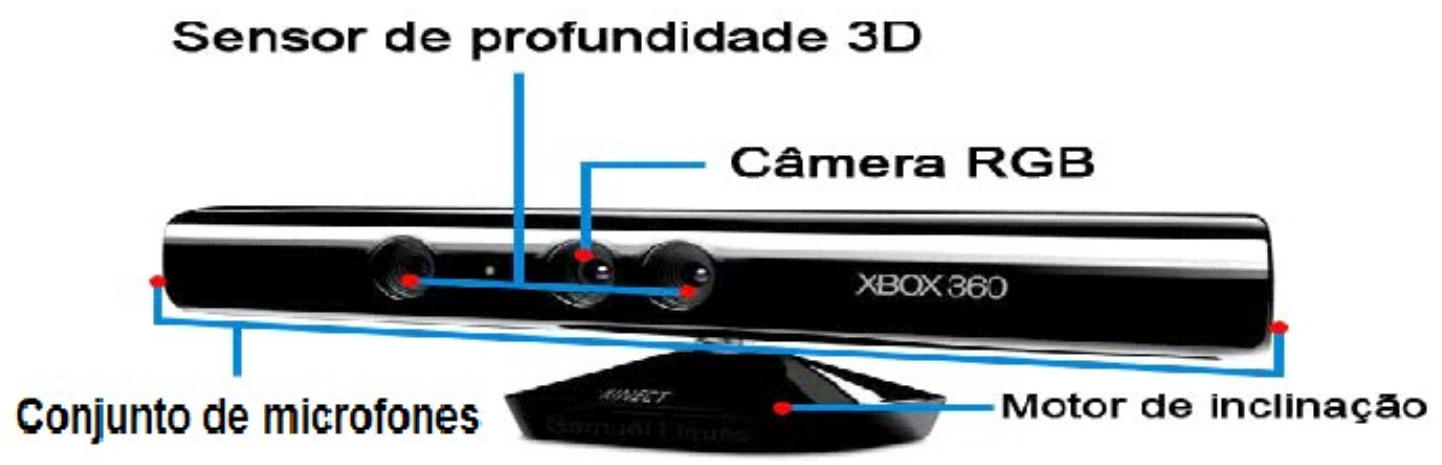

Figura 50 Sensor Kinect e seu hardware. Fonte: adaptado de YOUBOT, 2011.

- Uma câmera RGB(Red,Green,Blue)

Esta é uma câmera comum, semelhante a uma webcam. Capaz de captar 30 fps(imagens por segundo). É Utilizada para reconhecimento facial e construção do ambiente visualizado pelo periférico.

- Um emissor e um receptor infravermelho

O emissor cobre um espaço à frente, entre $800 \mathrm{~mm}$ e $4000 \mathrm{~mm}$ (MICROSOFT, 2011), os quais utilizam o método das projeções padronizadas, como o padrão de círculos, para obter um ambiente tridimensional, utilizase infravermelho por ser captado por uma câmera simples, é invisível a olho nu e é uma onda eletromagnética pouco energética, poupando energia.

- Um motor de inclinação

Capaz de girar o aparelho para adaptar-se a altura entre ele e os usuários. Tendo função de ajuste apenas.

- Um conjunto de microfones

Com um grupo de microfones é possível captar sons de diversas direções, calcular a posição da origem, uma melhor limpeza de ruídos, para reconhecimento de voz de diversos jogadores simultaneamente (MCCOWAN, 2010).

- Led 
Um emissor de luz com cor variável para exibir o status do Kinect, posicionado entre o emissor infravermelho e a câmera RGB, pisca em verde para demonstrar estar conectado à energia, mantém-se verde para demonstrar estar pronto para uso e pisca em laranja para demonstrar algum problema no hardware.

- Microchip de sistema

Responsável pela sincronia dos demais hardwares e contém dados de reconhecimento do corpo humanoide.

\subsubsection{Software}

O software do Kinect foi desenvolvido pela Microsoft (SCHRAMM, 2010), ele é essencial para dar significado ao que o hardware detecta. Ao ativá-lo pela primeira vez, ele lê condições do ambiente e configura o espaço viável para captura de dados de imagem e mapeamento tridimensional. O aparelho é capaz de detectar e rastrear 48 pontos do corpo (Figura 51), de cada usuário, mapeia-os em reprodução digital em forma de estrutura de esqueleto, ainda analisa detalhes faciais.

Para o Kinect, cada movimento do usuário é uma entrada de dados, o que permite uma combinação, virtualmente infinita, de comandos. No entanto, o software define certos gestos para utilizar como entrada válida, ainda é capaz de calibrar-se ao usuário, adaptando o sistema a quem o utiliza. Para tanto, o desenvolvimento deste reconhecedor de gestos contou com a captura de gestos feitos por um grande número de pessoas. A análise e o processamento destes dados foram capazes de garantir à máquina um algoritmo de aprendizado. Ele foi produzido para trabalhar com pessoas em aparências muito distintas, em idade, altura, peso, roupas, de forma que reduzisse assim a chance de alguém não ser reconhecido como humano (KUCHINSKA, 2010).

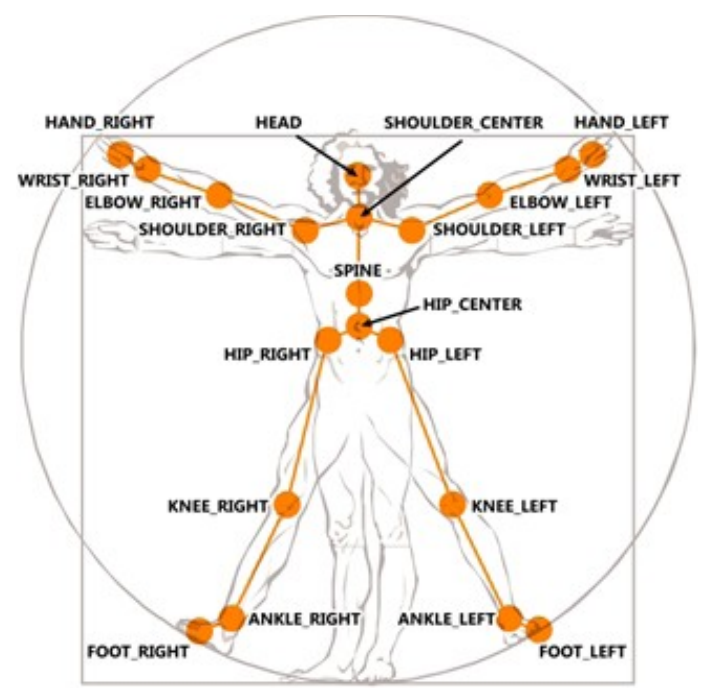

Figura 51 Juntas Conhecidas pelo Kinect. Fonte: adaptada de RAITEN, 2011

Por ter um vasto campo de reconhecimento do corpo humano, o equipamento é capaz de calcular a posição de algum membro mesmo sem poder captá-lo, o faz a partir dos demais pontos detectados, extrapolando pontos com base na forma esperada de um corpo humano. Além do reconhecimento do corpo e suas juntas de interesse para detectar movimentos, o Kinect é equipado com softwares de reconhecimento facial e de voz, com uso em 
entretenimento.

Além de tudo isso, seu software é aberto e disponibilizado pela própria Microsoft (KINECT, 2011), ainda outras SDK`s foram produzidas em paralelamente, com licença livre e versões para Linux e Mac. Este fator possibilita o uso acadêmico e recreativo por desenvolvedores de software, para diversas aplicações.

\section{METODOLOGIA}

Este trabalho desenvolveu um método de captura e processamento de imagens para capturar dados da movimentação do corpo humano, para tal fim desenvolve-se um software para captura de dados com o uso do Kinect, realizou-se um teste piloto e o desenvolvimento de um segundo software para leitura, análise e representação dos dados obtidos. Ambos os programas foram desenvolvidos na linguagem de programação $\mathrm{C}++$.

\subsection{Captura}

A captura de dados via Kinect é feita em um computador devidamente preparado para o uso do dele (Anexo C), o uso das bibliotecas do OpenNI e funções do middleware NITE. Por meio dessas ferramentas desenvolveuse um software na SDK Microsoft Visual Studio C++ 2010 Express capaz de receber informações do hardware e transcrevê-las de forma numérica em um arquivo que armazena as informações coletáveis pela execução deste programa. O software funciona da seguinte forma:

I. Recebe do operador um número de pontos por juntas a serem captados, os quais são medidos por um intervalo de tempo definido no algoritmo (100 milissegundos) por meio da função Sleep() da biblioteca "windows.h", a qual é inerente ao sistema operacional.

II. Em seguida ele faz a conexão entre hardware e software, ambientando o Kinect para trabalhar em conjunto com o computador. Uma mensagem é exibida logo em seguida indicando o sucesso ou falha desta conexão.

III. Após isso ele define as mensagens de interface e estabelece os parâmetros de captura e rastreamento, como modo de definição do "esqueleto", pose de calibração e busca de usuários. Assim como no item anterior, este exibe uma mensagem quanto a seu sucesso ou falha.

IV. Estando pronto o ambiente de captura, este programa acessa o arquivo de texto definido para receber os dados capturados, o abre e habilita sua edição.

V. Arquivo, software e hardware prontos, é iniciado um loop no qual a cada ciclo buscam-se formas humanas, define-se quantas podem ser captadas e aguarda que o usuário seja reconhecido.

VI. Após reconhecer o usuário como um humano, inicia-se a etapa de calibração, na qual se identifica o "esqueleto" do usuário. Para efetuar a calibração o usuário deve permanecer à frete e entre $4 \mathrm{~m}$ e $0,8 \mathrm{~m}$ do hardware, assumindo a posição chamada "Psi" pela biblioteca usada, por lembrar a letra grega homônima ( $\Psi)$ (Figura 52).

VII. Após a calibração do usuário o loop prossegue capturando as posições das juntas definidas, a cada captura ele aguarda o intervalo de tempo definido e reinicia a leitura. Permanece neste ciclo até capturar o 
número de pontos definidos inicialmente, para cada junta.

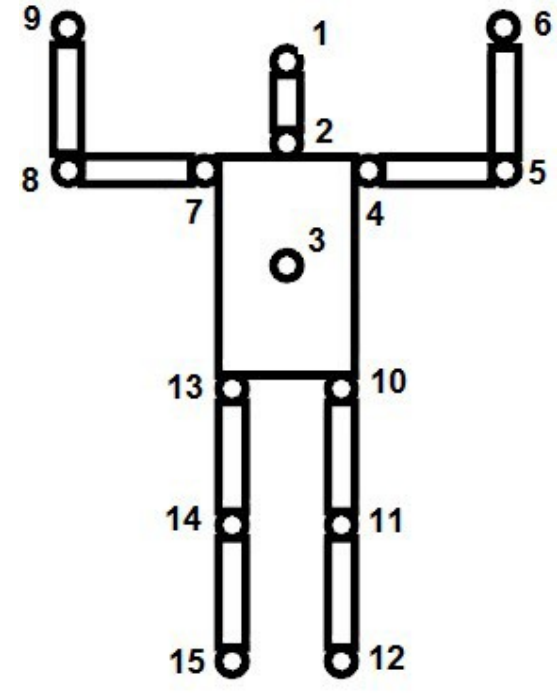

Figura 52 Pose de calibração"Psi”" simplificada com indicações das juntas capturadas, Fonte: adaptada de TIMMI et al., 2011

\subsection{Testes}

Para testar a funcionalidade do sistema desenvolvido, foram feitos diversos testes, a maioria deles com movimentações aleatórias feitas durante a programação, apenas para testar a captura e a compilação do programa.

O teste principal foi feito no Laboratório de Análise da Movimentação Humana no departamento de Fisioterapia da UFRN, sob a supervisão da fisioterapeuta $\operatorname{Dr}^{\mathrm{a}}$ Luciana de Andrade Mendes, aferindo o caminhar de um voluntário (Figura 53). Para critério de comparação, seu caminhar também foi aferido por um sistema de captura de movimento tradicional, baseado na visualização de marcadores afixados ao corpo do voluntário e o uso de 8 câmeras com captura de 60 quadros por segundo. 


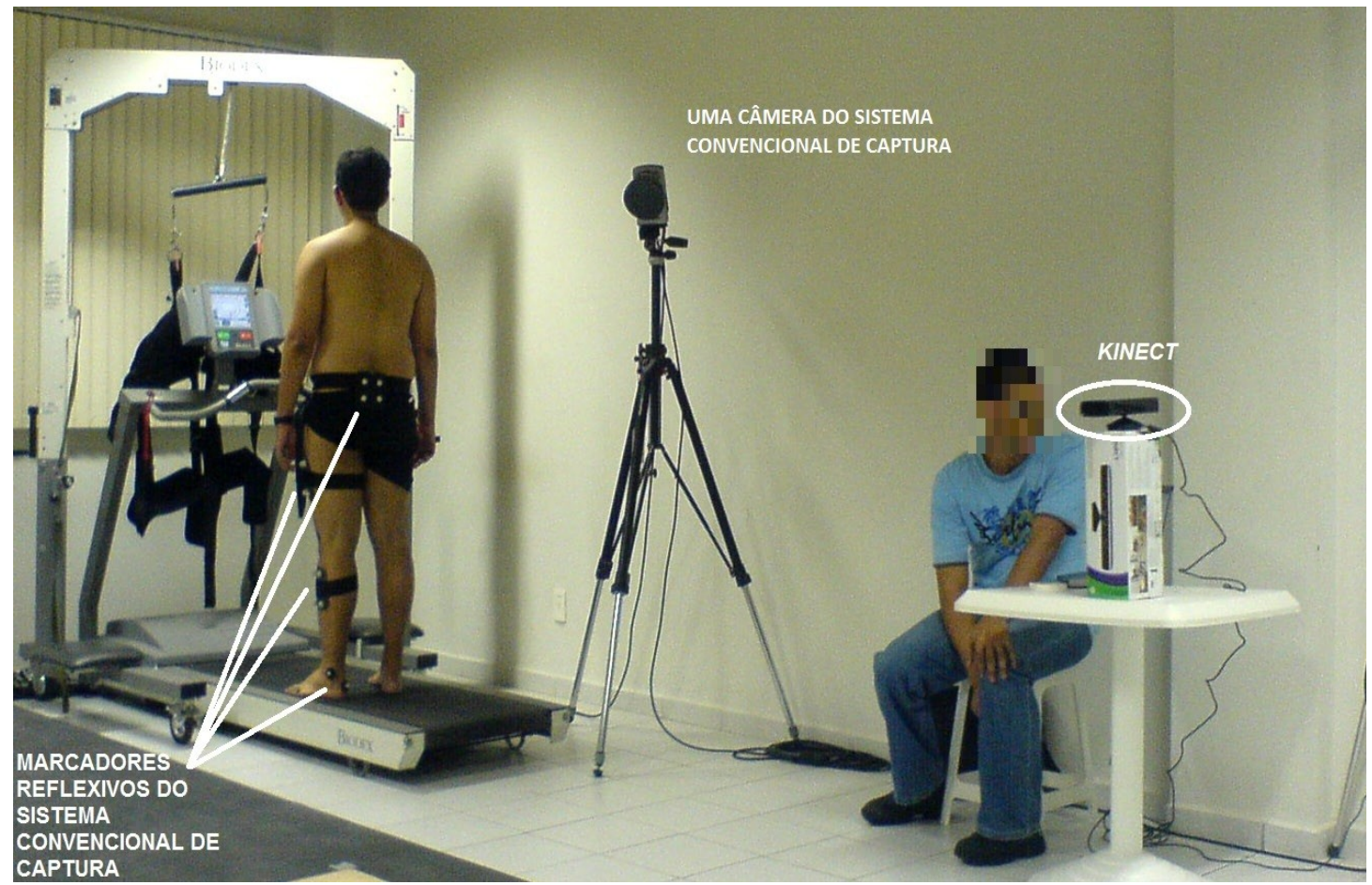

Figura 53 Teste em Esteira com voluntário no laboratório de análise da movimentação humana

A medição tradicional exigiu a fixação de marcadores passivos em pontos específicos do corpo do voluntário, calibração do equipamento e a minimização de roupas nele, para evitar encobrimento dos marcadores e erros de captura de dados, por parte das máquinas, sobre a posição dos membros dele. Este processo levou cerca de 20 minutos antes de iniciar a medição, enquanto o sistema proposto precisou de cerca de 30 segundo para calibração e não utiliza marcadores presos ao corpo. O software operou a captura por 60 segundos.

\subsection{Interface Gráfica}

Foi desenvolvida uma interface gráfica que buscou ser amigável e intuitiva, para fácil utilização do programa. Para tal, utilizou-se da ferramenta da Nokia, QtCreator que é uma SDK para produção rápida de softwares com interface gráfica convencional, sua plataforma de construção de interface usada é chamada de QtDesigner. Sua produção buscou a simplicidade de uso e o rápido acesso às funções disponíveis, com uma aparência semelhante a programas usuais e é facilmente instalada em diferentes computadores. É voltada para uso no sistema operacional Windows 7.

\subsection{Leitura e análise dos dados}

Um segundo software foi desenvolvido para leitura do arquivo gerado pelo primeiro e uso destes dados. Neste software foi implementada uma interface gráfica para uso mais intuitivo. Este acessa os arquivos gerados pelo primeiro e dos dados contidos nele pode executar as seguintes funções: 
I. Gerar um arquivo de vetores, para acessar o arquivo a ser escrito, ele abre uma tela padrão para abrir e buscar arquivos, na qual o arquivo destino deve ser escolhido. Após isto, ele utiliza os pontos que representam as posições das juntas provenientes do arquivo lido inicialmente e executa os cálculos vetoriais para velocidade e aceleração, na forma cartesiana e no sistema de coordenadas padrão do OpenNI, para cada momento registrado, ao passo que registra essas informações em um arquivo de texto, para futuro uso.

II. Gerar um arquivo com os planos do corpo humano (Sagital, Frontal e Transverso), utiliza os pontos do quadril e tronco para calculá-los, gera um arquivo com três planos por momento registrado e os define com um ponto (Aproximadamente o centro de gravidade) e um vetor normal a ele.

III. Visualização tridimensional do arquivo registrado que utiliza a classe do QtCreator, QGLWidget, que é uma adaptação da biblioteca gráfica da Linguagem $\mathrm{C}$, o Open $G L$, gerando um janela de exibição na qual há uma representação simplificada do corpo humano, os eixos do sistema de coordenadas do corpo humano e o plano frontal aplicado sobre a representação do humano.

IV. Gerar um gráfico com a variação de ângulo do joelho, considerando um plano formado pelos pé, joelho e quadril de cada perna.

\section{RESULTADOS E CONCLUSÕES}

Este trabalho desenvolveu um sistema de captura de imagens bastante compacto, detentor de fácil mobilidade de manipulação, de simples uso e baixo custo, capaz de mapear a posição de diversas juntas do corpo humano ao longo do tempo, assim permite um armazenamento destes dados para análise de movimento.

Também gerou um programa para leitura dos dados capturados pelo primeiro software, possuidor de uma interface gráfica amigável (Ilustração 37) capaz de utilizar estes dados para análises matemáticas e gerar visualizações (Ilustração 38) para análise visual de movimentos.

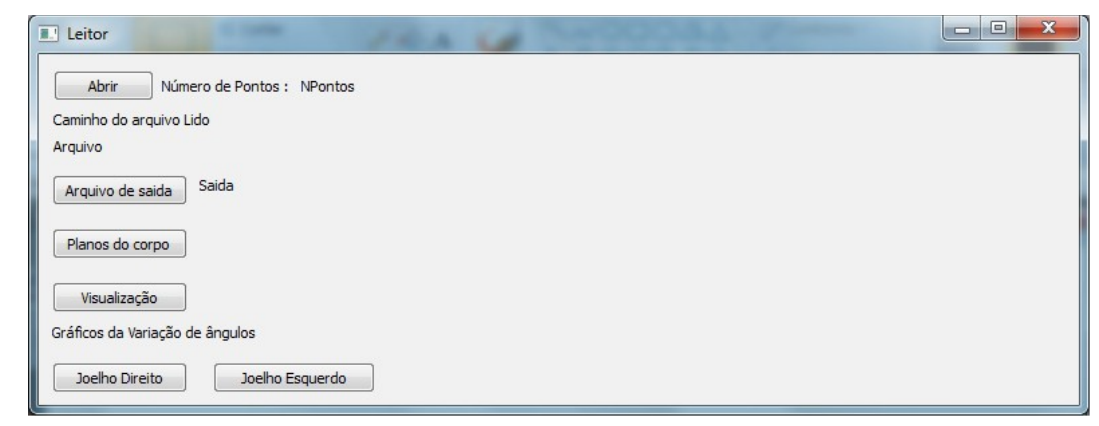

Figura 54 Interface Gráfica inicial do programa proposto 


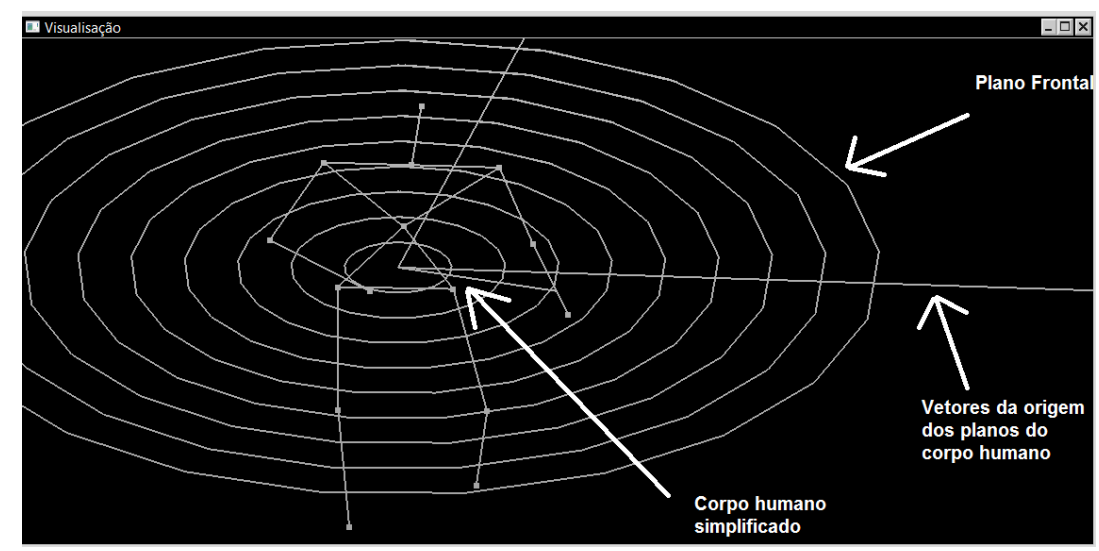

Figura 55 Visualização gerada pelo programa proposto

Este trabalho trouxe a possibilidade de um sistema de captura de movimentos, cujo uso é bastante simples e intuitivo, inicia medições rapidamente e não utiliza acessórios presos ao corpo da pessoa medida, por utilizar um hardware preparado para reconhecer o corpo humano.

Obtenção de dados bastante rápida com software de pouca exigência computacional, análise instantânea dos dados e visualização clara do que foi medido. É tão simples de transportar que pode ser carregado em uma mochila comum, com o laptop para acessar o software. Manuseio bastante simples por seu tamanho e massa.

Tudo isso com preço bastante acessível e muito inferior aos sistemas conhecidos no mercado. É uma excelente opção para sistemas de análise de caminhada e quantificação de parâmetros de marcha, tanto para diagnóstico clínico quanto para obter suas informações biomecânicas, as quais são cruciais para o projeto de equipamentos de auxílio à locomoção.

\section{AGRADECIMENTOS}

Agradeço aos professores, especialmente Márcio Valério pelo convite e Carlos Magno por ter me concedido o embasamento para realizar este trabalho, a $\mathrm{Dr}^{\mathrm{a}}$ Luciana pela ajuda com dados clínicos e o uso do laboratório de análise da marcha humana na UFRN, ao HUOL pelo espaço e aos integrantes do LAIS e do antigo LAI pelo apoio e companheirismo.

\section{REFERÊNCIAS}

\section{ACTION GAMES. Xbox 3604 GB Slim + Kinect | XBOX 360 | Console | ActionGame.com.br - Games}

e Informática em Geral. Comercial. Disponível em: $<$ http://www.actiongame.com.br/produtos_descricao.asp? lang=pt_BR\&codigo_produto=3362>. Acesso em: 6 dez. 2011.

EBIT. Controle para Videogame. Busca Comercial. Disponível em: $<$ http://shopping.ebit.com.br/prod_unico?id=10117\&idu=302749\&pos=1>. Acesso em: 7 dez. 2011.

EKSO BIONICS. About eLEGS | Berkeley Bionics. Comércial. Disponível em: 
$<$ http://www.eksobionics.com/blog/?tag=elegs $>$. Acesso em: 13 jun. 2011.

FREEDMAN, B.; SHPUNT, A.; MACHLINE, M.; ARIELI, Y. DEPTH MAPPING USING PROJECTED

PATTERNS. . [S.1: s.n.]. Disponível em: <http://www.faqs.org/patents/app/20100118123>. Acesso em: 6 dez. 2011. , 13 maio 2010

GOMIDE, J. V. B.; FLAM, D. L.; QUEIROZ, D. P. DE; ARAÚJO, A. DE A. Captura de Movimentos e Animação de Personagens em Jogos. . Belo Horizonte - MG: [s.n.]. Disponível em: $<$ http://laplace.dcc.ufmg.br/npdi/uploads/bd254485-3879-77ef.pdf>. Acesso em: 17 jan. 2012. , 2011

GREVE, J. Diagnóstico e tratamento da lesão da medula espinal. 1. ed. São Paulo SP: Roca, 2001.

HALLIDAY, D.; RESNICK, R.; WALKER, J. Fundamentos de Física. 8. ed. [S.1.]: LTC, 2009. v. 4

HOCOMA. Patient Stories. Comercial. Disponível em: $<$ http://www.hocoma.com/en/patients/lokomattherapie/patient-stories/>. Acesso em: 21 jun. 2011.

IBGE. Tabela Selecionada - Deficiência., Tabelas Seleciondas. Brasil: Instituto Brasileiro de Geografia e Estatística. Disponível em:

$<$ http://www.ibge.gov.br/home/estatistica/populacao/censo2000/populacao/deficiencia_Censo2000.pdf $>$. Acesso em: 14 jun. 2011. , 2000

KINECT, F. W. Microsoft Kinect SDK for Developers | Develop for the Kinect | Kinect for Windows. Desenvolvimento. Disponível em: <http://kinectforwindows.org/>. Acesso em: 7 dez. 2011.

KUCHINSKA, S. Scientific American. Microsoft's Hands-Free Answer to the Nintendo Wii Good-bye, controller: an Xbox upgrade reads natural gestures, 2 fev 2010.

LEAF, T. F. Small ideas for a big world: Kinect How they guess the depth : IR projection. Blog. Disponível em: $<$ http://smallideasforabigworld.blogspot.com/2010/11/kinect-ir-projection.html $>$. Acesso em: 7 dez. 2011.

MCCOWAN, I. Microphone Arrays. Acadêmico. Disponível em:

$<$ http://www.idiap.ch/ mccowan/arrays/arrays.html>. Acesso em: 6 dez. 2011.

MICROSOFT, R. D. S. Kinect Sensor. Disponível em: $<$ http://msdn.microsoft.com/enus/library/hh438998.aspx>. Acesso em: 6 dez. 2011.

OMS, O. M. DA S. Classificación internacional de las deficiencias actividades e participación: um manual de las dimensiones de la inhabilitacion de su funcionamento. . [S.l: s.n.]. , 1997

PRADA, R. Kinect: o Projeto Natal finalmente ganha vida! Jornalistíco. Disponível em: $<$ http://www.tecmundo.com.br/4413-kinect-o-projeto-natal-finalmente-ganha-vida-.htm>. Acesso em: $6 \mathrm{dez}$. 2011.

QUEIROZ, M. Tecnologia. Inteligente.» Blog Archive» Um cientista explica o Microsoft Kinect, Parte II. Blog. Disponível em: <http://blog.vettalabs.com/2010/11/02/um-cientista-explica-o-microsoft-kinect-parteii/>. Acesso em: 7 dez. 2011.

RAITEN, S. Kinect - Getting Started - Become The Incredible Hulk - Shai Raiten. Blog. Disponível em: $<$ http://blogs.microsoft.co.il/blogs/shair/archive/2011/06/17/kinect-getting-started-become-the-incrediblehulk.aspx>. Acesso em: 8 dez. 2011.

SCHRAMM, M. Kinect: The company behind the tech explains how it works | Joystiq. Disponível em: $<$ http://www.joystiq.com/2010/06/19/kinect-how-it-works-from-the-company-behind-the-tech/>. Acesso em: 6 
dez. 2011.

SPEKTOR, E.; MOR, Z.; RAIS, D. INTEGRATED PROCESSOR FOR 3D MAPPING. . [S.l: s.n.]. Disponível em: <http://www.faqs.org/patents/app/20100007717>. Acesso em: 6 dez. 2011. , 14 jan 2010

TIMMI, A.; PENNESTRÌ, E.; VALENTINI, P. P. et al. Virtual Sensei Lite ${ }^{\mathrm{TM}}$ Guide. Disponível em: $<$ http://www.virtualsensei.it/lite/help/>. Acesso em: 8 dez. 2011.

YOUBOT, S. KUKA youBot Store. Comercial. Disponível em: <http://youbotstore.com/drivers/7/software.aspx>. Acesso em: 6 dez. 2011.

\section{DIREITOS AUTORAIS}

Os autores são os únicos responsáveis pelo conteúdo do material impresso incluído no seu trabalho. 


\section{DEVELOPMENT OF A LOW COST SYSTEM OF MOTION CAPTURE DESTINADE FOR THE DESING OF LOCOMOTION GAIT ASSISTANTS EQUIPMENTS}

EIton Gil Xavier Moura, eltongxm@hotmail.com ${ }^{1}$

Danilo Alves Pinto Nagem, nagem@ufrnet.br ${ }^{1}$

${ }^{1}$ Federal University of Rio Grande do Norte

Resumo: The incapacity to walk is the reason for many losses for the human life, their locomotive capability is compromised, their organism does not work like it's to do and it is highly damages the deficient's self esteem. This work aims to develop an software for use of the Microsoft Kinect by use os the API OpenNI, able to promote a system of motion caption and determine the mechanical parameter on the gait to help projects of motion aiders equipments. So it is the initial step for the development of a equipment to for someone whose mobility is compromised may enjoy the benefits of gait, grow independent and self-esteem, and integrates to society.

Palavras-chave: Kinect, Rehabilitation, Gait, Motion Capture 


\title{
ANEXO C ARTIGO PUBLICADO NO CONGRESSO ESB 2012 E NA REVISTA JOURNAL OF BIOMECHNICS
}

\section{KINECT SENSOR USED AS A SUPPORT TOOL IN CLINICAL ANALYSIS}

\author{
Alessandro de Albuquerque (1), Elton Moura (2),Tomás Vasconcelos(2);L.A. Mendes(3); \\ D.A.P. Nagem (3),
}

1. Sc.M UFRN, Brasil; 2. UFRN, Brasil; 3. Sc.D UFRN, Brazil

\section{Introduction}

In recent years, non-invasive techniques such as computed tomography (TC) and magnetic resonance imaging (MRI) have been assuming great importance in clinical practice e.g. [Luigi, 2011]. The development of a low cost noninvasive sensor to be use in physiotherapy clinics and as a diagnostic tool attracts relevant interest due to its high precision in comparison to non-automated methods allowing the reduction of error during quick exams and the digital storage of data for future comparison. In the works in development in LAIS/UFRN (Laboratory of Technological Innovation in Health of the Federal University of Rio Grande do Norte, Brasil) the Kinect ${ }^{\circledR}$ sensor has been used to help the development of rehabilitation exoskeleton device to diagnoses dyslexia and to create a 3D mapping of physically deformed members. The sensor may offer portable 3-D motion capture capabilities that overcome the limitations of existing systems e.g. [Tilak, 2011]. Also, it does not have the disadvantages of laser so it can be used in human environment and facilitate the research in human detection e.g. [Xia, 2011]. Besides that they don't provide the necessary mobility because the bulky mechanisms and there high maintenance costs. Based on that this paper presents the firsts attempt to use Kinect $\AA$ sensors for multi-body tracking substituting traditional methods of clinical analysis in LAIS/UFRN.

\section{Methods}

The multi-body tracking system focuses on diagnoses dyslexia and movement analysis. The commercial sensors parameters have been studied and their limitations noted.

The Microsoft Kinect ${ }^{\circledR}$ sensor (FIGURE 1) was selected due to its low cost with its RGB camera, small size and infra-red sensor allowing a 3D mapping.. Those characteristics are being studied to analyse its quality to perform as a clinical diagnostic sensor. To development the software API open source from OpenNI. The motion analysis was realized using a treadmill in the Laboratory of Walk and Movement Analysis of UFRN in the Physiotherapy Department (FIGURE 2).

The Kinect and the traditional cameras were positioned to not interfere with each other. The traditional sensors were calibrated and the dimensions between passive marks were noted. The patient could control the 
walk speed and he performed one minute walk. The data from Kinect and tradicional methods was stored for posterior analysis.
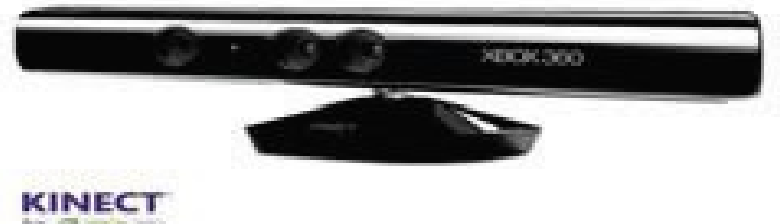

Figure 1: Kinect's hardware

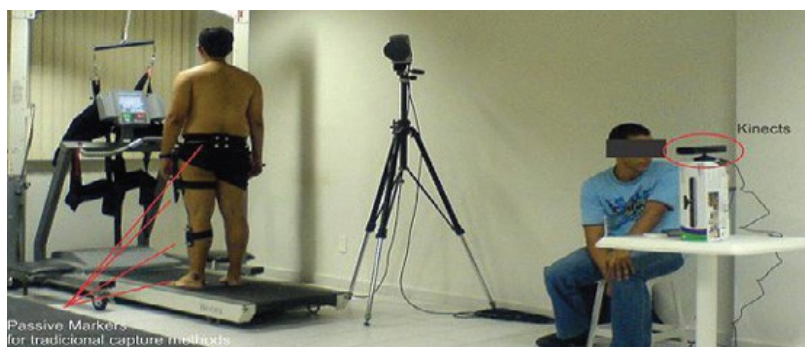

Figure 2: Movement Analysis

\section{Results}

The results present Kinects as much simpler system to install and to use in comparison with traditional methods. Its data presents less accuracy and a lower rate than traditional methods. The kinematic and dynamic analysis of the data will validate the use of Kinect Sensor for this proposes. The use of two or more Kinects for redundant data has been developed for have a better accuracy.

\section{References}

Dutta, T., Evaluation of the Kinect sensor for 3- D kinematic measurement in the workplace, 2011 Luigi et al, Controller-free exploration of medical image data: experiencing the Kinect, 2011

Xia, L. et al, Human Detection Using Depth Information by Kinect, 2011 S304 Presentation 1701 - Topic 24. Human movement Journal of 